Portland State University

PDXScholar

$12-7-2021$

\title{
Sustaining Boys' Motivation Over the Transition to Middle School: Can Interpersonal Resources Protect Boys from Engagement Declines Across Sixth Grade?
}

Brandy Anne Brennan

Portland State University

Follow this and additional works at: https://pdxscholar.library.pdx.edu/open_access_etds

Part of the Developmental Psychology Commons, and the Education Commons Let us know how access to this document benefits you.

\section{Recommended Citation}

Brennan, Brandy Anne, "Sustaining Boys' Motivation Over the Transition to Middle School: Can Interpersonal Resources Protect Boys from Engagement Declines Across Sixth Grade?" (2021). Dissertations and Theses. Paper 5880.

https://doi.org/10.15760/etd.7751

This Thesis is brought to you for free and open access. It has been accepted for inclusion in Dissertations and Theses by an authorized administrator of PDXScholar. Please contact us if we can make this document more accessible: pdxscholar@pdx.edu. 
Sustaining Boys' Motivation Over the Transition to Middle School:

Can Interpersonal Resources Protect Boys from Engagement Declines Across Sixth

Grade?

by

Brandy Anne Brennan

A thesis submitted in partial fulfillment of the

requirements for the degree of

Master of Science

in

Psychology

Thesis Committee:

Thomas A. Kindermann, Chair

Ellen A. Skinner

Andrew J. Mashburn

Portland State University

2021 
C 2021 Brandy Anne Brennan 


\title{
BOYS’ ENGAGEMENT AND INTERPERSONAL RESOURCES IN SIXTH GRADE
}

\author{
Abstract \\ Recent research has highlighted the challenges boys face in school. Boys are \\ overrepresented on indicators of negative academic outcomes, such as detention, \\ suspension, and dropout, as well as underperformance on state and national tests. \\ Moreover, these effects may be long lasting: Compared to females, male students are less \\ likely to graduate high school, enroll in college, and complete a college degree, and they \\ may be particularly vulnerable in middle school. As students enter middle school, their \\ motivation and engagement normatively decline, and these losses may be especially \\ problematic for boys. Nevertheless, research documents the importance of close \\ relationships with parents, teachers, and peers to academic motivation and engagement, \\ suggesting they may buffer students from motivational losses. This study used data from \\ an existing longitudinal dataset of a sixth-grade cohort $(\mathrm{N}=366 ; 52 \%$ boys $)$ to \\ investigate (1) whether gender disparities are present in mean levels and losses in \\ engagement and interpersonal resources, focusing on the supports from parents, teachers, \\ and peers that may buffer boys from losses in engagement; and (2) whether these \\ resources could support or buffer boys' engagement across sixth grade. In general, results \\ were promising but sobering. Independent-samples t-tests and repeated measures \\ Analysis of Variance (ANOVA) showed that boys are less engaged than girls during the \\ first year of middle school, and they lose emotional engagement as the year progresses. \\ Consistent with motivational theories, positive correlations were found between boys'
}




\section{BOYS' ENGAGEMENT AND INTERPERSONAL RESOURCES IN SIXTH GRADE}

engagement and most interpersonal factors in at least one time point, suggesting they held promise for buffering and protecting boys. However, as expected, gender disparities were present for most parent, teacher, and peer resources showing lower levels for boys at one or both time points. Little evidence was found of gender differences in losses of resources; instead, many resources showed declines over the school year for girls as well as boys. Two strategies were used to detect potential buffering effects. Comparisons of boys with higher levels of resources versus the rest of the sample showed that boys generally had higher engagement at both timepoints (but not gains in engagement) when they also had higher levels of adult provisions, relatedness to others, and (although fewer peer resources reached significance) peer group engagement, reciprocated friendships, and the lowest percentage of close friends lost. Teacher involvement and relatedness to father were identified as supports for boys' concurrent engagement and factors that protect against declines in engagement. Strategy Two compared boys with relatively high and stable engagement to those with low and stable engagement, and found indications that parent and teacher structure, parent autonomy support; and relatedness to fathers and teachers, as well as stable relatedness to mothers, may be important resources in supporting boys' engagement; and of peer resources, engaged peer groups and maintenance of closest friendships may support and buffer boys' engagement across the school year. Taken together, multiple factors were identified that showed promise in supporting boys' engagement and buffering losses; however, this study indicates that 


\section{BOYS' ENGAGEMENT AND INTERPERSONAL RESOURCES IN SIXTH GRADE}

boys have lower levels of these resources during a time when all students are

experiencing losses in these provisions across the school year. Strengths and limitations, implications, and avenues for future research are discussed. 


\section{BOYS' ENGAGEMENT AND INTERPERSONAL RESOURCES IN SIXTH GRADE}

\section{Dedication}

This thesis is dedicated to my children; my daughters Madeline and Isabelle, and especially to my son, Jonah, who inspired me to better understand what boys need to thrive in school. 


\section{BOYS' ENGAGEMENT AND INTERPERSONAL RESOURCES IN SIXTH GRADE}

\section{Acknowledgements}

I would first like to thank my thesis advisor, Thomas Kindermann. Throughout this project, he allowed me the space to run with my research interests while offering guidance along the way. I would also like to thank my thesis committee member, Ellen Skinner, for giving me the tools necessary to embrace the writing process. I would also like to acknowledge Andrew Mashburn, as a member of my thesis committee, and for his valuable comments on this project. Finally, I would like to thank my family for their support, especially my mother who encouraged me from a young age to attend college. Thank you. 


\section{BOYS’ ENGAGEMENT AND INTERPERSONAL RESOURCES IN SIXTH GRADE}

\section{Table of Contents}

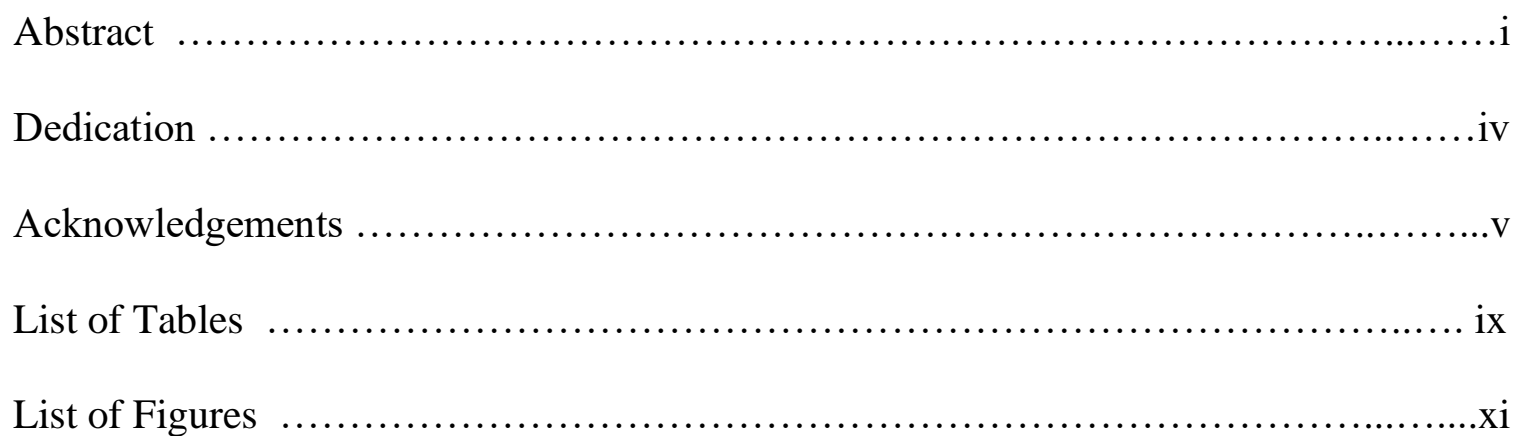

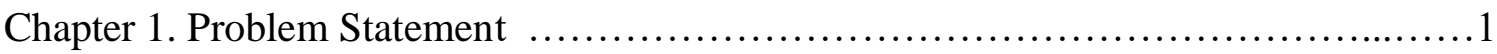

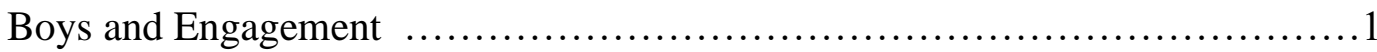

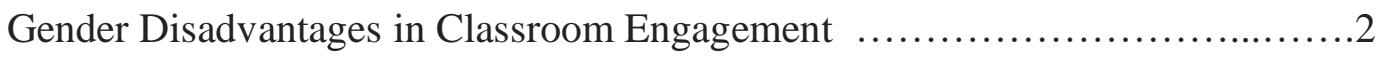

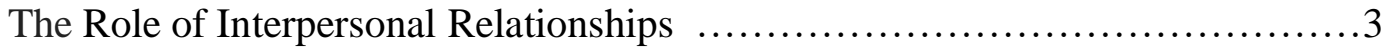

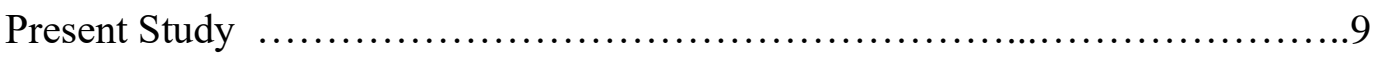

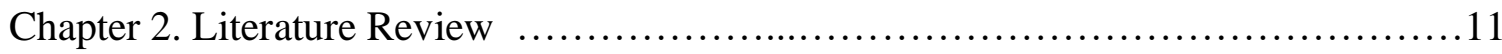

The Importance of Student Engagement ................................. 11

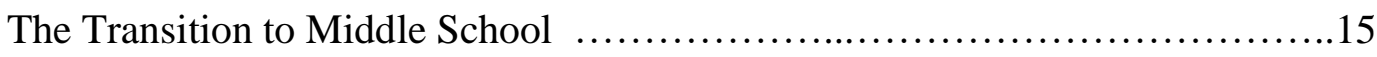

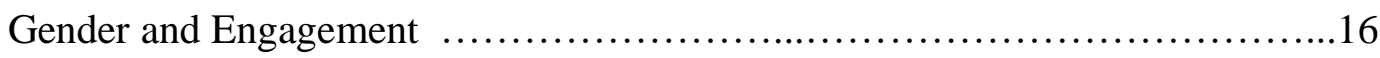

Behavioral, Emotional, and Cognitive Engagement $\ldots \ldots \ldots \ldots \ldots \ldots \ldots \ldots \ldots \ldots$

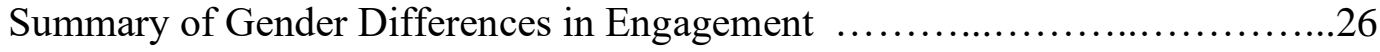

Stage-Environment Fit over the Transition to Middle School .................27

The Importance of High-Quality Relationships to Student Engagement

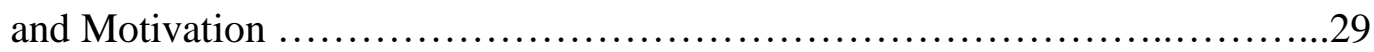




\section{BOYS' ENGAGEMENT AND INTERPERSONAL RESOURCES IN SIXTH GRADE}

Characteristics of Positive Interpersonal Relationships .........................31

Aspects of Positive Relationships with Parents and Teachers

that are Important for School Success .....................................34

Peer Contexts and Academic Functioning, Engagement, and

Achievement ......................................................... 42

Chapter 3. Research Questions and Hypotheses ......................................51

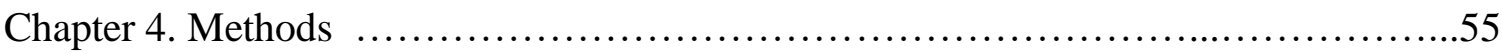

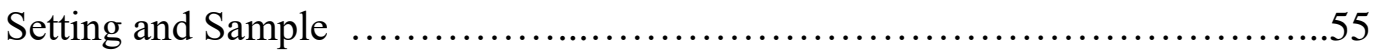

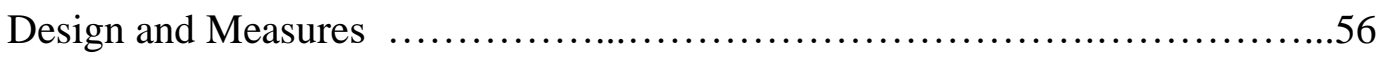

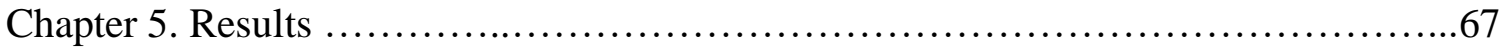

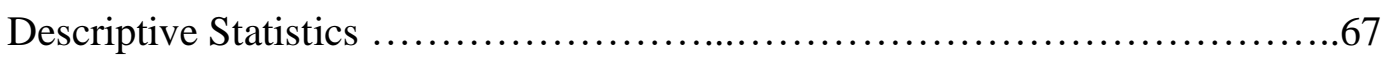

Research Question One: Gender Disadvantages of Engagement

and Interpersonal Resources ........................................... 74

Research Question Two: Interpersonal Resources that Buffer Boys’ Declines

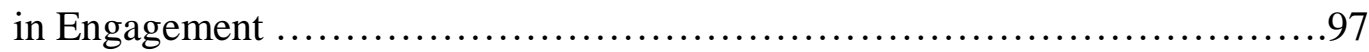

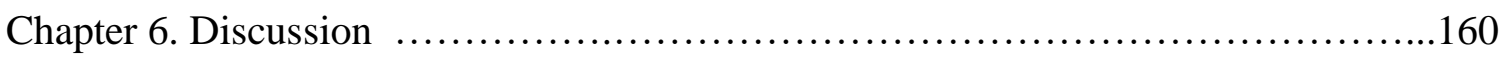

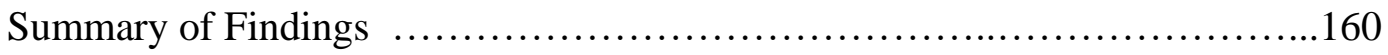

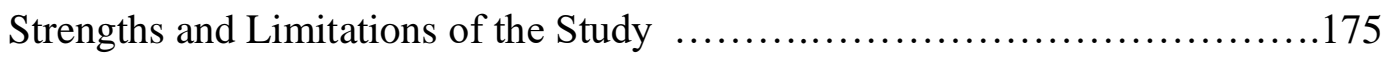

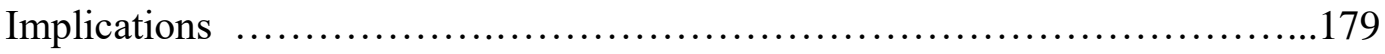

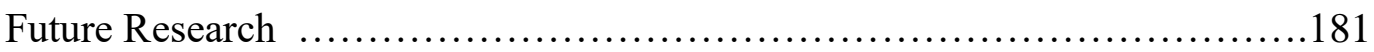


BOYS' ENGAGEMENT AND INTERPERSONAL RESOURCES IN SIXTH GRADE

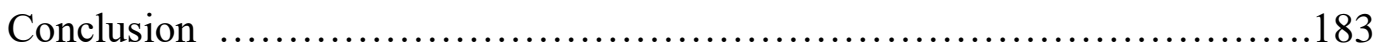

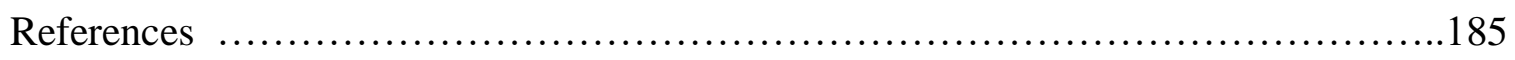

Appendix A. Literature Review of Gender and Engagement ..........................209

Appendix B. Follow-up Analyses for Research Question Two .........................221 


\section{BOYS' ENGAGEMENT AND INTERPERSONAL RESOURCES IN SIXTH GRADE}

\section{List of Tables}

Table 1. Descriptive Statistics of Studies Examining Gender Differences in Engagement.

Table 2. Number of Studies Examining Gender Differences by Engagement

Type and Reporter

Table 3. Teacher/Observer Reported Student Engagement ...........................20

Table 4. Studies Examining Gender Differences in Emotional Engagement .............22

Table 5. Descriptive Statistics for Student Engagement in Sixth Grade ..................68

Table 6. Means and Standard Deviations for Boys' and Girls' Interpersonal

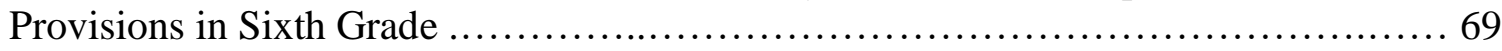

Table 7. Means and Standard Deviations for Boys' and Girls' Composite

Provisions in Sixth Grade ........................................................... 70

Table 8. Correlations Between Boys' and Girls' Academic Engagement and

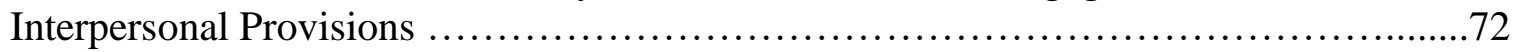

Table 9. Gender Differences in Engagement and Parent and Teacher Provisions ..........74

Table 10. Summary of Support: Gender Differences in Academic Engagement

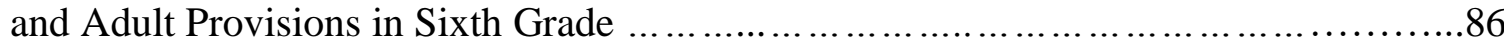

Table 11. Summary of Support: Gender Differences in Relatedness to Parents, Teacher, Classmates, and Friends in Sixth Grade ......................................91

Table 12. Results: Gender Differences in Peer Resources .............................92

Table 13. Summary of Support: Gender Differences in Peer Network Resources in

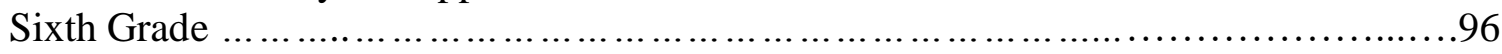

Table 14. Correlations Between Boys' Engagement and Interpersonal Resources .......100

Table 15. Correlations Between Boys' Academic Engagement and

Composites of Parent, Teacher, and Peer Resources 102 


\section{BOYS’ ENGAGEMENT AND INTERPERSONAL RESOURCES IN SIXTH GRADE}

Table 16. Summary of Support for the Hypotheses: Higher Levels of Parent and Teacher Provisions may Buffer Boys' Losses in Academic Engagement

Table 17. Summary of Support: Higher Levels of Relatedness with Parents, Teacher, Classmates, and Friends may Buffer Boys' Losses in Academic Engagement

Table 18. Summary of Support: Higher Levels of Peer Network Resources may Buffer Boys' Losses in Academic Engagement

Table 19. Summary of Support: Identifying Provisions most Powerful in Explaining Boys with Stable (or gains in) Academic Engagement in Sixth Grade

Table 20. Summary of Support: Identifying Types of Relatedness most Powerful in Explaining Boys with Stable (or gains in) Academic Engagement in Sixth Grade.....

Table 21. Summary of Support: Identifying Types of Peer Network Resources most Powerful in Explaining Boys with Stable (or gains in) Academic Engagement in Sixth Grade

Table 22. Boys' Engagement Profiles across Sixth Grade 182 


\section{BOYS' ENGAGEMENT AND INTERPERSONAL RESOURCES IN SIXTH GRADE}

\section{List of Figures}

Figure 1. Self-Systems Model for Student Engagement

Figure 2. Co-Occurrence Matrix of Group Observations (adapted from Kindermann,

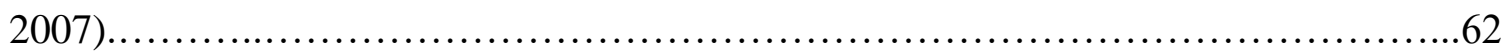

Figure 3. Binomial z-Tests Based on Nominations of Groups $(N=159$, Kindermann, 1993)

Figure 4. The Composite Socio-Cognitive Map of Sixth Graders'

Social Networks 64

Figure 5. A Subsection of a Boy's Social Network in Sixth Grade .65 


\section{BOYS' ENGAGEMENT AND INTERPERSONAL RESOURCES IN SIXTH GRADE Chapter 1. Problem Statement}

In recent years, research has increasingly highlighted the challenges boys face in school. Studies suggest that boys are overrepresented on indicators of poor academic outcomes such as detention $^{1}$, suspension (Snyder, De Brey, \& Dillow, 2018, 2019), grade retention (Warren, Hoffman, \& Andrew, 2014), and drop-out rates (Alexander, Entwisle, \& Horsey, 1997; Alspaugh, 2000), as well as underperformance on statewide and national tests, especially in reading (Oregon Department of Education, 2019; Rampey, Dion, \& Donahue, 2009). These issues seem to follow boys throughout their educational careers. Compared to girls, males are less likely to graduate high school or enroll in college and the males who do enroll in college are more likely to drop out and less likely to graduate (McFarland et al., 2019).

\section{Boys and Engagement}

Many of these academic problems seem to reflect motivational issues, dovetailing with studies indicating that, compared to girls, boys seem to be less engaged and more disaffected from learning in the classroom (Wigfield et al., 2015). Because success in the classroom is grounded in the capacity to pay attention and participate constructively in learning tasks, lack or loss of motivation has the potential to create multiple problems for

\footnotetext{
${ }^{1}$ There are no clear gender differences on outcomes of truancy and detention; however, the long-term consequences of these outcomes affect boys more negatively than girls (e.g., gender differences in consequent involvement with the criminal justice system).
} 


\section{BOYS' ENGAGEMENT AND INTERPERSONAL RESOURCES IN SIXTH GRADE}

boys. When boys are not engaged in schoolwork, they miss out on the kind of learning that is necessary for school advancement, putting them at risk for poor academic performance. Disaffection can also create problems in social relationships. Disruption or lack of engagement in the classroom can cause strained interactions and conflictual relationships with teachers and may even lead them to eventually exclude boys from class or school. Studies show that, compared to girls, boys are twice as likely to be suspended and three times as likely to be expelled (Snyder, De Brey, \& Dillow, 2018). These outcomes are concerning because disciplinary practices, along with exclusion from the classroom, have been found to be strong predictors of negative educational outcomes for boys (Archambault, Janosz, Morizot, \& Pagani, 2009; Janosz, Archambault, Morizot, \& Pagani, 2008; Li \& Lerner, 2011). Alongside relationships with teachers, less engaged boys may also experience increased rejection from peers, disrupting their relationships with classmates. Additionally, low academic engagement and negative school outcomes may create tension and conflict between parent and child, affecting boys' relationships with their parents.

\section{Gender Disadvantages in Classroom Engagement}

As students enter middle school, their motivation and engagement normatively decline, and such motivational losses may be especially problematic for boys (Anderman \& Mueller, 2010). Research indicates that boys are less academically engaged than girls at all middle school grade levels (Woolley \& Bowen, 2007). Studies also suggest that, 


\section{BOYS' ENGAGEMENT AND INTERPERSONAL RESOURCES IN SIXTH GRADE}

compared to girls, boys have lower levels of other markers of school engagement, such as school compliance, participation in extra-curricular activities, school interest, school identification, and valuing of learning (Wang \& Eccles, 2012). Additionally, boys report more disconnection and negative feelings toward school than do girls (Oelsner, Lippold, \& Greenberg, 2011). Even if boys and girls show similar rates of decline in behavioral, emotional, and cognitive engagement during middle school, this trend may be more worrisome for boys because they start out with lower levels of engagement than do girls.

\section{The Role of Interpersonal Relationships}

In order to figure out how to support boys during their first year in middle school, it is helpful to explore the interpersonal resources that could buffer them from motivational losses and promote their motivational resilience. Decades of research have shown that an important set of motivational resources is provided by the people in students' daily lives, and especially the people with whom they interact every day, namely, their parents, teachers, and peers (Anderman \& Kaplan, 2008; Martin \& Dowson, 2009; Wentzel \& Miele, 2016). Close and caring relationships with these social partners are important for adolescents' academic motivation and have been found to foster their engagement in school. For example, research suggests that higher levels of parental relatedness, positive interactions with parents, and firm, but receptive parenting styles are associated with higher levels of classroom engagement; and adolescents' perceptions of parental support and connection have been positively linked to their 


\section{BOYS' ENGAGEMENT AND INTERPERSONAL RESOURCES IN SIXTH GRADE}

interest and participation in school (Barger, Kim, Kuncel, \& Pomerantz, 2019;

Bempechat \& Shernoff, 2012; Grolnick, Friendly, \& Bellas, 2009; Rowe, Ramani, \&

Pomerantz, 2016; Vasquez et al., 2016).

In a similar vein, research indicates that students who perceive their teachers as warm, caring, and supportive are more likely to report feelings of belongingness, interest, and enjoyment in school, which in turn, promote increased levels of classroom engagement. Evidence suggests that perceptions of teacher support, including teacher sensitivity, positive classroom climate, and high regard for students' perspectives, also directly predicts multiple indicators of classroom engagement, such as greater school liking and compliance with the teacher, as well as lower levels of off-task behaviors (Gregory \& Korth, 2016; Martin \& Collie, 2016). When boys feel connected to and accepted by teachers, this may nurture more positive attitudes about school and higher classroom engagement.

Although the effects of peers on academic motivation have not been studied as intensively, research suggests that students can experience a heightened need for connection and intimacy with peers during the transition to middle school, and the quality of these connections has been linked to school engagement (Bukowski, Laursen, \& Rubin, 2019; Juvonen \& Knifsend, 2016; Kindermann, 2016; Ryan \& Shin, 2018; Wentzel, 2009). Perceptions of peer support, acceptance, and feelings of relatedness are associated with school involvement and compliance, and students with positive peer 


\section{BOYS' ENGAGEMENT AND INTERPERSONAL RESOURCES IN SIXTH GRADE}

relationships are more likely to be engaged in school (Ryan \& Shin, 2018). The positive connections boys have with their peers may contribute to academic goals by providing positive role models, as well as encouragement and emotional support during times of academic difficulty. Additionally, peer connections and positive interactions can be supported when teachers provide classroom experiences that bolster boys' perceptions of peers as positive, supportive, and respectful.

\section{Interpersonal Relationships as Protective Factors}

Not only can supportive relationships with parents, teachers, and positive peers promote students' engagement, but these close relationships may even buffer some of the motivational losses experienced in middle school, especially for at-risk students, such as boys. Evidence suggests that interpersonal resources have the potential to protect students from some of the declines in academic achievement and engagement over the transition to middle school (Anderman \& Kaplan, 2008; Wigfield et. al., 2015). For example, studies show that support from parents, teachers, and positive peers may slow declines in students' school compliance, school identification, and the value they place on learning (Wang \& Eccles, 2012). For at-risk students, including boys, the most important protective factor may be feeling safe and welcomed in school and in the classroom by teachers (Ripski \& Gregory, 2009; Woolley \& Bowen, 2007). Moreover, studies find that high teacher warmth and low conflict can protect boys from high absenteeism and risk of dropping out, as well as from losses in academic achievement and classroom engagement 


\section{BOYS' ENGAGEMENT AND INTERPERSONAL RESOURCES IN SIXTH GRADE}

(Gregory \& Korth, 2016). In the same vein, the quality of parent-child relationships and perceived parental support may also buffer declines in engagement and achievement (Pomerantz \& Moorman, 2010). For example, higher levels of parental involvement, another indicator of relationship quality, have been found to serve as a protective factor against school dropout, a risk factor that is heightened for boys (Cooper, Chavira, \& Mena, 2005). Research also indicates that higher levels of parental monitoring are related to smaller declines in school engagement and, interestingly, parental monitoring is less prevalent with boys, as compared to girls (Simons-Morton \& Crump, 2003).

The role of peers appears to be more complex. Studies indicate that the influences of peer groups can be positive or negative, depending on the type of peer support provided and the values held by the student's group of friends (Bukowski, Laursen, \& Rubin, 2019; Juvonen \& Knifsend, 2016; Kindermann \& Gest, 2018). For example, if a student's peer group is comprised of highly engaged students who value school, there is potential for the peer group to act as a buffer against academic loss as the members of the group serve as positive student role models, offer academic support, and exhibit norms supporting academic engagement. On the other hand, if a student's peer group is disaffected from school and engages in behaviors that are not academically supportive, the peer group may serve as a temptation for misbehavior rather than a buffer against normative school declines. Since boys' peer groups are more likely to be composed of 


\section{BOYS' ENGAGEMENT AND INTERPERSONAL RESOURCES IN SIXTH GRADE}

other boys, who in general are less engaged than girls, boys' peer groups are also likely to be less engaged than the peer groups of girls.

\section{Losses in Interpersonal Resources over the Transition to Middle School}

Even though parent, teacher, and peer relationships can promote engagement and may buffer motivational losses in middle school, there is some question about whether students maintain access to these interpersonal resources over the middle school transition and during the first year of middle school. Changes in school structure and normative adolescent development may affect the relational dynamics students have with parents, teachers, and peers and there is evidence of normative declines in some of these relationships (Eccles \& Midgley, 1989). For example, because the structural transition to middle school requires students to adjust to multiple teachers and classrooms, research indicates that students and teachers report lower levels of teacher-student connectedness, compared to elementary school (Feldlaufer, Midgley, \& Eccles, 1988).

Developmentally, adolescents in middle school experience a heightened need for autonomy and independence from parents, potentially resulting in shifts in parental involvement and connection (Wei et al., 2019). Adolescents also begin to take more interest in peer relationships, but evidence suggests that peer networks may be disrupted by the middle school transition, and complications with peers can arise in middle school, resulting in lower levels of friendship quality, higher levels of conflict, and friendship loss (Eccles \& Midgley, 1989). 


\section{BOYS' ENGAGEMENT AND INTERPERSONAL RESOURCES IN SIXTH GRADE Boys' Relationships}

At the same time that all students' relationships may show normative declines at the beginning of middle school, there is concern that compared to girls, boys' relationships may not be as positive and supportive. For example, some evidence suggests that boys have higher levels of conflict and lower levels of closeness with teachers, compared to girls (Hamre \& Pianta, 2001). Research also indicates that boys, in particular, experience a loss of intimacy and connection in their friendships beginning in early adolescence, making them particularly susceptible to academic disaffection (Way, 2011). The current study was inspired by research conducted by Niobe Way (2011), who examined the nature of boys' peer relationships. Way's qualitative work interviewing boys reveals that boys have and want intimate friendships, that they can articulate the emotional quality of their friendships, and that they are attuned to the feelings and desires to connect with others. However, these same boys report losses of peer intimacy and connection.

In middle school, social inclusion may be more challenging for boys. Evidence suggests that students who do not have reciprocated friends during the transition to middle school tend to earn lower grades and one line of research indicates that boys make up the majority of students with no social networks, and this sub-group of boys are less engaged than boys with social networks (Kindermann, 2007). Taken together, close relationships are just as important for boys as they are for girls, but there is an indication 


\section{BOYS' ENGAGEMENT AND INTERPERSONAL RESOURCES IN SIXTH GRADE}

that boys may begin losing these connections in adolescence during the middle school transition, when they may need them more than ever. In sum, research shows that adolescents experience a myriad of contextual and age normative changes over the transition to middle school, and these changes may cause the relationships they have with parents, teachers, and peers to be less accessible, resulting in losses of connection and declines in relationship quality. Furthermore, evidence suggests that boys may have fewer or lower quality connections, compared to girls, undermining boys' access to interpersonal resources just as they need them most.

\section{Present Study}

The aim of this study is to examine the link between boys' relationships and their engagement in the first year of middle school to better understand the ways boys can be academically supported during a time when they are experiencing losses in engagement and changes in their relationships. Exploring provisions of support from parents, teachers, and peers will help bring to light the interpersonal resources that may buffer boys from losses in engagement and promote their motivational resilience.

Chapter 2 provides a review of the literature on academic engagement and gender, the transition to middle school, and the role of interpersonal relationships in student motivation. Chapter 3 poses the present study's central research questions and hypotheses. Chapter 4 introduces the methods used, including the setting, sample, design, and measures. Chapter 5 presents descriptive statistics of the data and results of the 


\section{BOYS' ENGAGEMENT AND INTERPERSONAL RESOURCES IN SIXTH GRADE}

analyses to answer the research questions of this study. Chapter 6 follows with a

discussion that includes contributions of the study, its strengths and weaknesses, potential

implications of the current findings, as well as questions that will arise from this research that may become future directions. 


\section{BOYS' ENGAGEMENT AND INTERPERSONAL RESOURCES IN SIXTH GRADE \\ Chapter 2. Literature Review}

A review of the relevant literature is provided, divided into two main chunks. The first focuses on student engagement, including its importance and malleability, and the conceptual definitions of engagement and disaffection provided in the existing body research. This section also describes adolescents' experiences during the transition to middle school and reviews previous literature examining gender differences in engagement, with specific attention to boys. To understand why motivation during the middle school transition declines, theories of Stage-Environment Fit and Self-Systems Theory are presented to discuss the discrepancy between what adolescents need, during this transition, and the affordances of their environment. The second main section focuses on the role of interpersonal relationships in promoting student motivation and engagement, including their importance and the characteristics of relationships that contribute to academic functioning and success.

\section{The Importance of Student Engagement}

Engaged students are easy to identify. They pay more attention in class, exert more effort on learning tasks, and experience more positive academic emotions, compared to their less-engaged peers (Fredricks, Blumenfeld, \& Paris, 2004). Students who constructively engage in schoolwork are more attentive and focused during the learning process and so experience more opportunities to increase their knowledge and to build academic skills. In fact, some researchers argue that engagement in the classroom is 


\section{BOYS' ENGAGEMENT AND INTERPERSONAL RESOURCES IN SIXTH GRADE}

an essential condition for learning, and it may be a necessity for students to achieve their potential in learning environments.

\section{Engagement and Academic Success}

Research confirms the link between academic engagement and school success, including learning, academic performance, achievement, readiness for next school steps, retention, and protection from truancy and dropout. Studies indicate that engagement in the classroom is associated with positive academic student outcomes, such as homework completion, higher grades, and higher scores on achievement tests (Connell, Spencer, \& Aber, 1994; Furrer \& Skinner, 2003; Li \& Lerner, 2011; Skinner, Wellborn \& Connell, 1990). Engagement has also been found to be a strong predictor of long-term academic achievement (Ladd \& Dinella, 2009; Skinner et al., 1998; Upadyaya \& Salmelo-Aro, 2013; Wang \& Eccles, 2012). Students who are academically engaged are also more likely to learn key concepts that are necessary for successfully achieving course objectives, preparing them for grade advancement. Engaging in schoolwork also transforms learning into skill attainment in various subjects, promoting readiness for students' next school steps. Furthermore, engagement leads to college and career readiness, as seen in studies in which engagement predicts college enrollment, as well as education levels completed (Dubow, Boxer, \& Huesmann, 2009; Upadyaya \& SalmelaAro, 2013).

Engagement as a Protective Factor Against Truancy, Delinquency, and Drug Use 


\section{BOYS' ENGAGEMENT AND INTERPERSONAL RESOURCES IN SIXTH GRADE}

Evidence suggests that being engaged in school also protects students from truancy, delinquency, and drug use (Li \& Lerner, 2011; Snyder, De Brey, \& Dillow, 2018). Academic engagement is positively related to school retention (Finn \& Rock, 1997; Janosz, Archambault, Morizot, \& Pagani, 2008), and disaffection is a predictor of high school dropout (Archambault, Janosz, Morizot, \& Pagani, 2009). Longitudinal studies also indicate that early student engagement predicts high school retention (Alexander, Entwisle, \& Dauber, 1993). For example, Ekstrom, Goertz, Pollack, and Rock (1986) found that students who later dropped out of school were less likely to complete homework, show effort and participation, and have more problems with discipline in school. Research also indicates that students who are disengaged from school are more likely to engage in delinquent behaviors such as smoking, drinking, and using marijuana (Li \& Lerner, 2011).

\section{Malleability of Engagement}

Engagement continues to be a growing area of interest not only because of these many benefits, but also because it is potentially malleable. In other words, engagement can be molded by students' social and academic contexts. This process happens through interactions between the student and his context and can be altered by changes in the social or academic environment (Christenson, Reschly, \& Wylie, 2012; Connell, 1990; Fredricks, Reschly, Christenson, 2019; Wang, Degol, \& Henry, 2019). Studying the relationship between engagement and classroom context helps us to make sense of 


\section{BOYS' ENGAGEMENT AND INTERPERSONAL RESOURCES IN SIXTH GRADE}

students' school experiences and guides us in understanding how student engagement can be supported. This knowledge informs interventions aimed at improving student engagement and academic success including improving classroom climate, providing autonomy-supportive classrooms, and promoting positive parent, teacher, and peer relationships (Fredricks et al., 2019; Wigfield et al., 2015).

\section{Definition of Engagement}

Engagement, as a construct, is multidimensional, and is comprised of behavioral, cognitive, and emotional components related to a task (Fredricks, Blumenfeld, \& Paris, 2004). Although there is no clear agreement on its definition, motivational perspectives regard it as a manifestation of motivation, and is describe it as energized, directed, and sustained action toward an activity (Skinner, Kindermann, Connell, \& Wellborn, 2009; Reeve, 2012; Skinner \& Pitzer, 2012; Wang et al., 2019; Wigfield et al., 2015). From this perspective, academic engagement can be defined as constructive enthusiastic participation in learning activities in the classroom. Behavioral engagement involves observable on-task behaviors, like active effort, hard work, attentiveness, and task completion as well as compliance and adherence to class rules and norms (Finn \& Zimmer, 2012). Emotional or affective engagement includes feelings of enthusiasm, enjoyment, fun, interest, and energy while participating in academic activities (Deci \& Ryan, 2000; Skinner, Kindermann, Connell, \& Wellborn, 2009). Disaffection, which has been described as the opposite of engagement (Connell \& Wellborn, 1991), is comprised 


\section{BOYS' ENGAGEMENT AND INTERPERSONAL RESOURCES IN SIXTH GRADE}

of behavioral and emotional components. Behavioral indicators of disaffection include passivity, withdrawal from classroom participation, and lack of attention and are coupled with emotions including boredom, anxiety, disinterest, and frustration in the classroom. As would be expected, disaffection or disengagement is associated with a host of negative academic outcomes (e.g., Martin et al., 2011; Salmela-Aro et al., 2016).

\section{The Transition to Middle School}

It has been well established in prior literature that during the transition to middle school, many adolescents experience losses in motivation (Jacobs, Lanza, Osgood, Eccles, \& Wigfield, 2002) and declines in academic engagement (Simons-Morton \& Crump, 2003; Symonds \& Galton, 2014; Wang \& Eccles, 2012). As students transition from elementary to middle school, they experience major changes in their school environment in myriad ways. Alongside navigating through the hallways of a larger school shifting between various classrooms, adolescents must adjust to having multiple teachers with different sets of expectations, as well as an increased number of peers filling the hallways during passing time, which may leave adolescents feeling that their surroundings are less intimate and more impersonal.

A major social developmental task of early adolescence is to establish healthy relationships with others, however, the transition to middle school has been linked to declines in adolescents' sense of belonging and their perception of emotional support, especially from teachers (Furrer \& Skinner, 2003; Wigfield, Byrnes, \& Eccles, 2006). 


\section{BOYS' ENGAGEMENT AND INTERPERSONAL RESOURCES IN SIXTH GRADE}

Many adolescents may also experience boredom with schoolwork (Larson, 2000) and some may engage in deviant behaviors (Simmons \& Blyth, 1987), leading to conduct problems and strained relationships with parents, teachers, and peers. These contextual changes may be stressful to adolescents and have been associated with declines in student motivation, interest and valuing of school, expectancies of school success, and academic engagement and achievement (Anderman \& Mueller, 2010; Eccles \& Midgley 1989; Eccles \& Roeser, 2011; Wigfield \& Eccles, 1992). While research indicates that the transition to middle school can be challenging for many adolescents, it is encouraging that further exploration of these contextual changes can help bring to light the support and resources educators and parents can provide to students in order to buffer declines in their motivation and promote engagement in school.

\section{Gender and Engagement}

The literature examining engagement and gender strongly suggests that from middle school onward, boys are less academically engaged, as compared to girls (Van de Gaer, Pustjens, Van Damme, \& De Munter, 2009; Wigfield et al., 2015). Twenty-two studies were found in the engagement literature that measured gender differences in engagement or constructs related to engagement (see Appendix A). All but two of these studies found significant gender differences, showing that boys were generally less engaged than girls. Importantly, none of the studies indicated that boys show higher engagement levels. 


\section{BOYS' ENGAGEMENT AND INTERPERSONAL RESOURCES IN SIXTH GRADE}

Studies found in the literature typically examine engagement in middle or high school students, are cross-sectional in design, and use student-reported engagement measures (see Table 1for descriptive statistics of existing studies). A much smaller number of studies used teacher reports of student engagement, and they show gender differences similar to studies of self-reported engagement. Gender differences are typically found by significant correlations between gender and engagement or by mean differences, often located in the preliminary analyses of a study; however, usually, these are not the primary aim or research question posed in the study. Of the few longitudinal studies found, most examined school engagement across the middle and high school years making it difficult to see the change in engagement across a single middle school year.

\section{Table 1}

Descriptive Statistics of Studies Examining Gender Differences in Engagement

\begin{tabular}{lcc}
\hline Features of Study & Number of Studies & $\begin{array}{c}\text { Percentage of Studies } \\
(\%)\end{array}$ \\
\hline Study Design & & 68 \\
$\quad$ Cross-sectional & 15 & 32 \\
$\quad$ Longitudinal & 7 & \\
Reporter & 20 & 91 \\
$\quad$ Student & 5 & 23 \\
Teacher & 3 & 14 \\
Observer & & \\
School Level & 4 & 18 \\
$\quad$ Elementary & 14 & 64 \\
Middle & 12 & 55 \\
$\quad$ High & & \\
\hline
\end{tabular}




\section{BOYS’ ENGAGEMENT AND INTERPERSONAL RESOURCES IN SIXTH GRADE}

\begin{tabular}{lcc}
\hline Features of Study & Number of Studies & $\begin{array}{c}\text { Percentage of Studies } \\
(\%)\end{array}$ \\
\hline Type of Analyses & & 55 \\
Mean Differences & 12 & 36 \\
Zero-order Correlations & 8 & 9 \\
Slope-Intercepts & 2 & \\
\hline
\end{tabular}

\section{Behavioral, Emotional, and Cognitive Engagement}

Studies measured multiple types of student engagement, focusing on behavioral, emotional, and cognitive dimensions (see Table 2 for studies organized according to the type of engagement and reporter), as well as a related construct, school engagement, that reflects either a mixture of the engagement dimensions or a combination of indicators such as student effort, interest in learning, school identification, compliance, and valuing of school (see Appendix A).

\section{Behavioral Engagement}

Of the different dimensions studied, gender differences were most consistently found in behavioral engagement. Thirteen studies examined behavioral engagement and, of these, eleven found gender differences indicating that, compared to girls, boys are less behaviorally engaged. Some of these studies included multiple sources, and although most of these studies were based on self-reports, teachers also report that boys show significantly more disruptive behavior in the classroom than girls (Ryan \& Patrick, 2001). 


\section{BOYS' ENGAGEMENT AND INTERPERSONAL RESOURCES IN SIXTH GRADE}

\section{Table 2}

Number of Studies Examining Gender Differences by Engagement Type and Reporter

\begin{tabular}{cccc}
\hline & \multicolumn{3}{c}{ Reporter } \\
\cline { 2 - 4 } Engagement Type & Student & Teacher & Observer \\
\hline Behavioral & 16 & 5 & 3 \\
Emotional & 11 & 0 & 0 \\
Cognitive & 10 & 0 & 0 \\
\hline
\end{tabular}

Most of these studies are based on middle- and high school-age students' selfreports, indicating that boys' perceptions of their own engagement with school are significantly lower compared to girls'. For example, in a cross-sectional study, Hospel and Galand (2016) found significant gender differences in behavioral engagement indicating that ninth-grade boys reported lower levels of participation and following instructions, as compared to girls.

Alongside student reports of engagement, teacher, and observer reports similarly indicate that boys show lower levels of behavioral engagement before, during, and after middle school. Five studies in the literature examined gender and teacher perceptions of behavioral engagement, three of which included observer reports, and all studies indicated that boys were seen as less behaviorally engaged in school (see Table 3). In a first observer study, Baroody, Rimm-Kaufman, Larsen, and Curby (2016) conducted a longitudinal investigation of $3875^{\text {th }}$ grade students across 20 schools and examined observer and teacher ratings of student behavioral engagement, particularly, attention, focus, effort, and on-task behaviors of students. Mean level differences were found 


\section{BOYS' ENGAGEMENT AND INTERPERSONAL RESOURCES IN SIXTH GRADE}

indicating that boys showed lower levels of behavioral engagement, as compared to girls, across the fifth-grade year. In a second cross-sectional study of seventh-grade boys (Lietaert et. al., 2015), observers rated students' overall level of engagement in the classroom as either not engaged or highly engaged and never distracted, while teachers rated students' cooperative participation (i.e., "Listens carefully to the teacher's instructions and directions"). Based on mean differences, results indicate that teachers and observers reported seventh-grade boys to be less behaviorally engaged, compared to their female peers. In a third study, Ripski and Gregory (2009) cross-sectionally examined the behavioral engagement (i.e., attentiveness, disruptiveness, tardiness, and homework completion) of approximately 15,000 tenth graders and found a negative correlation between gender and engagement, indicating that teachers perceive boys to be less behaviorally engaged in the classroom, as compared to girls.

\section{Table 3}

\section{Teacher/Observer Reported Student Engagement}

\begin{tabular}{|c|c|c|c|c|}
\hline Study & $\mathrm{N}$ & $\begin{array}{l}\text { Grade } \\
\text { Level }\end{array}$ & Example Item & Finding \\
\hline $\begin{array}{l}\text { Baroody, Rimm- } \\
\text { Kaufman, Larsen, \& } \\
\text { Curby (2016) }\end{array}$ & 387 & 5 th & $\begin{array}{l}\text { "... works as } \\
\text { hard as she/he } \\
\text { can in class" }\end{array}$ & $\begin{array}{l}\text { Mean level differences } \\
\text { found; boys had lower } \\
\text { mean levels on } \\
\text { engagement }\end{array}$ \\
\hline Finn \& Cox (1992) & 1388 & 4 th & $\begin{array}{l}\text { "Pays attention } \\
\text { in class" }\end{array}$ & $\begin{array}{l}70 \% \text { of "non- } \\
\text { participant students" } \\
\text { were male. }\end{array}$ \\
\hline Lietaert et. al. (2015) & 385 & 7th & $\begin{array}{l}\text { "Listens } \\
\text { carefully to the } \\
\text { teacher's }\end{array}$ & $\begin{array}{l}\text { Mean level differences } \\
\text { found with observer } \\
\text { and teacher reports }\end{array}$ \\
\hline
\end{tabular}




\section{BOYS’ ENGAGEMENT AND INTERPERSONAL RESOURCES IN SIXTH GRADE}

\begin{tabular}{|c|c|c|c|c|}
\hline & & & $\begin{array}{l}\text { instructions and } \\
\text { directions" }\end{array}$ & $\begin{array}{l}\text { indicating that boys } \\
\text { were less engaged. } \mathrm{M}= \\
2.67 ; \mathrm{SD}=.30 \text { (girls) } \\
\mathrm{M}=2.46 ; \mathrm{SD}=.46 \\
\text { (boys) }\end{array}$ \\
\hline $\begin{array}{l}\text { Rimm-Kaufman et. al. } \\
\text { (2015) }\end{array}$ & 387 & 5 th & $\begin{array}{l}\text { "... participates } \\
\text { in discussion } \\
\text {.." }\end{array}$ & $\begin{array}{l}\text { Gender significantly } \\
\text { correlated with } \\
\text { observer }\left(.21^{* *}\right) \text { and } \\
\text { teacher }\left(.16^{* *}\right) \text { reports } \\
(0=\text { Male; } 1=\text { Female })\end{array}$ \\
\hline $\begin{array}{l}\text { Ripski \& Gregory } \\
(2009)\end{array}$ & 15,000 & 10th & $\begin{array}{l}\text { "How often } \\
\text { does this } \\
\text { student } \\
\text { complete } \\
\text { homework } \\
\text { assignments?" }\end{array}$ & $\begin{array}{l}\text { Gender and } \\
\text { engagement were } \\
\text { significantly correlated. } \\
\mathrm{r}=-.17^{* *} \text { (male) }\end{array}$ \\
\hline
\end{tabular}

Note. Asterisks $(* *)$ indicates $\mathrm{p}<.01$

\section{Emotional Engagement}

The results of studies examining gender differences in emotional engagement were mixed. Of the eight studies found, half reported significant gender differences in emotional engagement, all of which indicated that boys reported they were less emotionally engaged as compared to girls (see Table 4). For example, a cross-sectional study of 836 sixth, eighth, and tenth-grade students examined students' perceptions of their affective (emotional) engagement, particularly their motivation and feelings about school and classroom activities. Results revealed significant mean level differences between girls and boys in affective (emotional) engagement within each grade level and on average across all three grade levels, indicating that boys reported lower levels of emotional engagement at all grade levels, as compared to girls (Amir, Saleha, Jelas, \& 


\section{BOYS' ENGAGEMENT AND INTERPERSONAL RESOURCES IN SIXTH GRADE}

Hutkemri, 2014). However, in a longitudinal study of 387 fifth-grade students, students were asked to rate their level of emotional engagement on items in a questionnaire, particularly in math work, such as "math class was fun today" and "today I felt bored in math class". Gender was not found to significantly correlate with student-reported emotional engagement in math across the fifth-grade school year (Rimm-Kaufman, Baroody, Larsen, Curby, \& Abry, 2015). Taken together, while there is no clear picture of whether there are gender differences in emotional engagement, there are indications in the literature that, overall, boys may be less emotionally engaged as compared to girls. There may be multiple dimensions of emotional engagement, such as boredom (where boys may be scoring higher) and anxiety (where boys may be lower), which explain the mixed results found in emotional engagement between the genders.

\section{Table 4}

Studies Examining Gender Differences in Emotional Engagement

\begin{tabular}{lllll}
\hline Study & N & $\begin{array}{l}\text { Grade } \\
\text { Level }\end{array}$ & Example Item & Finding \\
\hline $\begin{array}{l}\text { Amir, Saleha, Jelas, } \\
\text { \& Hutkemri (2014) }\end{array}$ & 836 & $\begin{array}{l}\text { 6th, } \\
\text { 8th, } \\
\& \text { 10th }\end{array}$ & $\begin{array}{l}\text { Items measuring } \\
\text { feelings about } \\
\text { classroom } \\
\text { activities. }\end{array}$ & $\begin{array}{l}\text { Mean level differences } \\
\text { found; boys had lower } \\
\text { mean levels of emotional } \\
\text { engagement at 12, 14, } \\
\text { and 16 years of age. }\end{array}$ \\
$\begin{array}{l}\text { Hospel \& Galand } \\
\text { (2016) }\end{array}$ & 744 & 9 th & $\begin{array}{l}\text { Frequency of } \\
\text { positive/negative } \\
\text { emotions during } \\
\text { class }\end{array}$ & $\begin{array}{l}\text { No gender differences } \\
\text { found }\end{array}$ \\
& & & & \\
& & & & \\
\hline
\end{tabular}




\section{BOYS’ ENGAGEMENT AND INTERPERSONAL RESOURCES IN SIXTH GRADE}

\begin{tabular}{|c|c|c|c|c|}
\hline Study & $\mathrm{N}$ & $\begin{array}{l}\text { Grade } \\
\text { Level }\end{array}$ & Example Item & Finding \\
\hline King (2016) & 848 & $\begin{array}{l}7 \text { th }- \\
10 \text { th }\end{array}$ & "Class is fun" & $\begin{array}{l}\text { No significant gender } \\
\text { differences found with } \\
\text { emotional engagement ( } \mathrm{r} \\
=.047) \text {, however, a } \\
\text { negative correlation was } \\
\text { found with emotional } \\
\text { disaffection. ( } \mathrm{r}=- \\
.104^{* *} ; 0=\text { male, } 1= \\
\text { female) }\end{array}$ \\
\hline Lam et. al. (2012) & 3,420 & $\begin{array}{l}7 \text { th }- \\
9 \text { th }\end{array}$ & $\begin{array}{l}\text { "I like what I'm } \\
\text { learning in } \\
\text { school" }\end{array}$ & $\begin{array}{l}\text { Mean level differences } \\
\text { found. } \\
M=3.44 \text { (girls) } \\
M=3.31 \text { (boys) }\end{array}$ \\
\hline $\begin{array}{l}\text { Park, Holloway, } \\
\text { Arendtsz, \& } \\
\text { Bempechat (2012) }\end{array}$ & 94 & 9th & $\begin{array}{l}\text { "Did you enjoy } \\
\text { what you were } \\
\text { doing?" }\end{array}$ & $\begin{array}{l}\text { Engagement } \\
\text { significantly correlated } \\
\text { with gender. } \\
\left(\mathrm{r}=-.17^{*} ; 0=\text { male, } 1=\right. \\
\text { female })\end{array}$ \\
\hline $\begin{array}{l}\text { Rimm-Kaufman et. } \\
\text { al. (2015) }\end{array}$ & 387 & 5 th & $\begin{array}{l}\text { "Today I felt } \\
\text { bored in math } \\
\text { class" }\end{array}$ & $\begin{array}{l}\text { No correlation found } \\
\text { between gender and } \\
\text { emotional engagement. }\end{array}$ \\
\hline $\begin{array}{l}\text { Tyler \& Boelter } \\
(2008)\end{array}$ & 262 & $\begin{array}{l}\text { 6th }- \\
8 \text { th }\end{array}$ & $\begin{array}{l}\text { "My classrooms } \\
\text { are fun places to } \\
\text { be" }\end{array}$ & $\begin{array}{l}\text { No correlation found } \\
\text { between gender and } \\
\text { emotional engagement. }\end{array}$ \\
\hline $\begin{array}{l}\text { Wooley \& Bowen } \\
\text { (2007) }\end{array}$ & 7,764 & $\begin{array}{l}\text { 6th }- \\
8 \text { th }\end{array}$ & $\begin{array}{l}\text { "I look forward } \\
\text { to learning new } \\
\text { things" }\end{array}$ & $\begin{array}{l}\text { Mean level differences } \\
\text { found }\left(\mathrm{t}=216.8^{* *}\right) \\
\mathrm{M}=12.0 ; \mathrm{SD}=2.5 \\
(\text { girls) } \\
\mathrm{M}=11.0 ; \mathrm{SD}=2.8 \\
\text { (boys) }\end{array}$ \\
\hline
\end{tabular}

Note. Asterisks $(* *)$ indicates $\mathrm{p}<.01$

Cognitive Engagement 


\section{BOYS' ENGAGEMENT AND INTERPERSONAL RESOURCES IN SIXTH GRADE}

Eight studies were found in the literature that examined cognitive engagement, and of those, five found gender differences indicating boys had lower levels of cognitive engagement, as compared to girls (see Appendix A). For example, a cross-sectional study of fifth and seventh-grade students measured cognitive engagement by examining students' perceptions of their competence, abilities to achieve desired outcomes, and completing assignments. Students rated their level of agreement on items such as, "I have done well with my studies" and "I often succeed in the tasks the teacher gives me". Significant mean level differences were found showing that boys reported lower mean levels in cognitive engagement, as compared to girls (Pietarinen, Soini, \& Pyhältö, 2014). While the previously mentioned cross-sectional study by Wang, Willett, and Eccles (2011) indicated gender differences in behavioral and emotional engagement, the authors did not find significant mean differences in cognitive engagement. Cognitive engagement was conceptualized in terms of self-regulation and cognitive strategy and included student-reported questions such as, "How often are you very good at carrying out the plans you make for solving problems?" (Wang, Willett, \& Eccles, 2011).

\section{School Engagement}

School engagement appears to be less well-defined than the other engagement types; often, it is used as a label for a variety of school-related behaviors. To measure school engagement, studies use various combinations of items reflecting constructs of emotional and behavioral engagement, effort, compliance, participation, school 


\section{BOYS' ENGAGEMENT AND INTERPERSONAL RESOURCES IN SIXTH GRADE}

identification, and interest, valuing of school, attitude, school expectations, and relationships with teachers. Seven studies were found in the literature that tested for gender differences in school engagement. Over half of these studies found either significant correlations between gender and school engagement, favoring girls, or that boys have lower mean levels of school engagement, compared to girls (see Appendix A). For example, in a cross-sectional international study of 12 countries examining whether $7^{\text {th }}, 8^{\text {th }}$, and $9^{\text {th }}$-grade boys and girls report similar levels of school engagement, students rated items such as "I like what I'm learning in school", "I try hard to do well in school", and "When I study, I try to connect what I am learning with my own experiences". Significant mean level differences were found suggesting that boys perceived themselves as less engaged in school than compared to girls (Lam et al., 2012).

Some researchers include other student-reported measures, such as interest in learning tasks, as indicators of school engagement. No gender differences were found in the level of interest students took in learning tasks i.e., "I enjoy most of the subjects taught in this school" (Van de Gaer, Pustjens, Van Damme, \& De Munter, 2009). A longitudinal study by Wang \& Eccles (2012) followed a cohort of 1,479 students in their $7^{\text {th }}, 9^{\text {th }}$, and $11^{\text {th }}$-grade years and found that boys reported lower levels of school compliance (i.e., skipping class, homework completion, involvement in physical fights), participation in extra-curricular activities (i.e., time spent on school activities), school identification (i.e., a general liking for school, connecting school success with life 


\section{BOYS' ENGAGEMENT AND INTERPERSONAL RESOURCES IN SIXTH GRADE}

success), and subjective valuing (i.e., enjoys class and learning, values learning), during seventh grade. Across the grade levels, boys and girls did not differ in slopes, except for subjective valuing, indicating a widening of gender differences in class and learning enjoyment (Wang \& Eccles, 2012).

\section{Summary of Gender Differences in Engagement}

Taken together, the overarching pattern found in the current body of research suggests that gender differences may exist in various dimensions of engagement, indicating that boys are less engaged when compared to girls across school levels. It is noted, however, that many of these findings are based on self-reports, thus more studies including teacher reports may help in providing a richer understanding of the gender differences that exist. Of the multiple dimensions of engagement, it is most clear that boys and girls differ in levels of behavioral engagement, more specifically, that boys may be less likely to participate and pay attention in class, complete academic tasks, as well as follow class rules and norms.

It is less clear whether gender differences exist in emotional, cognitive, and school engagement. The majority of studies that did not find gender differences came from student-reported emotional and cognitive measures of engagement. Differences in how these dimensions are measured indicate that there are multiple perspectives about what constitutes emotional and cognitive engagement. For example, some studies measured emotional engagement by focusing on a student's general feelings in the 


\section{BOYS' ENGAGEMENT AND INTERPERSONAL RESOURCES IN SIXTH GRADE}

classroom and other studies measured emotional engagement by examining a student's feelings of belonging and value with teachers and/or peers (see Appendix A). In a similar vein, studies differed in how cognitive engagement was measured. For example, some studies measured a student's self-regulatory behavior, such as planning and monitoring, while other studies focused on students' perceptions of paying attention and working hard in class (measures that in other studies were often considered markers of behavioral engagement).

\section{Stage-Environment Fit over the Transition to Middle School}

The overarching pattern in the literature suggests that student motivation and engagement decline during the transition into middle school and many theorists have offered explanations for this trajectory. Eccles and Midgley (1989) posited that the interaction between changes in the developmental needs of adolescents and changes in the environment can result in either positive or negative outcomes depending on the "Stage-Environment Fit", that is, whether the changes in context can support and meet the needs of the adolescent. There is concern that there may be a discrepancy between adolescents' needs and the affordances and constraints of their environment, especially during the transition to middle school, a time when they are experiencing substantial normative changes in their school and classroom context. Research suggests that this misalignment between an adolescent's developmental needs and the changes of 


\section{BOYS' ENGAGEMENT AND INTERPERSONAL RESOURCES IN SIXTH GRADE}

environment entering middle school strongly relates to declines in student motivation and engagement (Eccles \& Roeser, 2011).

\section{Adolescent Needs in Middle School}

From a developmental perspective, the needs of adolescents change in middle school on a cognitive, social-emotional, and physical level, and understanding these shifts may be helpful when trying to meet these needs in the school environment. (Anderman, Maehr, \& Midgley, 1999). It has been suggested that adolescents may benefit from an academic environment that does not involve comparison and competition with peers because it can create feelings of vulnerability during a time when adolescents may already be self-conscious from pubertal changes and identity exploration (Eccles \& Midgley, 1989; Simmons, Burgeson, Carlton-Ford, \& Blyth, 1987). Furthermore, as their intellectual abilities increase, it is imperative that adolescents have more autonomy, have choices in their personal and academic life, and are given schoolwork more complex in nature (Deci \& Ryan, 2000; Eccles \& Midgley, 1989). When adolescents have the opportunity to make decisions, they may feel personally empowered leading to feelings of competence and achievement. Choices regarding peer relationships are at the forefront during this time making it important for adolescents to have regular contact with other students, leading to opportunities to make close connections and form friendships. In a similar vein, teachers become an important source of adult contact and mentorship during 


\section{BOYS' ENGAGEMENT AND INTERPERSONAL RESOURCES IN SIXTH GRADE}

a time when adolescents may strive for more autonomy and individualization from their parents.

\section{Changes in the School Context During the Transition to Middle School}

As mentioned previously, there are many environmental changes students experience as they transition from elementary to middle school. In terms of organization, instruction, and climate, adolescents experience an increase in school size and number of peers and may discover that teachers use competition to induce student motivation and compliance (Eccles \& Midgley, 1989). Students may also be confronted with stricter grading policies and standards, as well as increases in teacher control and discipline (Feldlaufer, Midgley, \& Eccles, 1988). As teachers exert more control in classrooms with increased quantities of students, youth may experience declines in autonomy, competence, the trust of the teacher, and feelings of interpersonal connection with their teachers and peers (Eccles \& Midgley, 1989; Simmons \& Blyth, 1987).

\section{The Importance of High-Quality Relationships to Student Engagement and}

\section{Motivation}

It is clear that positive relationships contribute to children's well-being and functioning, positively influence their socio-emotional development, and impact their capacity to actively engage in school (Wentzel \& Ramani, 2016). Relationships serve as sources of happiness and can also act as a buffer against stress during challenging times by providing emotional support and help with difficult tasks. However, when children 


\section{BOYS' ENGAGEMENT AND INTERPERSONAL RESOURCES IN SIXTH GRADE}

experience negative interactions or events in relationships, such as rejection or loss of a relationship, relationships can also become sources of distress (Baumeister \& Leary, 1995). The existing body of literature strongly suggests that positive relationships with parents, teachers, and peers play a substantial role in supporting (promoting) student success at school (Anderman \& Kaplan, 2008; Martin \& Dowson, 2009; Wentzel \& Miele, 2016; Wigfield et al., 2015). A literature review of achievement motivation and engagement shows that students who perceive their relationships as positive, especially with parents and teachers, are more engaged in the classroom, compared to their peers who do not see their relationships in a positive light (Wigfield et al., 2015). Popular belief may hold that boys are less social or may not need the same level of closeness in relationships as compared to girls, however, research indicates that boys need to have close social relationships and these social resources are important for positive outcomes for boys (Martin \& Dowson, 2009; Way, 2011). The degree of intimacy and closeness, or lack thereof, that boys experience in their relationships has been linked to academic outcomes, such as engagement and school completion (insert footnote: The absence of close relationships have also been linked to feelings of loneliness and mental health challenges (i.e., depression and suicide; Way 2011). In a theoretical review of achievement motivation theories, Martin and Dowson (2009) conclude that mechanisms involved in supporting motivation and promoting engagement are relational in nature and 


\section{BOYS' ENGAGEMENT AND INTERPERSONAL RESOURCES IN SIXTH GRADE}

the positive relationships students have with others are a crucial element to academic functioning.

\section{Characteristics of Positive Interpersonal Relationships}

There is little question that positive relationships with adults impact the academic development of youth. Previous literature has outlined features of positive parent, teacher, and peer relationships that are integral in promoting academic engagement (Martin \& Dowson, 2009; Wentzel \& Miele, 2016). Positive relationships are warm, caring, and supportive in nature. They include emotional closeness, such as feeling open to sharing thoughts and feelings. Spending time together and sharing activities are also found in positive relationships. Several aspects of positive relationships have been shown to contribute to school success.

\section{Self-Systems Theory}

Self-Systems Theory (Connell \& Wellborn, 1991), grounded in SelfDetermination Theory (Ryan \& Deci, 2017), can be used as a framework to understand the aspects of positive relationships that are key to promoting student engagement. As seen in Figure 1, Connell and Wellborn (1991) posit that individuals (students) have psychological needs for relatedness, competence, and autonomy, and these needs can be met or thwarted by their context or environment. Relatedness is the need to feel secure in one's social connections and "to experience oneself as worthy, and capable of love and respect” (Connell \& Wellborn, 1991). Competence is the need an individual has to see 


\section{BOYS' ENGAGEMENT AND INTERPERSONAL RESOURCES IN SIXTH GRADE}

himself as efficacious in generating positive results and averting negative ones. The need for autonomy refers to having a choice to begin, sustain, and monitor an activity, as well as the connection between the chosen behavior and an individual's own goals and values.

\section{Figure 1}

Self-Systems Model for Student Engagement

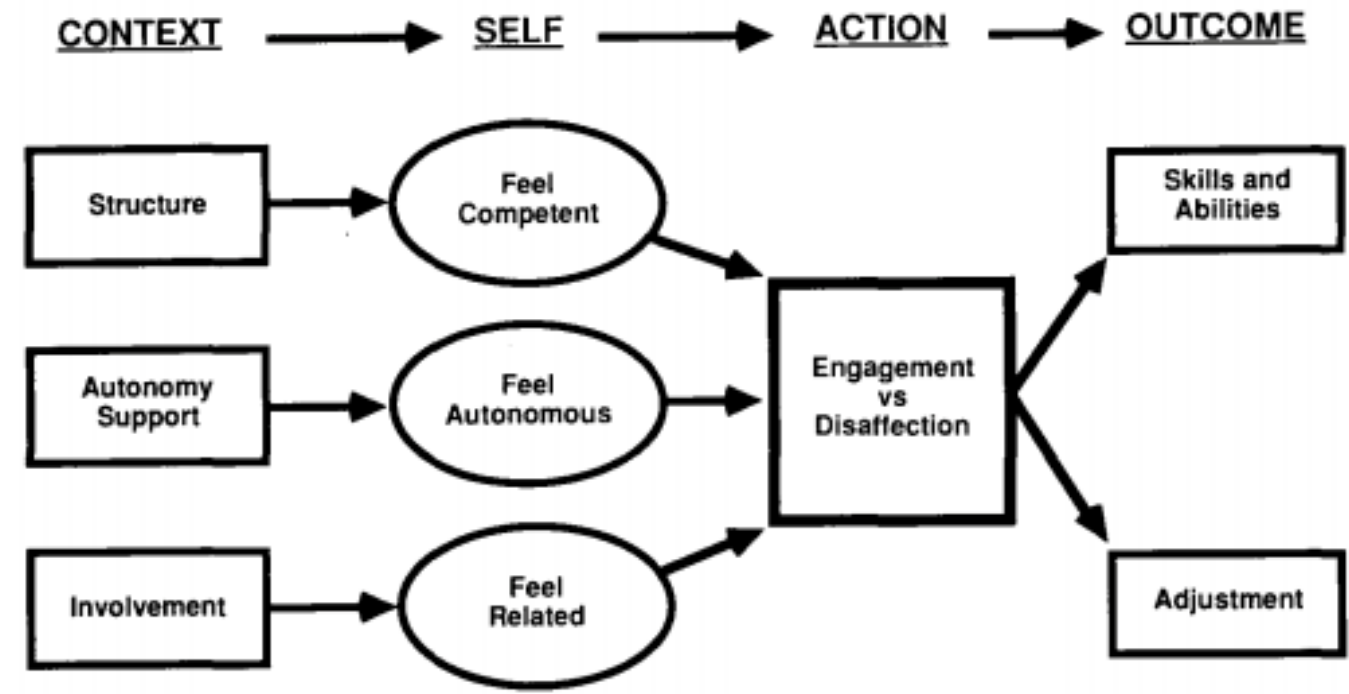

\section{Contextual Supports}

Self-systems theory also identifies the ways that contexts can meet these needs:

by providing involvement, structure, and autonomy support. Involvement depicts interactions in which parents and teachers pay attention to the youth, show that they personally know the youth, express genuine interest, and provide emotional support. As a result of these interactions, a student experiences a sense of closeness and connection. This fulfills the need for relatedness or belonging, which has been identified as a critical 


\section{BOYS' ENGAGEMENT AND INTERPERSONAL RESOURCES IN SIXTH GRADE}

factor in supporting student engagement in school (Martin \& Dowson, 2009). Feeling

accepted, important, special, and paid attention to by parents, teachers, and peers is

energizing to the student and promotes positive affect and mood, (Skinner \& Belmont, 1993) leading to engagement in the classroom.

Structure refers to contextual provisions of clear expectations, helpfulness when needed, and clear feedback. For students to feel competent in school, they need to know how to do well and must feel capable of accomplishing the tasks necessary to succeed. Parents and teachers can help to meet these needs by providing an environment with high levels of structure that include clear instructions about what is expected, as well as clear consequences for behavior. When structure is high, students are more likely to perceive themselves as competent, leading them to participate in class, engage in schoolwork, stay on-task, and experience positive emotions associated with school, such as excitement and interest.

The third key provision is autonomy support. The components of autonomy support include provisions of choice, respect, and relevance. In order for a student to feel autonomous, teachers and parents can provide an environment that supports a youth's autonomy by giving a range of choices within the given set of expectations and by establishing with students the connection between their behaviors and academic goals. When a student's autonomy is supported, it is likely that the student will value and desire to do well in school, leading to active engagement in the classroom. 


\section{BOYS' ENGAGEMENT AND INTERPERSONAL RESOURCES IN SIXTH GRADE}

Connell and Wellborn (1991) posit that students appraise interactions with parents, teachers, and peers within the social contexts of the home, school, and classroom and assess whether their needs are met by the contextual affordances provided. These interactions shape a student's internal working model about their sense of competence, autonomy, and belonging. When parents and teachers provide high levels of structure, autonomy support, and involvement, a student feels competent, autonomous, and connected and is likely to engage in academic work. Conversely, when structure, autonomy support, and involvement is low or absent, a student will experience low levels of competence, autonomy, and relatedness and it is likely that disaffection will occur.

\section{Aspects of Positive Relationships with Parents and Teachers that are Important for}

\section{School Success}

\section{Parents}

Research indicates that the quality of relationship between parent and child contributes to a child's academic engagement in school (Barger, Kim, Kuncel, \& Pomerantz, 2019; Bempechat \& Shernoff, 2012; Grolnick, Gurland, DeCourcey, \& Jacob, 2002; Rowe, Ramani, \& Pomerantz, 2016; Vasquez et al., 2016; Wigfield et al., 2015). A child's perception of his/her social context begins at home. The very first set of social interactions a child has is with a parent, and it is through the quality of these exchanges, a child's view of his/her social world begins to take form. A layer of social 


\section{BOYS' ENGAGEMENT AND INTERPERSONAL RESOURCES IN SIXTH GRADE}

context in the child's environment is introduced when a child starts school, leading to parent-child interactions that are academic in nature.

Several pathways have been identified showing how parents contribute to student engagement, including the quality of parent-child interactions, characteristics of the home environment, parenting practices, and general parental beliefs toward achievement, however, many researchers have emphasized a composite of parenting behaviors, that include appropriate structure, involvement and interest in the child, and autonomy support that promotes positive academic outcomes (Barger, Kim, Kuncel, \& Pomerantz, 2019; Bempechat \& Shernoff, 2012; Grolnick, Gurland, DeCourcey, \& Jacob, 2002; Rowe, Ramani, \& Pomerantz, 2016; Vasquez et al., 2016; Wigfield et al., 2015). These main behaviors are what is thought to be central to helping children feel related, competent, and autonomous, leading to an increased interest in and enthusiasm for academic activities (Grolnick et al., 2002).

The literature examining children's achievement motivation and behavior strongly suggests that children are more likely to be academically engaged when parents are warm, consistent, and supportive while also providing appropriate levels of structure and autonomy support in the home (Wigfield et al., 2015). In order for parents to adjust their parenting practices appropriately, it is clear that they must spend time and show interest in observing their child's developmental needs and competencies. When parents are actively involved and emotionally supportive, children will more likely desire to model 


\section{BOYS' ENGAGEMENT AND INTERPERSONAL RESOURCES IN SIXTH GRADE}

parents' academic goals, values, and behaviors (Wigfield, Eccles, \& Rodriguez, 1998).

By high school, parent involvement has been positively linked to student engagement, more specifically, higher effort, concentration, and attention are reported by students, and this effect may be stronger when parents exhibit an authoritative parenting style characterized by warmth, acceptance, structure, and autonomy support (Steinberg, Lamborn, Dornbusch, \& Darling, 1992).

Parent involvement. It is clear that parental involvement in a child's schooling can positively affect student engagement. Parent involvement has been defined as parents' commitment of resources to their child's academics, and from a developmental perspective, this involvement creates a context that depends on resources parents provide to the child, leading to potential benefits for the child (Grolnick \& Slowiaczek, 1994; Pomerantz \& Moorman, 2010). Parent involvement may offer a sense of security and connection, impart to children the value of school, the control over academic performance, and increase a child's competence in academics (Gonzalez-DeHass, Willems, \& Holbein, 2005; Pomerantz \& Moorman, 2010).

Parent involvement has been measured by examining various parental practices that contribute to a child's success in school, including participation in school activities and parent-teacher conferences, helping with homework and monitoring academic progress, reacting to grades and other feedback from teachers, engaging in a child's extra-curricular activities, communicating parental values such as the importance of 


\section{BOYS' ENGAGEMENT AND INTERPERSONAL RESOURCES IN SIXTH GRADE}

effort and success in school, and the degree of parent control and autonomy support the parent provides at home (Gonzalez-DeHass, Willems, \& Holbein, 2005). As early as elementary school, the extent to which parents provide at-home activities that promote a child's social and academic skills, were found to predict engagement in school (Izzo, Weissberg, Kasprow, \& Fendrich, 1999).

Parent structure. A second type of parenting practice identified as an important component to children's academic outcomes is parental structure. The ways in which parents organize the surroundings of a child are crucial in children's motivation.

Structure has been defined as clear and consistent rules and expectations parents have set for their children (Grolnick, 2009). Giving children information about what is expected, as well as guidelines clearly outlining how to attain positive outcomes while avoiding negative ones, helps children to feel in control and competent in pursuing desires and goals, and perceived competence is thought to lead to student engagement (Connell \& Wellborn, 1991). Farkas and Grolnick (2010), have identified six components of parental structure important for children's academics; clear and consistent rules and expectations, giving children opportunities to meet expectations while providing necessary provisions, predictability of consequences, offering feedback about how well expectations are being met, explaining why the rules and expectations are important, and taking the lead as an authority in decision making. In a study of seventh and eighth-grade students and their mothers, clear and consistent guidelines were found to be positively correlated with 


\section{BOYS' ENGAGEMENT AND INTERPERSONAL RESOURCES IN SIXTH GRADE}

children's competence and knowledge about how to be academically successful (Farkas \& Gronlick, 2006). While less is known about the direct relationship between parental structure and engagement, it can be concluded that children feel more competent and in control when parents provide clear and consistent expectations with opportunities to meet them, leading children to be motivated in the classroom.

Parent Autonomy Support. Supporting a child's autonomy has been identified as another parenting practice that promotes children's academic functioning (Pomerantz \& Moorman, 2010; Vasquez et al., 2016). Autonomy support has been described as permitting children to explore their environment, initiate their own behavior, and allowing children to engage in problem-solving (Deci \& Ryan, 1987). When parents allow children to interact with their surroundings and give them time and space to initiate behavior, children are more likely to feel in control of themselves and feel competent in governing their environment. Children are more likely to be intrinsically motivated when they initiate the behavior, leading to them being more engaged with their surroundings. In contrast, controlling behavior from a parent can inhibit children's academic functioning (Pomerantz, Grolnick, \& Price, 2005). Controlling behavior has been described as parents pressuring children by means of commands, restrictions, or love withdrawal to produce particular outcomes, such as getting good grades in school (Pomerantz \& Moorman, 2010). When parents give directives, children do not have the opportunity to explore their surroundings, initiate behaviors, and solve problems independently, and by this, they 


\section{BOYS' ENGAGEMENT AND INTERPERSONAL RESOURCES IN SIXTH GRADE}

miss out on experiencing a sense of autonomy and agency, leading to low levels of motivation and engagement.

Academically, parents can provide autonomy support in both the school and home contexts. When parents are visiting school, they can wait for children to lead conversations and activities and allow them to present the projects they have been working on, rather than directing the agenda. At home, parents can allow youth to choose the classes they would like to enroll in rather than controlling the choice by pressuring the child to take a specific class. A robust body of literature has shown that children who have positive perceptions of their academic competence tend to have parents who are more autonomy-supportive and less controlling (Pomerantz, Grolnick, \& Price, 2005). Higher levels of intrinsic motivation in school, versus extrinsic motivation, has been found in children whose parents exhibit more autonomy-support and less control (Grolnick \& Ryan, 1989), and children's perceptions of high parental autonomy support has been positively linked to competence and engagement in school (Grolnick, Ryan, \& Deci, 1991).

\section{Teachers}

A robust body of literature suggests that the nature and quality of student-teacher relationships is strongly associated with student academic outcomes (Wentzel, 2010, 2016). Warm, caring, and supportive relationships with teachers are an important aspect in a student's motivation to engage in schoolwork (Gregory \& Korth, 2016; Martin \& 


\section{BOYS' ENGAGEMENT AND INTERPERSONAL RESOURCES IN SIXTH GRADE}

Collie, 2016; Wigfield et al., 2015). Research indicates that positive student-teacher interactions may be a vital link to student engagement (Pianta, Hamre \& Allen, 2012).

Teacher Involvement. Teacher involvement has been defined as the quality of relationship between the student and teacher (Skinner \& Belmont, 1993). Highly involved teachers take time with, enjoy interacting with, are attuned to, and express affection toward students, and it is these provisions of involvement that positively influence student engagement (Quin, 2017; Skinner \& Belmont, 1993). In the classroom environment, interactions perceived as warm and caring between teacher and student create a positive emotional climate suited for learning. Research indicates that emotional climate is a component of teacher involvement that is vital for promoting student engagement (Pianta, Hamre, Allen, 2012; Wang \& Degol, 2016). A specific kind of teacher involvement is called sensitivity and refers to attunement and responsiveness of the teacher to students' needs in the classroom (Paro, Pianta, \& Stuhlman, 2004). Research shows that consistent and timely responses from teachers are positively related to student engagement (Pianta, Hamre, Allen, 2012). When teachers are available and provide reliable responses, a sense of safety is created that affords students the opportunity to explore and learn (Pianta, Hamre, Allen, 2012).

Teacher Structure. Structure has been defined as the amount of information the student is provided about how to successfully meet classroom expectations (Skinner \& Belmont, 1993). Teachers can provide high structure in the classroom by clearly 


\section{BOYS' ENGAGEMENT AND INTERPERSONAL RESOURCES IN SIXTH GRADE}

expressing to students the expectations and predictable consequences, responding consistently, offering instrumental help, and having flexibility in teaching strategies to align with the needs of the student (Skinner \& Belmont, 1993). By providing structure, teachers give students a roadmap to know how to behave in socially acceptable ways, helping students to feel socially and academically competent, which in turn, leads students to engage in schoolwork and classroom activities (Roorda, Koomen, Spilt, \& Oort, 2011; Wentzel, 2010).

Teacher Autonomy Support. Autonomy support has been defined as the amount of space a student is allowed to willfully act or behave (Skinner \& Belmont, 1993). Teachers that provide high autonomy support are flexible in the choice of learning activities, according to the interest of the child (Skinner \& Belmont, 1993). Research indicates that autonomy-supportive and student-focused classrooms are important in promoting academic engagement (Pianta, Hamre, \& Allen, 2012). When interactions in the classroom are structured around students' interest, rather than the teacher's interest), students report more positive feelings about school, and in turn, this leads to higher classroom participation and engagement with schoolwork (Reeve et al., 2004).

\section{Summary of Parents' and Teachers' Context Provisions}

Taken together, parents and teachers play a strong role in children's academic functioning. It is clear that warm, caring, and supportive relationships in the home and at school are important resources for promoting children's academic engagement. These 


\section{BOYS' ENGAGEMENT AND INTERPERSONAL RESOURCES IN SIXTH GRADE}

high-quality relationships characterized by contextual supports of involvement, structure, and autonomy support lead to positive academic outcomes for children.

\section{Peer Contexts and Academic Functioning, Engagement, and Achievement}

The previous literature examining the influence of peer relationships on student motivation and academic engagement suggests that there are multiple aspects of peer relationships that contribute to student engagement (Bukowski, Laursen, \& Rubin, 2019; Wentzel, 2009; Wentzel \& Muenks, 2016). The majority of this work highlights various facets of peer relationships, such as socialization, relatedness, also known as belonging, social support, and social status (Juvonen, Espinoza, Knifsend, 2012; Juvonen \& Knifsend, 2016; Ryan \& Ferguson, 2019). Taken together, the peer literature suggests that positive peer relationships are also important for promoting student engagement. However, while parents and teachers are (genetically or culturally) assigned to students, peer affiliations are self-selected. This makes the examination of peer influences more complex: Examinations of peer influences need to take into account how peer affiliations come about (usually called selection processes).

\section{Socialization and Selection}

Peers can influence a youth's thoughts, beliefs, and behaviors about their world and school through the socialization of norms and values (Kindermann \& Gest, 2009). Research indicates that students who spend more time with peers who are engaged in school also show a higher level of academic engagement, while spending time with peers 


\section{BOYS' ENGAGEMENT AND INTERPERSONAL RESOURCES IN SIXTH GRADE}

who are less engaged can lead to lower levels of individual academic engagement (Ryan \& Shin, 2018). Much of the positive association between peer and individual engagement can be explained by the occurrence of homophily, which is the finding that students affiliate with peers who are similar to themselves; students select friends that are similar as well as becoming similar to each other over time. Research indicates that youth are similar to friends in effortful behavior with academic work (Kindermann, 1993), as well as in disruptive behavior in class (Shin \& Ryan, 2014). There is also evidence of similarity of emotional engagement between friends in that they are alike in interests and enjoyment of school tasks (Ryan, 2001).

Longitudinal studies examining peer networks suggest that similar engagement levels between peers can also be due to peer influence over time, not just selection factors. Specifically, it has been found that the behavioral engagement of a student's peer group predicts changes in that individual's behavioral and emotional engagement over time (Kindermann, 1993; Ryan, 2001). Overall, youth may select friends similar to their personal interests and academic engagement while also becoming more like their friends over time.

\section{Sense of Relatedness to Peers and Social Support}

There is a robust body of literature indicating that a sense of relatedness or belonging with peers is positively related to engagement (Juvonen, Espinoza, \& Knifsend, 2012). Relationships with peers provide companionship and shared time 


\section{BOYS' ENGAGEMENT AND INTERPERSONAL RESOURCES IN SIXTH GRADE}

together. Social acceptance and emotional connection with peers, dyadically or in a group, may promote a student's academic competency to engage in schoolwork (Wentzel \& Muenks, 2016). The desire to be accepted and have strong bonds with others may lead students to mirror other peer members' academic goals and interests, as well as to follow norms of engaging in schoolwork (Deci \& Ryan, 2002). Juxtaposed with social belonging and acceptance, students who experience peer rejection may not have access to interpersonal resources that afford information about acceptable social and academic norms, positive peer role models, and extrinsic social rewards pertaining to academic behaviors (Parker \& Asher, 1987).

Peer relationships perceived as warm and caring can foster a student's academic engagement. A review of peer influence on student motivation shows that students are more interested and engaged in school activities when they feel their peers care about them. Conversely, students are more at risk for academic problems when they lack positive and caring peer relationships (Wentzel \& Muenks, 2016). Peer relationships offer multiple provisions to students that serve as a resource in promoting academic engagement. Different types of peer support have surfaced as important sources of academic support that help students engage with academic activities. Peers provide academic support by offering instrumental help and guidance on assignments, sharing information, and giving encouragement as well as working on schoolwork together (Juvonen, Espinoza, \& Knifsend, 2012). 


\section{BOYS' ENGAGEMENT AND INTERPERSONAL RESOURCES IN SIXTH GRADE}

\section{Kinds of Peer Relationships}

In the field of peer research, various types of peer relationships have been identified that are thought to influence academic motivation and student engagement, namely, friendships, crowds, and peer groups (Kindermann, 2016). These different kinds of peers are distinguished by whether they are self-identified or identified from other peers as well as by the characteristics of the relationship (Kindermann \& Skinner, 2012). The different types of relationships overlap with one another and uniquely contribute to various aspects of a student's motivation and academic functioning.

Friendships. Have been a prominent focus in peer research. Friendships are connections that tend to be more private and intimate, as compared to affiliated peers, and are based on more specific shared interests (Wentzel \& Muenks, 2016), values, and beliefs. This type of peer relationship is characterized by children liking and enjoying being with each other, helping one another, and sharing personal information with one another (Bukowski, Motzoi, \& Meyer, 2009). Children's friendships are self-selected and reciprocal and are more intimate in nature. In this line of research, friendships are largely identified by reciprocal nominations, meaning, two children individually report being friends with one another (Berndt, 2004; Kindermann \& Skinner, 2012).

Friendships and Achievement. Friendship studies indicate that the achievement orientation of friends may influence a student's achievement motivation and academic outcomes. For example, Altermatt and Pomerantz (2005) found that low-achieving 


\section{BOYS' ENGAGEMENT AND INTERPERSONAL RESOURCES IN SIXTH GRADE}

students in fifth, sixth, and seventh grade had more positive academic outcomes when they had stable friendships with students who were high achieving, compared to lowachieving students who had friendships with other low-achieving students. In a study examining the influence of friends on adolescent motivation, Berndt, Laychak, and Park (1990) found that close friends were likely to become more similar in academic decisions over time. Taken together, friends can be a source of academic influence and may be a social resource for students in promoting academic motivation and functioning.

High-Quality Friendships. Friendship quality is an important feature of peer relationships that has been found in the literature to promote engagement. High-quality friendships are close and committed relationships that are positive in nature and low in conflict, providing companionship and support (Berndt, 2002). High-quality friendships are positively related to student engagement, and research indicates that having close and supportive friendships positively predicts a student's engagement across a school year. Conversely, the lack of high-quality friendships is negatively associated with student engagement, especially during school transitions (Juvonen, Espinoza, \& Knifsend, 2012).

Friends' Classroom Behavior. Along with having high-quality friendships, studies also show that a student's perception of friends' classroom behavior is positively related to changes in individual engagement over time (Berndt \& Keefe, 1995). This finding suggests that when students see their friends acting in acceptable ways in class, they are also more likely to follow suit and be engaged in the classroom. 


\section{BOYS' ENGAGEMENT AND INTERPERSONAL RESOURCES IN SIXTH GRADE}

Friendship Stability. Some adolescent friendships are stable over time, while others come and go, especially during the transition to middle school. The stability of friendships across a school year is an important indicator of whether a student has long, enduring close friendships. Berndt and Keefe (1995) found that students with stable friendships across a school year are higher in teacher-rated engagement and less disruptive, as compared to students with unstable friendships. Taken together, these findings indicate that fluctuations in friendships, whether it be gains or losses, may contribute to lower levels of student engagement.

Social Crowds. Social crowds are based on children's reputations in school. Reputations can be formed from the physical attributes, interests, or behaviors of a student, as well as whether the student is accepted or disliked. Typically, the end result is that children are placed in named social categories based on similar behaviors or share a similar reputation, such as "nerds" or "jocks". Group membership of a crowd is not selfselected, rather, is based on the decision of the larger social group. Furthermore, members of a crowd may not even know one another or interact with each other on a daily basis. Crowd affiliation research has used both self-reports to identify members of crowds, as well as peer ratings (Brown \& Dietz, 2009). Self-reports have directed participants to either select a single group or multiple groups they identify most with or groups they perceive that other peers would associate them with. Studies examining peer influences indicate that members of social crowds can be a source of influence for 


\section{BOYS' ENGAGEMENT AND INTERPERSONAL RESOURCES IN SIXTH GRADE}

academic motivation and achievement, and the strength of this influence may differ between groups (Kindermann, 2016; Wentzel \& Muenks, 2016). For example, "Jocks" and "Popular" crowds tend to exert more pressure on members to participate in schoolwork (Brown \& Dietz, 2009). In sum, the experience that students have in crowds as an academic influence varies in strength and depends on the crowds they are associated with.

Peer Groups: Groups Defined by Social Interactions. While friendships occur at any age, peer groups tend to appear during middle school and continue through high school and begin to lessen toward the end of high school (Wentzel \& Muenks, 2016). Affiliated peers are others with whom a student spends time or hangs out with, and the group structure is publicly acknowledged and identifiable by others (Wentzel \& Muenks, 2016). However, identifying peer groups empirically can be complicated. Self-reported peer group data is potentially unreliable. In self-reports, students may over-report their personal group membership with "popular" students or leave out peer groups they spend time with if they consider these groups to be seen as unfavorable to others. An alternative method to obtain peer group data, socio-cognitive mapping (SCM; Cairns \& Cairns, 1994), is a preferable data collection method in which students act as "expert" participant observers identifying "who hangs out with whom" on a daily basis at school. An advantage of this method is that data are included about non-participating students (e.g., students who are absent from school on days of data collection; often, these are students 


\section{BOYS' ENGAGEMENT AND INTERPERSONAL RESOURCES IN SIXTH GRADE}

who experienced problems with academics and or friendships - such students are dummy-coded). This method allows for student observers to identify multiple peer groups, including groups of which they themselves are members. Binomial z-tests and Fisher's exact tests can be used to identify significant connections between students based on observations that are more frequent than expected by chance (Kindermann, 2007).

There are various characteristics of peer groups that are related to an individual's level of engagement. The number of friends a student has, and the size of a student's peer group is positively related to student engagement (Juvonen, Espinoza, \& Knifsend, 2012). For example, peer acceptance and the number of friends before the transition to middle school positively correlates with class participation after the transition (Kingery \& Erdley, 2007), and the number of members in a student's peer group predicts increases in individual engagement across the school year (Kindermann, 2007). It has also been found that the average engagement level of a student's peer group can also be a source of academic support or academic stifling. Kindermann (2007) found that changes in student's engagement over the school year are positively predicted from the average engagement level of their peer group, so that students with highly engaged groups do better over time while students with disaffected groups sharply decrease. In sum, peers

provide a social context that can either support or stifle a student's engagement in school and positive peer relationships are vital in promoting student academic engagement. 


\section{BOYS' ENGAGEMENT AND INTERPERSONAL RESOURCES IN SIXTH GRADE}

Taken together, this review of the current body of literature on engagement and the role interpersonal relationships play in promoting engagement indicates that little is known regarding how these processes transpire for boys. The purpose of this study is to utilize what we do know about engagement and interpersonal relationships during middle school and explore how these processes unfold for boys and identify what boys need from their social context to support their engagement in school. 


\section{BOYS' ENGAGEMENT AND INTERPERSONAL RESOURCES IN SIXTH GRADE Chapter 3. Research Questions and Hypotheses}

To better understand how boys' motivation can be sustained over the transition to middle school, this study aims to investigate how their interpersonal resources, namely provisions of support from parents, teachers, and peers, play a role in boys' engagement during sixth grade, the first year of middle school. Most studies on engagement are crosssectional in design, so the current study will contribute longitudinal information by utilizing two time points to examine whether boys' interpersonal relationships matter to changes in their engagement.

The study is organized around two research questions. First, this study explores gender disparities in student engagement and interpersonal relationships with parents, teachers, and peers. Although there is a robust line of research suggesting that boys are academically underperforming (compared to girls), less is known about gender differences in academic engagement. This study adds to the current research by examining whether boys are less engaged than girls at the beginning and at the end of the first year of middle school and whether the declines in engagement experienced over sixth grade are steeper for boys, compared to girls. While research suggests that positive relationships are important for school success, it is less clear whether there are gender differences in these interpersonal resources. This study adds to previous research by exploring whether boys experience lower levels of these interpersonal resources at the beginning and at the end of the first year of middle school and, if students experience 


\section{BOYS' ENGAGEMENT AND INTERPERSONAL RESOURCES IN SIXTH GRADE}

losses of these resources over sixth grade, whether there are steeper losses for boys, compared to girls.

Second, focusing only on boys, the present study explores the kinds of interpersonal resources that buffer declines in engagement by examining whether boys with higher levels of interpersonal resources show higher levels of engagement at the beginning and at the end of the first year of middle school, and if these boys show smaller declines in engagement over sixth grade, compared to boys with lower levels of interpersonal resources. Further, interpersonal resources are analyzed to identify the level of interpersonal resources needed to partially or fully buffer boys' declines in engagement. The existing literature indicates that boys' positive relationships can lead to their success in school, however, less is known about how boys' interpersonal resources are connected to their engagement. This study adds to current research by examining the role of boys' interpersonal resources as a potential buffer against declines in engagement. Above examining gender differences in mean levels of engagement, this study contributes to the current literature by focusing solely on boys' engagement and the kinds of interpersonal resources boys need during the first year of middle school.

\section{Research Question 1: Gender Disadvantages in Engagement and Interpersonal}

\section{Resources}

Do boys show lower levels of engagement and experience lower levels of interpersonal resources than girls during the first year of middle school? 


\section{BOYS' ENGAGEMENT AND INTERPERSONAL RESOURCES IN SIXTH GRADE}

1a1. Compared to girls, do boys show lower levels of engagement in school at the beginning and at the end of sixth grade?

1a2. Compared to girls, do boys show greater declines in engagement over sixth grade?

1b1. Compared to girls, do boys experience lower levels of interpersonal resources in school at the beginning and at the end of sixth grade?

1b2. Do boys experience greater losses of interpersonal resources over sixth grade, than compared to girls?

Hypothesis 1a1. Boys will show lower levels of engagement in school at the beginning and at the end of sixth grade, as compared to girls.

Hypothesis 1a2. Boys will show greater declines in engagement over sixth grade, as compared to girls.

Hypothesis 1b1. Boys will experience lower levels of interpersonal resources in school at the beginning and at the end of sixth grade, as compared to girls.

Hypothesis 1b2. Boys will experience greater losses of interpersonal resources over sixth grade, as compared to girls.

\section{Research Question 2}

What kinds of interpersonal resources buffer boys' declines in engagement?

2a. Compared to boys with lower levels of interpersonal resources, do boys with more resources show higher levels of engagement in school at the beginning 


\section{BOYS' ENGAGEMENT AND INTERPERSONAL RESOURCES IN SIXTH GRADE}

and at the end of sixth grade?

2b. Compared to boys with lower levels of interpersonal resources, do boys with more resources show smaller declines in engagement over sixth grade?

2c. What levels of interpersonal resources are needed to buffer boys' declines in engagement?

Hypothesis 2a. Boys with more resources will show higher levels of engagement in school at the beginning and at the end of sixth grade, as compared to boys with lower levels of interpersonal resources.

Hypothesis 2 b. Boys with more resources will show smaller declines in engagement over sixth grade, as compared to boys with lower levels of interpersonal resources.

Hypothesis 2c. It is expected that boys with stable or increased levels of engagement across the school year, or who show no declines in engagement, will score relatively high on all types of interpersonal resources. This will indicate the provisions boys need to maintain their engagement across sixth grade. A portion of boys will not decline in engagement across the school year (approximately 40\%). 


\section{BOYS' ENGAGEMENT AND INTERPERSONAL RESOURCES IN SIXTH GRADE \\ Chapter 4. Methods}

The current study will use data from an existing larger longitudinal dataset on the entire cohort of sixth graders in a small town (Kindermann, 2007); only a small number of sixth graders may have been missed who attended private schools in the vicinity. The previous study had approval from the University of Rochester and the local school district. The data were collected in the 1990-1991 school year. The Portland State University Human Subjects Review Boards continues to approve this research.

\section{Setting and Sample}

The sample consisted of 366 sixth-grade students in a small rural/suburban town in New York. Of the 366 sixth grade students, 340 (93\%) consenting students participated in questionnaire assessments; 193 were males (53\%). Parents were informed prior to data collection and passive parental consent procedures were used (about 10 parents declined participation). Information on ethnic background was not obtained, however, of the town's 8,000 residents, 90\% were Caucasian (of European American descent, mostly Italian or Scandinavian) and $87 \%$ of the adults had at least a high school degree.

Data were collected during the first months of middle school (sixth grade), and again during the last month of the school year. In the school, sixth grade was structured around Homeroom teachers: Each student was assigned to one homeroom teacher who saw the students daily in the homeroom classroom. Thus, homeroom teachers were those 


\section{BOYS' ENGAGEMENT AND INTERPERSONAL RESOURCES IN SIXTH GRADE}

teachers who knew a given student best (typically, homeroom teachers also taught substantive lessons, mostly in their own homeroom class). In the school, there were 13 homeroom teachers, and all participated in the study, and all indicated that they knew their students well or very well.

Of the 340 participating sixth-grade students, teachers provided information for 318 students in the beginning of the school year. Seven students were missed who hadn't arrived at school, 8 students were new to the school and teachers did not know them well, and 7 had changed homeroom teachers. At the end of the school year, teachers provided reports for 322 students. The differences were due to students leaving the school (18 students of which 11 were boys) and/or new students arriving at the school after the study had begun (11 students of which 11 were boys). There were 300 students for which teacher reports were collected at both time points. 181 were male students who provided data at both measurement points (193 male students provided self-report data for at least a single time point).

\section{Design and Measures}

An advantage of the data set is the use of multiple independent reporters: The study used teacher-reports on boys' observed classroom engagement (academic motivation), student self-reports measuring perceptions of relationship quality with parents and teachers (involvement, structure, and autonomy support), student reports of relatedness with parents, teachers, and peers, self-reports of friendship quality, and peer 


\section{BOYS' ENGAGEMENT AND INTERPERSONAL RESOURCES IN SIXTH GRADE}

observer reports (Socio-Cognitive Mapping) assessing peer group composition and network size.

\section{Engagement Versus Disaffection}

13 homeroom teachers completed a 14-item Likert-type scale report measuring their perceptions of students' academic engagement (Wellborn, 1992). Two components of engagement were assessed: behavioral engagement (e.g., When we start something new in class, this student participates in the discussions," "In my class, this student comes unprepared") and emotional engagement (e.g., "When we start something new in class, this student is enthusiastic", "In my class, this student seems unhappy"). Earlier studies have shown that the two dimensions of engagement are significantly intercorrelated $(\mathrm{r}=$ $.31, \mathrm{n}=144 ;$ Skinner \& Belmont, 1993; $\mathrm{r}=.72, \mathrm{n}=1,018 ;$ Skinner, Kindermann, Furrer, 2009) and together form an internally consistent indicator of engagement $(\alpha=.95, \mathrm{n}=$ 144; Skinner \& Belmont, 1993, $\alpha=.90, \mathrm{n}=1,018$; Skinner, Marchand, \& Furrer \& Kindermann, 2009). Teacher reports of student engagement are highly stable over time (r $=.73, \mathrm{p}<.001, \mathrm{n}=144 ;$ Skinner \& Belmont, 1993; $\mathrm{r}=.78, \mathrm{p}<.001, \mathrm{n}=1,018 ;$ Skinner, Kindermann, \& Furrer, 2009).

\section{Student Perceived Relationship Quality with Parents and Teachers}

Students answered self-report questionnaires about the quality of their relationship with parents and teachers regarding levels of involvement, structure, and autonomy support, using a 4-pt Likert type scale (not at all true, not very true, sort of 


\section{BOYS' ENGAGEMENT AND INTERPERSONAL RESOURCES IN SIXTH GRADE}

true, very true) with scores ranging from 1 to 4 . A score of 4 represented more a higher level of relationship quality (negative items reverse coded). A composite score was calculated by averaging the three constructs for each social partner to represent an overall level of relationship quality for each.

Parental involvement, structure, and autonomy support were assessed by student reports of their perceived level of parental involvement, structure, and autonomy support. Parental Involvement was assessed on an 18-item self-report questionnaire (Skinner, Johnson \& Snyder, 2005). 10 of the items measured student's perception of "warm" parental involvement on dimensions of parental knowledge, time spent, affection, availability, and dependability (e.g., "When I want to talk about school my parents take the time"). These items have been found to be an internally consistent indicator of warm parental involvement ( $\alpha=.86$, Snyder, 2011) and remain stable across the school year (r $=.63 ; \mathrm{p}<.001)$. Eight of the items measured student's perception of parental "rejection" on the dimension of parental knowledge, affection, availability, and dependability (e.g., “Sometimes I think my parents don't care about what goes on for me in school”). Subscales have been shown to have high internal consistencies $(\alpha=.88$ and .83$)$ and to be negatively intercorrelated $(\mathrm{r}=.67, \mathrm{p}<.001, \mathrm{n}=1,247)$. These items have been found to be an internally consistent indicator of non-supportive parent involvement or rejection ( $\alpha$ $=.93 ;$ Snyder, 2011) and remain stable across the school year $(\mathrm{r}=.71 ; \mathrm{p}<.001)$.

Parental structure was assessed using 5 items measuring the clarity of expectations (e.g., 


\section{BOYS' ENGAGEMENT AND INTERPERSONAL RESOURCES IN SIXTH GRADE}

"A lot of times I don't know what my parents want me to do") and contingency, or the consistency of parenting (e.g., "My parents always do what they say they are going to do"). Parental autonomy support was measured with 5 items assessing respect for the child (e.g., "My parents listen to me when I have something to say about school") and choice (e.g., "When decisions are made about my schoolwork, my parents usually don't ask me what I think").

Teacher involvement, structure, and autonomy support were assessed via students' perceived level of teacher involvement, structure, and autonomy support. Students completed a 28-item self-report questionnaire (Belmont, Skinner, Wellborn, \& Connell, 1988) to assess the quality of interactions they have with their teacher. Teacher involvement items aimed at measuring student perceptions on how available, caring, warm, and affectionate their teacher was (e.g., "My teacher knows a lot about me", "My teacher is always there for me"). Teacher structure items tapped into how clear the teacher is with expectations (e.g., "My teacher makes it clear what he/she expects of me in school"), consistency and predictability (e.g., "I know what to expect from my teacher when I make a mistake"), help and support offered (e.g., "My teacher shows me how to solve problems for myself"), and monitoring and adjustment of teaching strategies (e.g., "My teacher makes sure that he/she doesn't teach faster than I can learn"). Teacher autonomy-support measured student's perception of choice (e.g., "When it comes to assignments, my teacher gives me all kinds of things to choose from"), teacher control 


\section{BOYS' ENGAGEMENT AND INTERPERSONAL RESOURCES IN SIXTH GRADE}

(e.g., "My teacher makes me do everything his/her way"), respect for the student (e.g., "My teacher listens to my ideas"), and relevance of schoolwork (e.g., "My teacher talks about how I can use the things we learn in school"). Stability was .55 across a school year with an internal consistency of $\alpha=.79$ (Skinner \& Belmont, 1993).

\section{Student Perceived Relatedness to Parents, Teachers, and Peers}

Relatedness, or the sense of emotional security a student perceives to have with parents (mother and father), teachers, and peers (classmates and friends), was assessed by a 20-item self-report questionnaire (Skinner, Johnson, \& Snyder, 2005). The item stems were the same for each social partner and aimed at measuring student's perceptions of acceptance and importance (e.g., "When I'm with my teacher, I feel accepted", "When I'm with my mother, I feel like someone special”, "When I'm with my classmates, I feel like I belong”, "When I with my friends, I feel left out"). Negative items were reversecoded. Subscales have been shown to have high internal consistencies; parents $(\alpha=.76)$, teachers $(\alpha=.79$,$) , and peers (\alpha=.81$; Furrer $\&$ Skinner, 2003).

\section{Peer Group Measures}

To assess naturally occurring peer groups, Social Cognitive Mapping (SCM; Cairns, Perrin, \& Cairns, 1985; Cairns \& Cairns, 1994) was used. In this method, students report, as participant observers, on those agemates whom they see frequently "hanging around" with one another. Participants were given a form to list as many groups of students they could recall who hang out together in a group, including groups with only 


\section{BOYS' ENGAGEMENT AND INTERPERSONAL RESOURCES IN SIXTH GRADE}

two members and groups that included the respondents themselves. There was space for up to 20 groups and 20 members for each group. Participants were instructed that a child could be listed in more than one group; they were also reminded to not forget about themselves.

At the beginning of sixth grade (Fall), 280 students (76\% of sixth graders, $44 \%$ boys) completed the peer group questionnaire to identify peer networks in their grade. Informants provided 3,047 nominations of group membership totaling 694 groups. Each group was comprised of 2 to 15 members, and on average, students nominated 2.7 groups with about 5 members. In spring, 219 students (60\% of the sample) completed peer group questionnaires to assess stability of the network information. Informants nominated 3,590 group memberships totaling 664 groups. Each student, on average, nominated 3 groups with about 5.4 members (Kindermann, 2007).

Network Identification. Using the group lists from the peer group questionnaire, the frequencies of co-nominations of each child belonging to the same group were arranged in a co-occurrence matrix. This matrix indicates the frequencies of each possible pair of students who were observed interacting in a group together (See Figure 2). 


\section{BOYS’ ENGAGEMENT AND INTERPERSONAL RESOURCES IN SIXTH GRADE}

\section{Figure 2}

Co-Occurrence Matrix of Group Observations (adapted from Kindermann, 2007)

\begin{tabular}{|c|c|c|c|c|c|c|c|c|c|c|c|c|c|c|}
\hline & KER & RYB & DAL & COD & SUO & ROM & STQ & CHR & KAA & KAW & ELT & JEP & LIP & $\begin{array}{c}\text { Total } \\
\text { nominations }\end{array}$ \\
\hline KER & - & 28 & 23 & 12 & 10 & 3 & 3 & 0 & 0 & 0 & 0 & 0 & 0 & 36 \\
\hline RYB & 28 & - & 20 & 11 & 12 & 3 & 4 & 0 & 0 & 0 & 0 & 0 & 0 & 32 \\
\hline DAL & 23 & 20 & - & 10 & 9 & 4 & 2 & 0 & 0 & 0 & 0 & 0 & 0 & 28 \\
\hline COD & 12 & 11 & 10 & - & 19 & 8 & 13 & 0 & 0 & 0 & 0 & 0 & 0 & 29 \\
\hline SUO & 10 & 12 & 9 & 19 & - & 9 & 10 & 0 & 0 & 0 & 0 & 0 & 0 & 29 \\
\hline ROM & 3 & 3 & 4 & 8 & 9 & - & 4 & 0 & 0 & 0 & 0 & 0 & 0 & 11 \\
\hline STQ & 3 & 4 & 2 & 13 & 10 & 4 & - & 0 & 0 & 0 & 0 & 0 & 0 & 17 \\
\hline CHR & 0 & 0 & 0 & 0 & 0 & 0 & 0 & - & 10 & 10 & 9 & 10 & 0 & 14 \\
\hline KAA & 0 & 0 & 0 & 0 & 0 & 0 & 0 & 10 & - & 13 & 13 & 12 & 0 & 16 \\
\hline KAW & 0 & 0 & 0 & 0 & 0 & 0 & 0 & 10 & 13 & - & 13 & 10 & 0 & 17 \\
\hline ELT & 0 & 0 & 0 & 0 & 0 & 0 & 0 & 9 & 13 & 13 & - & 10 & 0 & 18 \\
\hline JEP & 0 & 0 & 0 & 0 & 0 & 0 & 0 & 10 & 12 & 10 & 10 & - & 0 & 13 \\
\hline LIP & 0 & 0 & 0 & 0 & 0 & 0 & 0 & 0 & 0 & 0 & 0 & 0 & - & 24 \\
\hline No. of informants & & & & & & & & & & & & & & 260 \\
\hline Total nominations & & & & & & & & & & & & & & 3,047 \\
\hline No. of groups generated & & & & & & & & & & & & & & 694 \\
\hline
\end{tabular}

Binomial z-tests were used to test whether a child was more likely to be nominated as being in a group with any other child than would be expected by chance. (See Figure 3 on the next page; see also p. 1191-1192, in Kindermann, 2007, for a more detailed description of the method of analysis). According to Table 4.1, out of ALF's 31 group nominations, JOE was nominated 29 times (94\%) as being a member of the same group. Overall, JOE was nominated to be in 33 of the 159 reported groups (21\%). The conditional probability of JOE being a member of ALF's group, given that ALF had a group $(29 / 31=.94)$ is compared to the unconditional probability that JOE was found in any group $(33 / 159=.21)$. The significant $\mathrm{z}$ score $(\mathrm{z}=11.14)$ indicates that JOE is a member of ALF's group. Additionally, due to the many low cell frequencies, Fisher's 


\section{BOYS' ENGAGEMENT AND INTERPERSONAL RESOURCES IN SIXTH GRADE}

exact test was used (Sterling's approximation; Von Eye, 1990). Both tests had to be significant $(\mathrm{p}<.01)$ in order for connections to be accepted. Significant connections for single co-nominations were mostly children's self-nominations and were not accepted.

\section{Figure 3}

Binomial z-Tests Based on Nominations of Groups ( $N=159$, Kindermann, 1993)

\begin{tabular}{|l|l|l|l|}
\hline & $\begin{array}{l}\text { JOE is observed as } \\
\text { a group member }\end{array}$ & $\begin{array}{l}\text { JOE is not observed } \\
\text { as a group member }\end{array}$ & $\begin{array}{l}\text { Sums of Group } \\
\text { Nominations }\end{array}$ \\
\hline $\begin{array}{l}\text { Given that ALF } \\
\text { has a group }\end{array}$ & $29(.94)$ & $2(.06)$ & 31 \\
\hline $\begin{array}{l}\text { Given that ALF } \\
\text { does not have a } \\
\text { group }\end{array}$ & 4 & 124 & 128 \\
\hline $\begin{array}{l}\text { Sums (expected) } \\
\text { Sums }\end{array}$ & $33(.21)$ & $126(.79)$ & 159 \\
\hline
\end{tabular}

Socio-Cognitive Map. A composite map was created from the significant

combinations in the co-occurrence matrix. A subset of the social network of the sixth grade is presented as Figure 4.2 (Kindermann, 2007). The average kappa (Gest, Farmer, Cairns, \& Xie, 2003) was .88, indicating consistency between individual reports and the composite map (Kindermann, 2007). Rather than identifying distinct groups, this method identifies all children's connections with one another. This not only surfaces multiple group memberships, but also allows for children to be in groups with others they may not be connected to in other groups. Another advantage this method offers is the capability to 


\section{BOYS' ENGAGEMENT AND INTERPERSONAL RESOURCES IN SIXTH GRADE}

examine interindividual differences in group influences by specifying a child's group context that is individualized to that child.

\section{Figure 4}

The Composite Socio-Cognitive Map of Sixth Graders'Social Networks

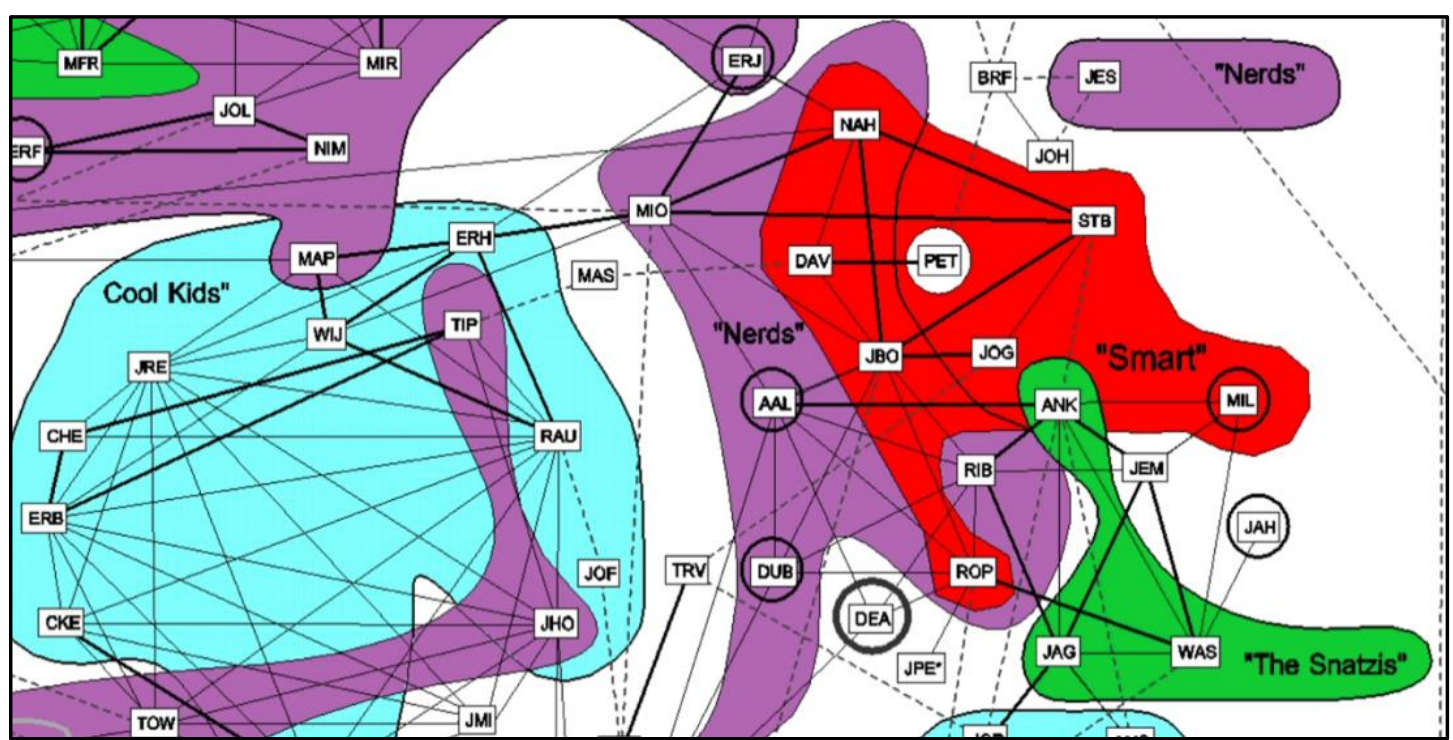

Circles represent girls and squares represent boys; letters represent students' names.

\section{Network Measures}

Peer group engagement profiles were formed from the individual teacher-rated engagement scores of all peers with whom a child affiliated (not including the individual child). This composite number represents an engagement profile of each child's affiliates as a group and is called the peer network average engagement score (see Figure 5). 


\section{BOYS’ ENGAGEMENT AND INTERPERSONAL RESOURCES IN SIXTH GRADE}

\section{Figure 5}

A Subsection of a Boy's Social Network in Sixth Grade

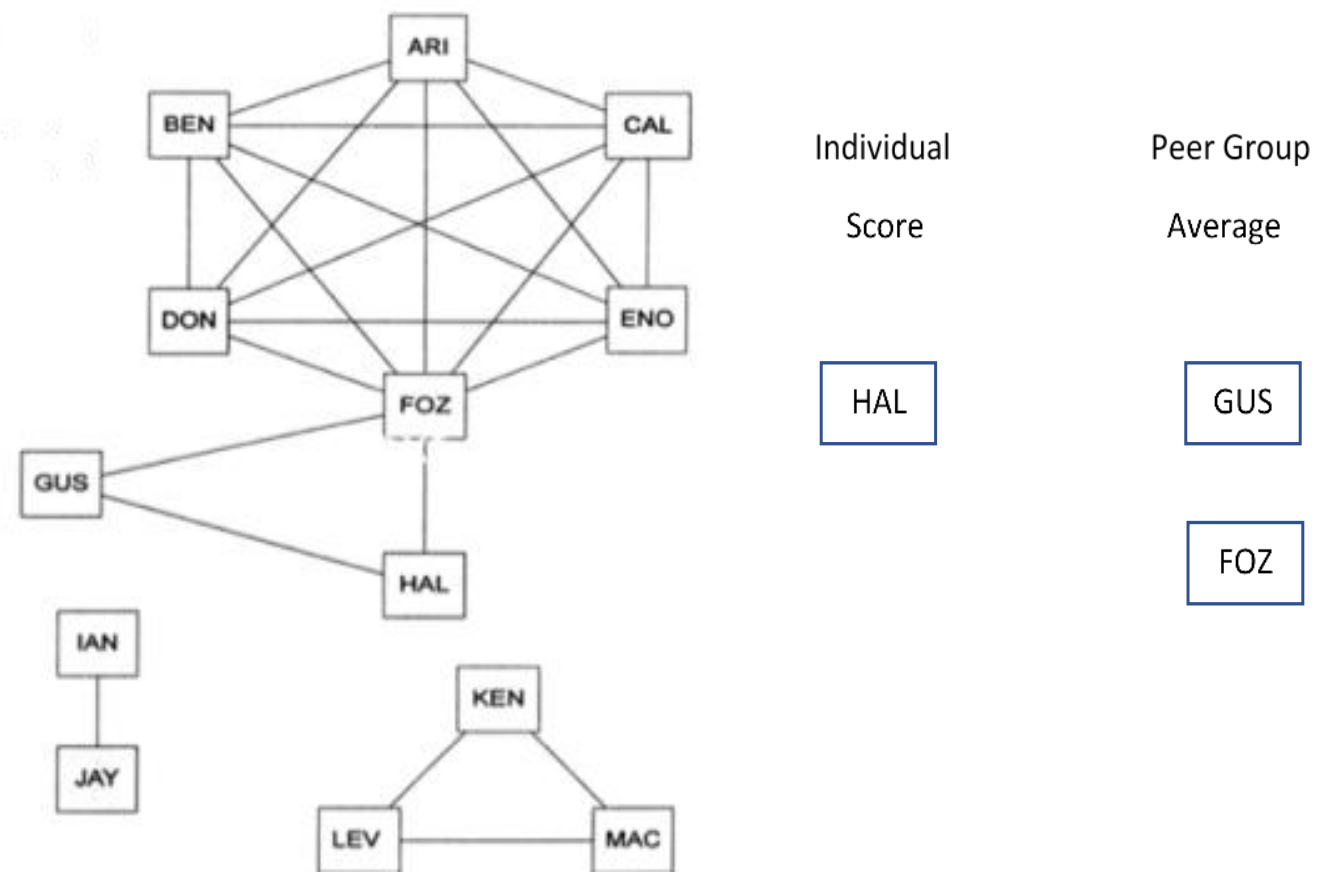

Peer group engagement scores are an average of each member's engagement, excluding the target student.

Network size was captured as the number of members with significant connections in each student's group. For example, Figure 4.3 shows a portion of a boys' social network and denotes HAL is significantly connected to GUS and FOZ, thus, there are two members in HALs group. In addition, the percent of network members was computed who were of the same sex as a target student.

Boys' self-reported friendships were also examined. At the beginning of sixth grade, boys listed their best friends in class, in school, and outside of school. All of these 


\section{BOYS' ENGAGEMENT AND INTERPERSONAL RESOURCES IN SIXTH GRADE}

nominations were combined. Approximately 163 boys issued friendship nominations (84\%). The number of friends that a student reported having was taken as his number of friends. Friendships were distinguished according to whether the nominations were reciprocated or not (unilateral nominations). To identify the change in boys' close friendships from Fall to Spring in sixth grade, the number of friends was computed that a student lost.

Boys' friendship quality was assessed. Boys were asked to name their close friends and rate each friendship on a Likert-type scale (e.g., sort of good friend, good friend, very good friend) with scores ranging from 1 to 3 . A score of 3 represented closest friendships. Two categories of friendship loss were created based on student's perceived closeness of their friendships. One group consisted of lost friends who were considered "sort of good" friends or "good" friends; and the other group contained friends who were rated as a "very good" friend. The two less severe losses were combined in order to distinguish potentially devastating losses from losses that may be tolerable in the boys' own views. 


\section{BOYS’ ENGAGEMENT AND INTERPERSONAL RESOURCES IN SIXTH GRADE}

\section{Chapter 5. Results}

Preliminary analyses were conducted to confirm that assumptions of normality and homogeneity of variance among random variables were met. Descriptive statistics, including means, standard deviations, and zero-order correlations, were obtained to get an overall view of the data. Hypotheses were tested using independent-samples t-tests and repeated measures Analysis of Variance (ANOVA) in SPSS (version 28). For all analyses, Expectation-Maximization (EM) was used to handle missing data. The EM method makes inferences of likelihood based on the distribution of the data through iterations of estimating means, correlations, and covariances between variables (Allison, 2012; Dempster, Laird, \& Rubin, 1977).

\section{Descriptive Statistics}

Mean levels, standard deviations, minimums, maximums, skewness, and kurtosis for student engagement in Fall and Spring are shown in Table 5. Mean levels show student engagement was relatively high, above the mid-point of the scale (i.e., 2.5), and stable across the school year (Fall: $M=3.06, S D=.60$; Spring: $M=3.06, S D=.64$ ), indicating a generally high functioning sample. Skewness and kurtosis were within acceptable levels under 2.0. 
BOYS' ENGAGEMENT AND INTERPERSONAL RESOURCES IN SIXTH GRADE

Table 5

Descriptive Statistics for Student Engagement in Sixth Grade

\begin{tabular}{lcccccc}
\hline Variable & $n$ & $M(S . D)$. & Min & Max & Skew & Kurtosis \\
\hline Student Engagement Fall & 366 & $3.06(.60)$ & 1.06 & 4.00 & -.47 & .25 \\
Student Engagement Spring & 366 & $3.06(.64)$ & 1.35 & 4.00 & -.27 & -.71 \\
Boys' Engagement: & & & & & & \\
\hline Fall & 193 & $2.95(.63)$ & 1.06 & 4.00 & -.17 & -.53 \\
Spring & 193 & $2.93(.64)$ & 1.35 & 4.00 & -.15 & -.66 \\
Girls' Engagement: & & & & & & \\
\hline Fall & 173 & $3.18(.54)$ & 1.69 & 4.00 & -.14 & -.69 \\
Spring & 173 & $3.21(.61)$ & 1.69 & 4.00 & -.69 & -.76 \\
\hline
\end{tabular}

Means and standard deviations of boys' and girls' interpersonal provisions in sixth grade are shown in Table 6 and Table 7. In general, student provisions were relatively high, above the mid-point of the scale (i.e., 2.5), and relatively stable. Mean levels indicate higher resources from parents than from teachers, especially high levels of relatedness to mothers and friends. Mean levels show relatively high levels of peer group engagement in fall and spring $(M=3.11$ and $M=3.12$, respectively). Self-reported friendships were greater than both reciprocated and peer-reported friendships with relatively moderate levels of friendship quality in fall $(M=2.50)$. 


\section{BOYS' ENGAGEMENT AND INTERPERSONAL RESOURCES IN SIXTH GRADE}

\section{Table 6}

Means and Standard Deviations for Boys' and Girls' Interpersonal Provisions in Sixth Grade

\begin{tabular}{|c|c|c|c|c|c|c|}
\hline \multirow[b]{2}{*}{ Variable } & \multicolumn{2}{|c|}{ Overall } & \multicolumn{2}{|c|}{ Boys } & \multicolumn{2}{|c|}{ Girls } \\
\hline & $\begin{array}{c}\text { Fall } \\
M(S . D .)\end{array}$ & $\begin{array}{l}\text { Spring } \\
M(S . D .)\end{array}$ & $\begin{array}{c}\text { Fall } \\
M(S . D .)\end{array}$ & $\begin{array}{c}\text { Spring } \\
M(S . D .)\end{array}$ & $\begin{array}{c}\text { Fall } \\
M(S . D .)\end{array}$ & $\begin{array}{l}\text { Spring } \\
M(\text { S.D. })\end{array}$ \\
\hline \multicolumn{7}{|l|}{ Parent } \\
\hline Involvement & $3.13(.53)$ & $3.21(.53)$ & $3.07(.50)$ & $3.17(.50)$ & $3.19(.55)$ & $3.25(.61)$ \\
\hline Structure & $2.96(.43)$ & $2.89(.47)$ & $2.96(.42)$ & $2.81(.45)$ & $2.96(.43)$ & $2.97(.46)$ \\
\hline $\begin{array}{l}\text { Autonomy } \\
\text { Support }\end{array}$ & $3.06(.46)$ & $2.98(.51)$ & $3.04(.45)$ & $2.93(.51)$ & $3.08(.47)$ & $3.03(.52)$ \\
\hline \multicolumn{7}{|l|}{ Teacher } \\
\hline Involvement & $2.89(.54)$ & $2.82(.52)$ & $2.79(.50)$ & $2.74(.48)$ & $3.00(.56)$ & $2.90(.55)$ \\
\hline Structure & $2.96(.48)$ & $2.89(.44)$ & $2.88(.45)$ & $2.80(.41)$ & $3.05(.51)$ & $2.98(.44)$ \\
\hline $\begin{array}{l}\text { Autonomy } \\
\text { Support }\end{array}$ & $2.75(.49)$ & $2.65(.49)$ & $2.72(.48)$ & $2.62(.44)$ & $2.78(.50)$ & $2.69(.54)$ \\
\hline \multicolumn{7}{|l|}{ Relatedness } \\
\hline Mother & $3.49(.63)$ & $3.46(.68)$ & $3.47(.65)$ & $3.40(.69)$ & $3.52(.62)$ & $3.53(.67)$ \\
\hline Father & $3.37(.72)$ & $3.41(.69)$ & $3.35(.71)$ & $3.35(.70)$ & $3.39(.73)$ & $3.48(.67)$ \\
\hline Teacher & 2.99 (.66) & $2.91(.68)$ & $2.95(.65)$ & $2.86(.66)$ & $3.03(.68)$ & $2.98(.70)$ \\
\hline Classmate & $3.20(.74)$ & $3.13(.73)$ & $3.18(.72)$ & $3.08(.74)$ & $3.21(.77)$ & $3.18(.72)$ \\
\hline Friend & $3.46(.60)$ & $3.46(.62)$ & $3.43(.62)$ & $3.45(.57)$ & $3.50(.58)$ & $3.47(.68)$ \\
\hline \multicolumn{7}{|l|}{ Peers } \\
\hline $\begin{array}{l}\text { Peer Group } \\
\text { Engagement }\end{array}$ & $3.11(.37)$ & $3.12(.37)$ & $3.03(.39)$ & $3.00(.34)$ & $3.19(.33)$ & $3.26(.35)$ \\
\hline Group Size & $4.81(3.99)$ & & $3.78(3.51)$ & & $5.97(4.17)$ & \\
\hline \% Same Sex & $.75(.40)$ & & $.67(.45)$ & & $.85(.30)$ & \\
\hline
\end{tabular}

\section{Friends}




\section{BOYS' ENGAGEMENT AND INTERPERSONAL RESOURCES IN SIXTH GRADE}

\begin{tabular}{|c|c|c|c|c|c|c|}
\hline \multirow[b]{2}{*}{ Variable } & \multicolumn{2}{|c|}{ Overall } & \multicolumn{2}{|c|}{ Boys } & \multicolumn{2}{|c|}{ Girls } \\
\hline & $\begin{array}{c}\text { Fall } \\
M(S . D .)\end{array}$ & $\begin{array}{l}\text { Spring } \\
M(S . D .)\end{array}$ & $\begin{array}{l}\text { Fall } \\
M(S . D .)\end{array}$ & $\begin{array}{c}\text { Spring } \\
M(S . D .)\end{array}$ & $\begin{array}{c}\text { Fall } \\
M(\text { S.D. })\end{array}$ & $\begin{array}{l}\text { Spring } \\
M(S . D .)\end{array}$ \\
\hline Reciprocated & $2.50(2.06)$ & & $2.16(1.97)$ & & $2.87(2.11)$ & \\
\hline Self-Reported & $8.29(4.01)$ & & $7.61(4.04)$ & & $9.05(3.85)$ & \\
\hline Peer-Reported & $5.92(4.05)$ & & $5.58(4.05)$ & & $6.30(4.02)$ & \\
\hline $\begin{array}{l}\text { Friendship } \\
\text { Quality }\end{array}$ & $2.50(.54)$ & & $2.51(.56)$ & & $2.50(.53)$ & \\
\hline $\begin{array}{l}\text { Close Friends } \\
\text { Lost } \%\end{array}$ & & & & $.55(.19)$ & & \\
\hline Closest Lost \% & & & & $.27(.27)$ & & \\
\hline
\end{tabular}

\section{Table 7}

Means and Standard Deviations for Boys' and Girls' Composite Provisions in Sixth Grade

\begin{tabular}{|c|c|c|c|c|c|c|}
\hline \multirow[b]{2}{*}{ Variable } & \multicolumn{2}{|c|}{ Overall } & \multicolumn{2}{|c|}{ Boys } & \multicolumn{2}{|c|}{ Girls } \\
\hline & $\begin{array}{c}\text { Fall } \\
M(S . D .)\end{array}$ & $\begin{array}{c}\text { Spring } \\
M(S . D .)\end{array}$ & $\begin{array}{c}\text { Fall } \\
M(S . D .)\end{array}$ & $\begin{array}{c}\text { Spring } \\
M(S . D .)\end{array}$ & $\begin{array}{c}\text { Fall } \\
M(S . D .)\end{array}$ & $\begin{array}{l}\text { Spring } \\
M(\text { S.D. })\end{array}$ \\
\hline $\begin{array}{l}\text { Parent } \\
\text { Average }\end{array}$ & $3.05(.39)$ & $3.02(.41)$ & $3.02(.38)$ & $2.97(.40)$ & $3.07(.41)$ & $3.08(.42)$ \\
\hline $\begin{array}{l}\text { Teacher } \\
\text { Average } \\
\text { Adult a }\end{array}$ & $2.87(.47)$ & $2.79(.44)$ & $2.80(.44)$ & $2.72(.40)$ & $2.95(.49)$ & $2.86(.48)$ \\
\hline Involvement & $2.98(.47)$ & $3.01(.47)$ & $2.92(.45)$ & $2.95(.44)$ & $3.05(.48)$ & $3.08(.50)$ \\
\hline Structure & $2.96(.39)$ & $2.89(.39)$ & $2.92(.38)$ & $2.80(.38)$ & $3.00(.41)$ & $2.98(.39)$ \\
\hline Support & $2.90(.39)$ & $2.82(.43)$ & $2.88(.38)$ & $2.78(.42)$ & $2.93(.41)$ & $2.86(.44)$ \\
\hline Relatedness ${ }^{b}$ & $3.30(.47)$ & $3.28(.49)$ & $3.27(.46)$ & $3.23(.48)$ & $3.33(.48)$ & $3.33(.50)$ \\
\hline Peer Average & $2.71(.62)$ & $3.02(.41)$ & $2.57(.59)$ & & $2.86(.61)$ & \\
\hline
\end{tabular}

Note: ${ }^{a}$ Adult is combined parent and teacher. ${ }^{b}$ Averaged relatedness to parent, teacher, classmate, and friend. 


\section{BOYS' ENGAGEMENT AND INTERPERSONAL RESOURCES IN SIXTH GRADE}

Table 8 contains the correlations among all study variables for boys and girls combined. Of most interest were the correlations between student engagement in spring and fall and potential interpersonal resources in fall. Overall, as expected, interpersonal provisions were significantly and positively correlated with teacher-reported engagement in both fall and spring; the single exception was friendship quality in fall. The first two blocks of predictors showed similar patterns of moderate correlations with engagement at both time points. Correlations with parent and teacher provisions ranged from .19 to .34, all $p<.01$. Correlations with relatedness ranged from .18 to .30 , all $p<.01$. Peer provisions, however, appeared to have differential relations with engagement. The highest correlations were found for peer group engagement, whereas correlations between other peer network resources and engagement were weaker (range $=.02-.36$ )

As expected, intraconstruct correlations among the resources provided by each social partner were higher, especially for teachers: Intercorrelations among provisions from parents, teachers, and peers averaged $.49, .82$, and .37 , respectively. Within peer resources, however, differential relations were found. For example, different types of reported friendships were moderately intercorrelated, whereas peer group engagement was correlated only weakly with the remaining peer resources and no association was found between peer group engagement and friendship quality. 
BOYS' ENGAGEMENT AND INTERPERSONAL RESOURCES IN SIXTH GRADE

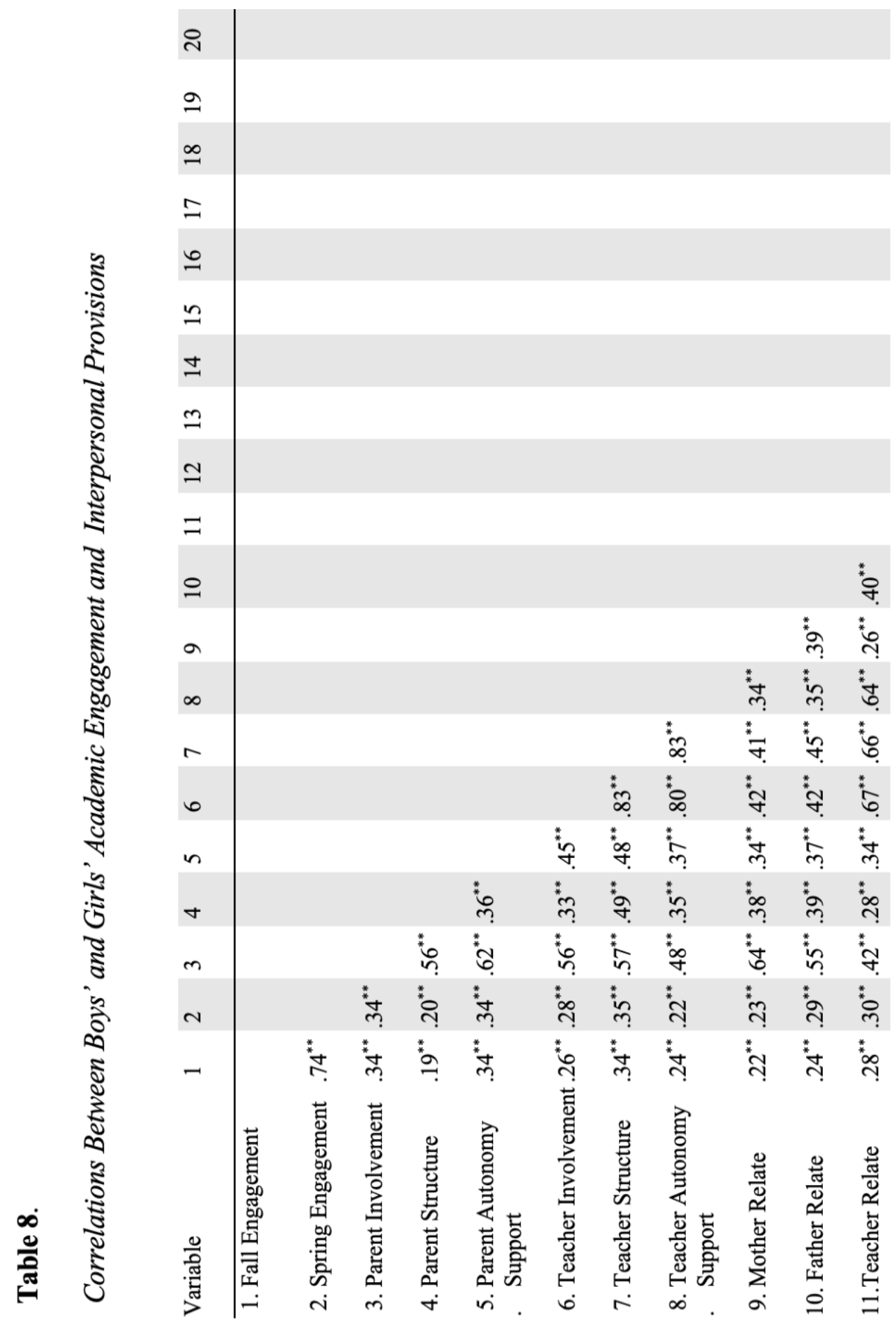


BOYS' ENGAGEMENT AND INTERPERSONAL RESOURCES IN SIXTH GRADE

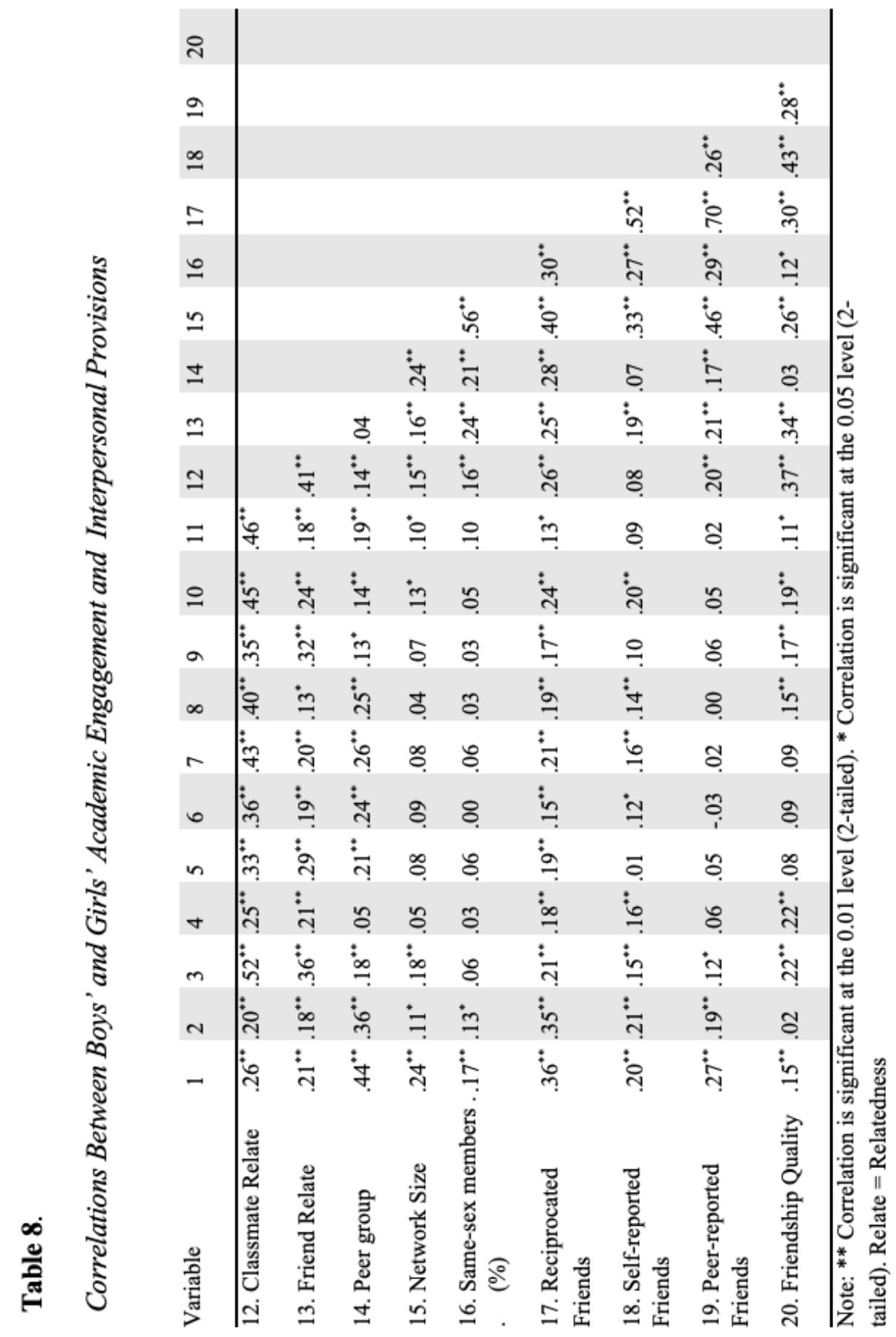




\section{BOYS' ENGAGEMENT AND INTERPERSONAL RESOURCES IN SIXTH GRADE}

\section{Research Question One: Gender Disadvantages of Engagement and Interpersonal}

\section{Resources}

\section{Gender Disadvantages in Engagement}

Part one of the first research question was: Compared to girls, do boys show lower levels of engagement in school at the beginning and at the end of sixth grade, and do boys show greater declines in engagement over sixth grade? It was hypothesized that boys would show lower levels of engagement, both at the beginning and end of sixth grade, and show greater declines in engagement across the school year, compared to girls. Independent-samples t-tests were conducted to test the hypothesis that boys are less engaged at the beginning and end of the school year, compared to girls. Repeated measures ANOVA were used to test the hypothesis that, compared to girls, boys show greater declines in engagement across the sixth-grade year. The hypotheses were partially supported (see Table 9 and 10 for summaries).

\section{Table 9}

Gender Differences in Engagement and Parent and Teacher Provisions

\begin{tabular}{|c|c|c|c|c|c|c|}
\hline \multirow[b]{2}{*}{ Provision } & \multicolumn{2}{|c|}{ Fall } & \multicolumn{2}{|c|}{ Spring } & \multicolumn{2}{|c|}{ ANOVA } \\
\hline & $t$ & Cohen's $d$ & $t$ & Cohen's d & $F$ & $\eta^{2}$ \\
\hline Engagement & $3.67 * * *$ & .38 & $.44 * * *$ & .46 & $n s$ & \\
\hline Parent & & & & & & \\
\hline Involvement & $1.98 *$ & .21 & $n s$ & .36 & $n s$ & \\
\hline Structure & $n s$ & & $3.46 * * *$ & & $16.02 * * *$ & .04 \\
\hline $\begin{array}{l}\text { Autonomy } \\
\text { Support }\end{array}$ & $n s$ & & $n s$ & & $n s$ & \\
\hline $\begin{array}{l}\text { Parent } \\
\text { Average }\end{array}$ & $n s$ & & $2.65 * *$ & .28 & $4.89 *$ & .01 \\
\hline
\end{tabular}


BOYS' ENGAGEMENT AND INTERPERSONAL RESOURCES IN SIXTH GRADE

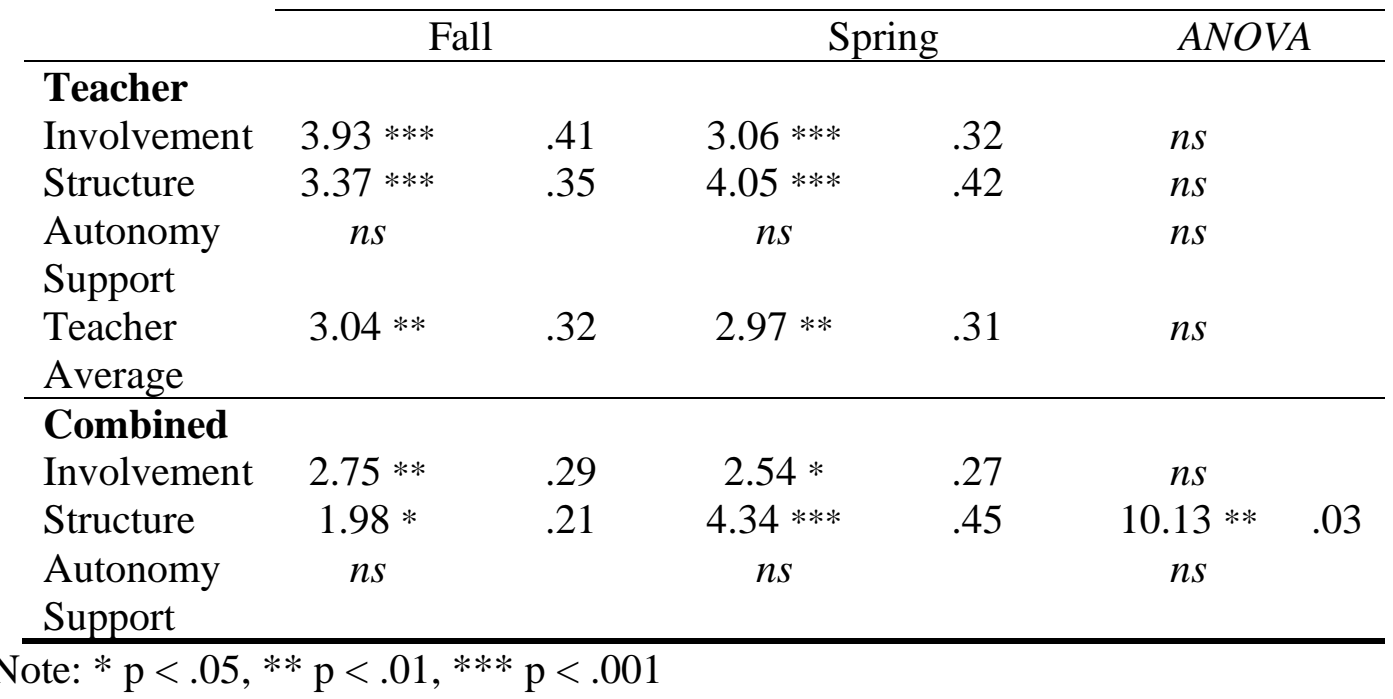

Results of an independent-samples t-test indicated that boys experienced lower levels of teacher-reported engagement than girls both in the beginning (boys: $M=2.95$, $S D=.63, N=193$; girls: $M=3.18, S D=.54, N=173, t=3.67, p<.001, C I, .11, .35$, with a small effect size, $d=.38$ ), as well as at the end of sixth grade (boys: $M=2.92, S D$ $=.64$; girls: $M=3.21, S D=.61, t=.44, p<.001, C I, .16, .41$ with a moderate effect size, $d=.46)$. The findings support the research hypothesis that boys were less engaged than girls, in fall and spring of sixth grade (see Table 9).

A repeated measures ANOVA showed that student engagement did not change significantly over the school year, Wilks' Lambda $=1.00, F(1,364)=.01, n s$, and boys and girls did not change differently, Wilks' Lambda $=1.00, F(1,364)=1.52$, ns. The analyses do not confirm that boys experienced greater losses in overall engagement than girls across sixth grade. 


\section{BOYS’ ENGAGEMENT AND INTERPERSONAL RESOURCES IN SIXTH GRADE}

An exploratory follow-up repeated measures ANOVA considered the two components of emotional and behavioral engagement separately. Contrary to expectations, there were no interaction effects with students' gender. There was only an interaction between average changes in emotional and behavioral engagement for both genders combined, indicating that behavioral engagement remained relatively stable (from $M=2.95$ to $M=2.97$, mean difference of $.02, N=366$ ) while emotional engagement declined (from $M=3.21$ to $M=3.17$; mean difference of -.04, Wilks' Lambda $=.98, F(1,364)=6.25, p<.05$. Exploratory follow ups for each gender separately did reveal different patterns for boys and girls. When boys were considered by themselves, they showed declines in emotional engagement (from $M=3.13$ to $M=3.04$, Wilks' Lambda $=.96, F(1192)=9.01, p<.01)$, but not in behavioral engagement (from

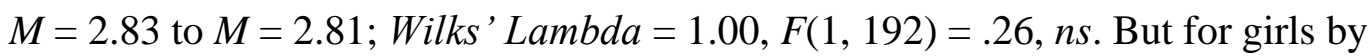
themselves, no significant decline was seen in emotional engagement (from $M=3.29$ to $M=3.19$, Wilks' Lambda $=1.00, F(1,172)=.68, n s)$, but significant gains were found in behavioral engagement (from $M=3.08$ to $M=3.12$; Wilks' Lambda $=1.00, F(1,172)=$ 48.96, $p<.001)$.

Summary of Gender Disparities in Engagement. Counter to expectations, overall student engagement did not show normative declines across the school year or differential losses for boys. Despite its relative stability, however, teachers did report that boys showed lower levels of overall engagement at both the beginning and the end of the 


\section{BOYS' ENGAGEMENT AND INTERPERSONAL RESOURCES IN SIXTH GRADE}

school year. When behavioral and emotional engagement were examined separately, this pattern held for both dimensions: Gender disparities were found for both types of engagement, indicating lower levels for boys in both fall and spring. In exploratory analyses, gender differences were also uncovered in patterns of change for these engagement dimensions. Girls showed significant gains in behavioral engagement, while remaining stable in emotional engagement. In contrast, boys showed no gains in behavioral engagement and registered significant losses in emotional engagement.

\section{Gender Disadvantages in Interpersonal Resources}

Part two of the first research question was: Compared to girls, do boys show lower levels of interpersonal resources in school at the beginning and at the end of sixth grade, and do boys show greater declines of interpersonal resources over sixth grade? It was hypothesized that boys would show lower levels of interpersonal resources, both at the beginning and end of sixth grade, and greater declines in interpersonal resources across the school year than girls.

Tests were conducted for each interpersonal resource variable (parent and teacher involvement, structure, and autonomy support, relatedness to parents, teachers, classmates, and friends, and peer variables; average peer group engagement and peer group size, number of same-sex group members, number of reciprocated, self-reported and peer-reported friendships, and friendship quality). In addition, all interpersonal 


\section{BOYS' ENGAGEMENT AND INTERPERSONAL RESOURCES IN SIXTH GRADE}

resource variables were averaged to construct a composite score of parent, teacher, and peer resources for each child.

Independent-samples t-tests were conducted to test the hypothesis that boys had lower levels of interpersonal resources at the beginning and end of the school year, compared to girls. Repeated measures ANOVA were used to test the hypothesis that, compared to girls, boys show greater declines in interpersonal resources across the sixthgrade year. First, the results of each resource variable will be presented separately. Then, analyses on parent, teacher, and peer composite scores will be presented. These hypotheses were also partially supported. For summaries, see Tables 9 and 10.

Relationship Quality with Parents. Parent Involvement. Results of an independent-samples t-test indicated that boys reported lower levels of parent involvement at the beginning of the school year than girls (boys: $M=3.07, S D=.51$; girls: $M=3.19, S D=.55, t=1.98, p<.05, C I, .00, .22$, with a small effect size, $d=.21)$. However, no differences in parent involvement were found at the end of the school year (boys: $M=3.17, S D=.50$; girls: $M=3.25, S D=.56, t=1.49, n s$ ). The findings partially support the research hypothesis that boys experienced lower levels of parent involvement at the beginning of the year, compared to girls, but not the end of sixth grade.

A repeated measures ANOVA showed that parent involvement for both boys and girls increased significantly over the school year (from $M=3.13$ to $M=3.21$, Wilks' Lambda $=.97, F(1,364)=13.23, p<.001)$ with a small effect size, $\eta^{2}=.04$. However, 


\section{BOYS' ENGAGEMENT AND INTERPERSONAL RESOURCES IN SIXTH GRADE}

boys and girls did not change differently, Wilks' Lambda $=1.00, F(1,364)=.40$, $n s$.

Thus, the findings do not support the hypothesis that boys experienced greater losses in parent involvement.

Parent Structure. Results of an independent-samples t-test indicated that boys and girls did not significantly differ in self-reported parent structure at the beginning of the school year (boys: $M=2.96, S D=.42$; girls: $M=2.96, S D=.43, t=.15, n s$ ).

However, boys reported lower levels of parent structure at the end of sixth grade (boys: $M=2.81, S D=.45$; girls: $M=2.97, S D=.46, t=3.46, p<.001 ; C I, .07, .26$; with a small effect size, $d=.36$ ). The findings partially support the research hypothesis; boys experienced lower levels of parent structure than girls at the end, but not the beginning of sixth grade.

A repeated measures ANOVA showed that parent structure declined significantly over the school year, Wilks' Lambda $=.97, F(1,364)=10.53, p=.001$; with a small effect size, $\eta^{2}=.03$. Boys declined and girls remained stable. So, boys and girls changed differently, Wilks' Lambda $=.96, F(1,364)=16.02, p<.001$; with a small effect size, $\eta^{2}$ $=.04$. The findings support the research hypothesis that boys experienced greater losses in parent structure than girls across sixth grade.

Parent Autonomy Support. Results of an independent-samples t-test indicated that boys and girls did not significantly differ in self-reported parent autonomy support at the beginning (boys: $M=3.04, S D=.45$; girls: $M=3.08, S D=.47, t=.96, n s$ ) or end of 


\section{BOYS' ENGAGEMENT AND INTERPERSONAL RESOURCES IN SIXTH GRADE}

the sixth-grade year (boys: $M=2.93, S D=.51$; girls: $M=3.03, S D=.52, t=1.72, n s$ ).

The findings do not support the research hypothesis that boys experienced lower levels of parent autonomy support, compared to girls at the beginning and end of sixth grade.

A repeated measures ANOVA showed that parent autonomy support declined significantly over the school year, Wilks' Lambda $=.97, F(1,364)=11.22, p<.001$, with a small effect size, $\eta^{2}=.03$. Nevertheless, boys and girls did not change differently, Wilks' Lambda $=1.00, F(1,364)=.96, n s$. The findings do not support the research hypothesis that boys experienced greater losses in parent autonomy support than girls, across sixth grade.

\section{Composite of Parent Provisions (Averaged Involvement, Structure, and}

Autonomy Support). Results of an independent-samples t-test indicated that, compared to girls, boys had lower levels of averaged parent resources (involvement, structure, and autonomy support) in the spring (boys: $M=2.97, S D=.40$; girls: $M=3.08, S D=.42, t=$ $2.65, p<.01, C I, .03, .20$, with a small effect size; $d=.28)$, but not in the fall of sixth grade (boys: $M=3.02, S D=.38$; girls: $M=3.07, S D=.41, t=1.22, n s$ ).

A repeated measures ANOVA showed that parent resources did not significantly change across the school year for boys and girls (Wilks' Lambda $=.99, F(1,364)=2.53$, $n s)$, however, the two groups changed differently (Wilks' Lambda $=.99, F(1,364)=4.89$, $\left.p<.05, \eta^{2}=.01\right)$. The analyses support the hypothesis that boys experience steeper losses of parent provisions than girls across sixth grade. 


\section{BOYS' ENGAGEMENT AND INTERPERSONAL RESOURCES IN SIXTH GRADE}

Summary of Gender Disparities in Parent Provisions. In terms of the overall composite of parent provisions, boys and girls started with comparable mean levels in fall, but gender differences were found in patterns of change, such that girls' levels remained stable, while boys experienced significant losses. As a result, by the end of the year boys showed significantly lower levels than girls. Individual parent dimensions showed different patterns of gender differences and changes, including gains in some dimensions. In terms of parental involvement, boys began the year with lower mean levels than girls, but both genders reported gains over the school year, so that by spring mean levels were no longer significantly different. Structure mirrored the pattern found for the overall composite: Boys and girls reported comparable levels of parent structure in fall but based on greater losses over the school year for boys, boys ended the year with lower levels of structure than girls. No gender differences were found in autonomy support: Both boys and girls experienced losses in this support across sixth grade.

Relationship Quality with Teachers. Teacher Involvement. Results of an independent-samples t-test indicated that boys report lower levels of teacher involvement, compared to girls, at the beginning (boys: $M=2.79, S D=.50$; girls: $M=3.01, S D=.56, t$ $=3.93, p<.001, C I, .11, .33$, with a small effect size, $d=.41)$ and at the end of the school year (boys: $M=2.74, S D=.48$; girls: $M=2.90, S D=.55, t=3.06, p<.001, C I, .06, .27$, with a small effect size, $d=.32$ ). The findings support the hypothesis that boys 


\section{BOYS' ENGAGEMENT AND INTERPERSONAL RESOURCES IN SIXTH GRADE}

experienced lower levels of teacher involvement than girls, at the beginning and end of the sixth-grade year.

A repeated measures ANOVA showed that teacher involvement declined significantly across the school year for both boys and girls, Wilks' Lambda $=.94, F(1$, $364)=25.01, p<.001$, with a medium effect size, $\eta^{2}=.06$. However, boys and girls did not change differently, Wilks' Lambda $=.99, F(1,364)=2.76, n s$. The findings do not support the hypothesis that boys experienced greater losses in teacher involvement, than girls, across sixth grade.

Teacher Structure. Results of an independent-samples t-test indicated that boys reported lower levels of teacher structure, compared to girls, at the beginning (boys: $M=$ $2.88, S D=.45 ;$ girls: $M=3.05, S D=.51, t=3.37, p<.001, C I, .07, .27$, with a small effect size, $d=.35$ ), and at the end of the school year (boys: $M=2.80, S D=.41$; girls: $M$ $=2.98, S D=.44, t=4.05, p<.001, C I, .09, .27$, with a small effect size, $d=.42)$. The findings support the research hypothesis that boys experienced lower levels of teacher structure than girls, at the beginning and end of sixth grade.

A repeated measures ANOVA showed that teacher structure declined significantly over the school year (from $M=2.96$ to $M=2.89$, Wilks' Lambda $=.95, F(1$, $364)=18.92, p<.001)$ with a small effect size, $\eta^{2}=.05$. However, boys and girls did not change differently, Wilks' Lambda $=1.00, F(1,364)=.16, n s$. The findings do not 


\section{BOYS' ENGAGEMENT AND INTERPERSONAL RESOURCES IN SIXTH GRADE}

support the research hypothesis that boys experienced greater losses in teacher structure, than girls, across sixth grade.

Teacher Autonomy Support. Results of an independent-samples t-test indicated that boys and girls did not differ in their levels of teacher autonomy support at the beginning of the school year (boys: $M=2.72, S D=.48$; girls: $M=2.78, S D=.50, t=$ $1.19, n s$ ) nor at the end of the school year (boys: $M=2.62, S D=.44$; girls: $M=2.69, S D$ $=.54, t=1.22, n s)$. The findings do not support the research hypothesis that boys experienced lower levels of teacher autonomy support compared to girls, at the beginning or end of the sixth-grade year.

A repeated measures ANOVA showed that teacher autonomy support decreased significantly across the school year (from $M=2.75$ to $M=2.65$, Wilks' Lambda $=.95$, $F(1,364)=20.21, p<.001)$, with a small effect size, $\eta^{2}=.05$. However, boys and girls did not change differently, Wilks' Lambda $=1.00, F(1,364)=.00, n s$. The findings do not support the hypothesis that boys experienced greater losses in teacher autonomy support than girls, across sixth grade.

\section{Composite of Teacher Provisions (Averaged Involvement, Structure, and}

Autonomy Support). Results of an independent-samples t-test indicated that, compared to girls, boys had lower levels of averaged teacher resources (involvement, structure, and autonomy support) in the fall (boys: $M=2.80, S D=.44$; girls: $M=2.95, S D=.49, t=$ $3.04, p<.01, C I, .05, .24$, with a small effect size; $d=.32$ ), and spring of sixth grade 


\section{BOYS' ENGAGEMENT AND INTERPERSONAL RESOURCES IN SIXTH GRADE}

(boys: $M=2.72, S D=.40$; girls: $M=2.86, S D=.48, t=2.97, p<.01, C I, .05, .23$, with a small effect size; $d=.31$ ).

A repeated measures ANOVA showed that teacher resources decreased significantly across the school year for boys and girls $(M=2.87$ to $M=2.79$, Wilks' Lambda $\left.=.92, F(1,364)=32.23, p<.001, \eta^{2}=.08\right)$. It is worth noting that boys lost in overall teacher resources, as well as in all individual teacher resources, even though the analyses do not support the hypothesis that boys experienced steeper declines of teacher provisions across the school year (Wilks' Lambda $=1.00, F(1,364)=.19$, ns; see Table 9).

Summary of Gender Disparities in Teacher Provisions. Patterns of gender differences were similar for the averaged composite of teacher provisions as well as two of the individual dimensions, involvement and structure. For all three indicators, boys showed lower levels than girls at both timepoints, but gender differences were not found in changes over the school year. Instead, all students experienced declines in teacher involvement, structure, and the teacher composite across sixth grade. As with parents, no gender differences in teacher autonomy support were found, but both boys and girls reported losses over the school year. As a result, both boys and girls experienced losses in all teacher provisions across sixth grade.

\section{Follow-up Analyses of Adult Involvement, Structure, and Autonomy Support}

(Combined Parent and Teacher Composites). A first follow-up analysis averaging 


\section{BOYS' ENGAGEMENT AND INTERPERSONAL RESOURCES IN SIXTH GRADE}

parent and teacher involvement confirmed that boys experienced lower levels of adult involvement in the beginning (boys: $M=2.92, S D=.45$; girls: $M=3.04, S D=.48, t=$ $2.75, p<.01, C I, .04, .23, d=.29$ ) and end of the school year than girls (boys: $M=2.95$, $S D=.44$; girls: $M=3.08, S D=.50, t=2.54, p<.05, C I, .03, .22, d=.27)$. A repeated measures ANOVA showed that adult involvement increased across the school year for all students $(M=2.98$ to $M=3.01$, Wilks' Lambda $=.99, F(1,364)=5.45, p<.05$, with a small effect size, $\eta^{2}=.02$ ), and both groups did not change differently, Wilks' Lambda = $1.00, F(1,364)=.19, n s$. The analyses do not support the hypothesis.

A second follow-up analysis averaging parent and teacher structure confirmed that, compared to girls, boys experienced lower levels of adult structure in the beginning (boys: $M=2.92, S D=.38$; girls: $M=3.00, S D=.41, t=1.98, p<.05, C I, .00, .16, d=$ .21 ) and at the end of the school year (boys: $M=2.80, S D=.38$; girls: $M=2.98, S D=$ $.39, t=4.34, p<.001, C I, .10, .25, d=.45)$. A repeated measures ANOVA showed that adult structure declined significantly across the school year for all students $(M=2.96$ to $M=2.89$, Wilks' Lambda $=.94, F(1,364)=23.44, p<.001$, with a small effect size, $\eta^{2}=$ .06 , and boys experienced greater losses in adult structure, than girls, across sixth-grade, Wilks' Lambda $=.97, F(1,364)=10.13, p<.01, \eta^{2}=.03$. The analyses support the hypothesis.

A third follow-up analysis averaging parent and teacher autonomy support confirmed that boys and girls did not differ in adult autonomy support in the beginning 


\section{BOYS' ENGAGEMENT AND INTERPERSONAL RESOURCES IN SIXTH GRADE}

(boys: $M=2.88, S D=.38$; girls: $M=2.93, S D=.41, t=1.30, n s$ ) nor at the end of the school year (boys: $M=2.78, S D=.42$; girls: $M=2.86, S D=.44, t=1.71, n s$ ). Although a repeated measures ANOVA showed that adult autonomy support declined significantly across the school year for all students $(M=2.90$ to $M=2.82$, Wilks' Lambda $=.94, F(1$, $364)=24.38, p<.001$, with a small effect size, $\eta^{2}=.06$ ), boys did not experience greater losses in adult autonomy support, than girls, across sixth-grade, Wilks' Lambda $=1.00$, $F(1,364)=.46, n s$. The analyses do not support the hypothesis (See Table 10 for a summary of support for adult provisions).

\section{Table 10}

Summary of Support: Gender Differences in Academic Engagement and Adult Provisions in Sixth Grade

\begin{tabular}{lcc}
\hline Expectations: & $\begin{array}{c}\text { Boys are Lower in } \\
\text { Engagement and } \\
\text { Provisions than Girls }\end{array}$ & $\begin{array}{c}\text { Boys Have Greater } \\
\text { Losses in Engagement } \\
\text { and Provisions than Girls }\end{array}$ \\
\hline Test Type & T-tests in fall and spring & $\begin{array}{c}\text { Repeated } \\
\text { measures ANOVA }\end{array}$ \\
\hline Engagement & ++ & $n s$ \\
Provisions from: & & \\
Parent & & $n s$ \\
Involvement & + & ++ \\
Structure & + & $n s$ \\
Autonomy Support & $n s$ & ++ \\
Parent SSP Average & + & $n s$ \\
Teacher & & $n s$
\end{tabular}


BOYS' ENGAGEMENT AND INTERPERSONAL RESOURCES IN SIXTH GRADE

\begin{tabular}{lcc}
\hline Expectations: & $\begin{array}{c}\text { Boys are Lower in } \\
\text { Engagement and } \\
\text { Provisions than Girls }\end{array}$ & $\begin{array}{c}\text { Boys Have Greater } \\
\text { Losses in Engagement } \\
\text { and Provisions than Girls }\end{array}$ \\
\hline Test Type & $T$-tests in fall and spring & $\begin{array}{c}\text { Repeated } \\
\text { measures ANOVA }\end{array}$ \\
\hline Autonomy Support & $n s$ & $n s$ \\
Teacher SSP Average & ++ & $n s$ \\
Combined Parent & & \\
and Teacher & & $n s$ \\
Involvement & ++ & ++ \\
Structure & ++ & $n s$ \\
Autonomy Support & $n s$ & \\
\hline
\end{tabular}

Note: + + supported, + partially supported, $n s$ not supported.

Summary of Gender Disparities in Adult Provisions. Combining parent and teacher resources helped to consider the patterns of provisions offered to students within the adult context as a whole. Again, patterns of gender differences differed by dimension. For involvement, both boys and girls experienced small increases from fall to spring, but boys showed lower levels than girls at both time points. For structure, gender disparities were also found at both time points, but for this provision boys also showed greater losses over the school year. Finally, for autonomy support, mirroring the findings for each adult separately, no gender differences were found; instead, both boys and girls reported losses in this provision across sixth grade.

Relatedness to Parents, Teacher, Classmates, and Friends. The study hypothesized that boys would have fewer socioemotional resources available in some 


\section{BOYS' ENGAGEMENT AND INTERPERSONAL RESOURCES IN SIXTH GRADE}

areas during sixth grade. The following analyses aim to identify the kinds of relatedness boys may be lacking.

Maternal Relatedness. Results of an independent-samples t-test indicated that boys and girls did not differ in their levels of maternal relatedness at the beginning (boys: $M=3.47, S D=.65$; girls: $M=3.52, S D=.62, t=.76, n s$ ) or end of the school year (boys: $M=3.40, S D=.69 ;$ girls: $M=3.53, S D=.67, t=1.81, n s)$. The findings do not support the research hypothesis that boys experienced lower levels of maternal relatedness than girls, at the beginning or end of the sixth-grade year.

A repeated measures ANOVA showed that maternal relatedness did not change significantly across the school year, Wilks' Lambda $=1.00, F(1,364)=.83, n s$, and boys and girls did not change differently, Wilks' Lambda $=1.00, F(1,364)=1.86, n s$. The findings do not support the research hypothesis that boys experienced greater losses in maternal relatedness than girls, across sixth grade.

Paternal Relatedness. Results of an independent-samples t-test indicated that boys and girls did not differ in their levels of paternal relatedness at the beginning (boys: $M=3.35, S D=.71$; girls: $M=3.39, S D=.73, t=.43, n s$ ) or end of the school year (boys: $M=3.35, S D=.70$; girls: $M=3.48, \mathrm{SD}=.67, \mathrm{t}=1.75, n s)$. The findings do not support the research hypothesis that boys experienced lower levels of paternal relatedness than girls, at the beginning or end of the sixth-grade year. 


\section{BOYS' ENGAGEMENT AND INTERPERSONAL RESOURCES IN SIXTH GRADE}

A repeated measures ANOVA showed that paternal relatedness did not change significantly across the school year, Wilks' Lambda $=1.00, F(1,364)=1.76, n s$, and boys and girls did not change differently, Wilks' Lambda $=.99, F(1,364)=2.03, n s$. The findings do not support the research hypothesis that boys experienced greater losses in paternal relatedness than girls across sixth grade.

Teacher Relatedness. Results of an independent-samples t-test indicated that boys and girls did not differ in levels of teacher relatedness at the beginning (boys: $M=2.95$, $S D=.65$; girls: $M=3.03, S D=.68, \mathrm{t}=1.17, n s$ ) or end of the school year (boys: $M=$ 2.86, $S D=.66$; girls: $M=2.98, S D=.70, t=1.63, n s)$. The findings do not support the research hypothesis that boys experienced lower levels of teacher relatedness than girls, at the beginning or end of the sixth-grade year.

A repeated measures ANOVA showed that teacher relatedness lessened significantly across the school year for both boys and girls, Wilks' Lambda $=1.00, F(1$, $364)=4.07, p<.05$, with a small effect size; $\eta^{2}=.01$. However, boys and girls did not change differently, Wilks' Lambda $=1.00, F(1,364)=.25, n s$. The findings do not support the research hypothesis that boys experienced greater losses in teacher relatedness than girls across sixth grade.

Classmate Relatedness. Results of an independent-samples t-test indicated that boys and girls did not differ in levels of relatedness to classmates at the beginning (boys: $M=3.18, S D=.72$; girls: $M=3.21, S D=.77, t=.48, n s$ ) or end of the school year (boys: 


\section{BOYS' ENGAGEMENT AND INTERPERSONAL RESOURCES IN SIXTH GRADE}

$M=3.08, S D=.74$; girls: $M=3.18, S D=.72, t=1.25, n s)$. The findings do not support

the research hypothesis that boys experienced lower levels of classmate relatedness than girls, at the beginning or end of the sixth-grade year.

A repeated measures ANOVA showed that relatedness to classmates did not change significantly across the school year, Wilks' Lambda $=.99, F(1,364)=2.99, n s$, and boys and girls did not change differently, Wilks' Lambda $=1.00, F(1,364)=.61, n s$. The findings do not support the research hypothesis that boys experienced greater losses in classmate relatedness than girls across sixth grade.

Friends Relatedness. Results of an independent-samples t-test indicated that boys and girls did not differ in levels of relatedness to friends at the beginning (boys: $M=$ $3.43, S D=.62$; girls: $M=3.50, S D=.58, t=1.25, n s$ ) or end of the school year (boys: $M$ $=3.45, S D=.57$; girls: $M=3.47, S D=.68, t=.30, n s)$. The findings do not support the research hypothesis that boys experienced lower levels of friend relatedness than girls, at the beginning or end of the sixth-grade year.

A repeated measures ANOVA showed that relatedness to friends did not change significantly across the school year, Wilks' Lambda $=1.00, F(1,364)=.003$, ns, and boys and girls did not change differently, Wilks' Lambda $=1.00, F(1,364)=.89$, ns. The findings do not support the research hypothesis that boys experienced greater losses in friend relatedness than girls, across sixth grade. 


\section{BOYS' ENGAGEMENT AND INTERPERSONAL RESOURCES IN SIXTH GRADE}

\section{Composite of Relatedness (Averaged Maternal, Paternal, Teacher, Classmate,}

and Friend). Results of an independent-samples t-test indicated that boys and girls did not differ in their averaged relatedness (with mother, father, teacher, classmates, and friends) in the fall (boys: $M=3.27, S D=.46$; girls: $M=3.33, S D=.48, t=1.15, n s$ ) nor spring (boys: $M=3.23, S D=.48$; girls: $M=3.33, S D=.50, t=1.90, p=.058$ ) of the sixth-grade year, however, differences approached significance at the end of the school year.

A repeated measures ANOVA showed that averaged relatedness did not significantly change across the school year for boys and girls (Wilks' Lambda $=1.00$, $F(1,364)=1.60, n s)$. The analyses did not support the hypothesis that boys experience steeper losses of averaged relatedness than girls across sixth grade (Wilks' Lambda= $1.00, F(1,364)=1.19, n s ;$ see Table 11).

\section{Table 11}

Summary of Support: Gender Differences in Relatedness to Parents, Teacher, Classmates, and Friends in Sixth Grade

\begin{tabular}{lccc}
\hline Expectations: & $\begin{array}{c}\text { Boys are Lower } \\
\text { in Relatedness } \\
\text { than Girls }\end{array}$ & $\begin{array}{c}\text { Boys Lose } \\
\text { Relatedness over } \\
\text { Sixth Grade }\end{array}$ & $\begin{array}{c}\text { Boys Have } \\
\text { Greater Losses in } \\
\text { Relatedness than } \\
\text { Girls. }\end{array}$ \\
\hline Test Type & $\begin{array}{c}T \text {-tests in fall and } \\
\text { spring }\end{array}$ & $\begin{array}{c}\text { Repeated } \\
\text { measures ANOVA }\end{array}$ \\
\hline
\end{tabular}

Relatedness to:

Mother

Father

Teacher

$\begin{array}{lcc}n s & n s & n s \\ n s & n s & n s \\ n s & ++ & n s\end{array}$


BOYS' ENGAGEMENT AND INTERPERSONAL RESOURCES IN SIXTH GRADE

\begin{tabular}{lccc}
\hline Expectations: & $\begin{array}{c}\text { Boys are Lower } \\
\text { in Relatedness } \\
\text { than Girls }\end{array}$ & $\begin{array}{c}\text { Boys Lose } \\
\text { Relatedness over } \\
\text { Sixth Grade }\end{array}$ & $\begin{array}{c}\text { Boys Have } \\
\text { Greater Losses in } \\
\text { Relatedness than } \\
\text { Girls. }\end{array}$ \\
\hline $\begin{array}{l}\text { Classmates } \\
\text { Friends }\end{array}$ & $n s$ & $n s$ & $n s$ \\
Relatedness Average $^{\text {a }}$ & $n s$ & $n s$ & $n s$ \\
\hline
\end{tabular}

Note: + + supported, + partially supported, $n s$ not supported.

Note: ${ }^{a}$ spring average was approaching significance, $\mathrm{p}=.058$

Summary of Gender Disparities in Relatedness. Contrary to predictions, gender disparities were not found for student-reported relatedness. Instead, relatedness to most social partners was stable across the school year. The one exception was relatedness to teachers, which showed declines from fall to spring for both boys and girls. Taken together with prior results showing losses in all three teacher provisions, it appears that both boys and girls are experiencing declines in all teacher resources over the first year of middle school.

Peer Network Resources. Results of the analyses of peer network resources are summarized in Tables 12 and 13.

Table 12

Results: Gender Differences in Peer Resources

\begin{tabular}{lcccccc}
\cline { 2 - 7 } Resource & \multicolumn{2}{c}{ Fall } & \multicolumn{2}{c}{ Spring } & \multicolumn{2}{c}{ ANOVA } \\
\cline { 2 - 7 } & $t$ & Cohen's $d$ & $t$ & Cohen's d & $F$ & $\eta^{2}$ \\
\hline Peer Engagement & $4.20 * * *$ & .44 & $7.12 * * *$ & .75 & $6.46 *$ & .02 \\
Peer Group Size & $5.39 * * *$ & .57 & & & & \\
Same-sex members & $4.70 * * *$ & .48 & & & & \\
$(\%)$ & & & & & & \\
Friendships & & & & & &
\end{tabular}


BOYS' ENGAGEMENT AND INTERPERSONAL RESOURCES IN SIXTH GRADE

Reciprocated $\quad 3.33 * * * \quad .35$

Self-Reported $\quad 3.48 * * * \quad .37$

Peer-Reported $\quad n s$

Friendship Quality $\quad n s$

$\begin{array}{ccc}\text { Peer Composite } & 4.58 * * * \quad .48 \\ \text { Note }^{*} \mathrm{p}<.05, * * \mathrm{p}<.01, * * * \mathrm{p}<.001\end{array}$

Peer Group Engagement. Results of an independent-samples t-test indicated that the average engagement of boys' peer networks in the beginning of the school year was lower than that of girls' networks (boys: $M=3.03, S D=.39$; girls: $M=3.19, S D=.33, t$ $=4.20, p<.001, C I, .08, .23)$. The difference between the two groups was small, $d=.44$. The findings support the research hypothesis that, on average, boys' peer networks are lower in engagement than those of girls, at the beginning of the sixth-grade year.

Results of an independent-samples t-test indicated that the average engagement of boys' peer networks at the end of the school year was lower than that of girls' networks (boys: $M=3.00, S D=.34$; girls: $M=3.26, S D=.35, t=7.12, p<.001, C I, .19, .33$ ). The difference between the two groups was moderately large, $d=.75$. The findings support the research hypothesis that, on average, boys' peer networks are lower in engagement than those of girls, at the end of the sixth-grade year.

A repeated measures ANOVA showed that the average engagement of students' peer networks did not change significantly across the school year, Wilks' Lambda $=1.00$, $F(1,364)=.86, n s$. Boys and girls, however, changed differently in that boys' peer groups experienced losses in group engagement while girls' peer groups increased in their peer group engagement average, Wilks' Lambda $=.98, F(1,364)=6.46, p<.05, \eta^{2}$ 


\section{BOYS' ENGAGEMENT AND INTERPERSONAL RESOURCES IN SIXTH GRADE}

$=.02$. The findings support the research hypothesis that boys experienced greater losses in their peer group's average engagement than girls, across sixth grade.

Peer Group Size. Peer group size at the beginning of the school year was used because it is a time of much variation in peer-group composition, especially during a school transition. Results of an independent-samples t-test indicated that boys' peer group size was smaller than girls' peer groups at the beginning of the school year (boys: $M=$ 3.78, $S D=3.51$; girls: $M=5.97, S D=4.17, t=5.39, p<.001, C I, 1.40,2.98$, equal variances not assumed), with a moderate effect size; $d=.57$. The findings support the research hypothesis that boys have smaller peer networks than girls, at the beginning of the sixth-grade year.

Number of Same-Sex Group Members. Results of an independent-samples t-test indicated that boys and girls differed in their percentage of same-sex peer group members (boys: $M=.67, S D=.45$; girls: $M=.85, S D=.30, t=4.70, p<.001, C I, .11, .26$ ). The difference between the two groups was moderate, $d=.48$. The findings support the research hypothesis that boys' peer networks are less gender-homogeneous having a smaller percentage of same-sex group members than girls at the beginning of the sixthgrade year. Such a constellation can be a resource, because having better functioning girls in your peer group should facilitate engagement, but it can also be a liability because attention may be directed away from schoolwork in mixed-sex groups. 


\section{BOYS' ENGAGEMENT AND INTERPERSONAL RESOURCES IN SIXTH GRADE}

Reciprocated Friendships. Results of an independent-samples t-test indicated that boys had also fewer reciprocated friends than girls at the beginning of the school year (boys: $M=2.16, S D=1.97$; girls: $M=2.87, S D=2.11, t=3.33, p<.001, C I, .29,1.13$, with a small effect size, $d=.35$ ). The finding supports the hypothesis that boys have fewer reciprocated friends than girls, at the beginning of the sixth-grade year.

Self-Reported Friendships. Results of an independent-samples t-test indicated that boys had also fewer self-reported friends than girls (boys: $M=7.61, S D=4.04$; girls: $M=9.05, S D=3.85, t=3.48, p<.001, C I, .63,2.26$, with a small effect size $d=.37$ ). The findings support the hypothesis that boys have fewer self-reported friends than girls at the beginning of the sixth-grade year.

Peer-Reported Friendships. Results of an independent-samples t-test indicated that boys and girls did, nevertheless, not differ in the number of peers who reported them as friends at the beginning of the school year (boys: $M=5.58, S D=4.05$; girls: $M=6.30$, $S D=4.02, t=1.70, n s)$. The findings do not support the research hypothesis that boys have fewer peers who report them as friends.

Quality of Friendships. Results of an independent-samples t-test indicated that boys and girls did not differ in their levels of the quality of their friendships at the beginning of the school year (boys: $M=2.51, S D=.56$; girls: $M=2.50, S D=.53, t=.31$, $n s)$. The hypothesis that boys experienced lower levels of friendship quality than girls, was not supported. 


\section{BOYS' ENGAGEMENT AND INTERPERSONAL RESOURCES IN SIXTH GRADE}

Composite of Peer Resources. A composite of peer resources was obtained by averaging peer group engagement, peer group size, reciprocal, self-reported, and peerreported friends, and friendship quality. Results of an independent-samples t-test indicated that, compared to girls, boys had lower levels of averaged peer resources at the beginning of the school year (boys: $M=2.57, S D=.59$; girls: $M=2.86, S D=.61, t=$ $4.58, p<.001, C I, .16, .41, d=.48)$. The hypothesis that boys experienced lower levels of peer resources in sixth grade is supported (See Table 13).

\section{Table 13}

Summary of Support: Gender Differences in Peer Network Resources in Sixth Grade

\begin{tabular}{lcc}
\hline Expectations: & $\begin{array}{c}\text { Boys are Lower in } \\
\text { Peer Resources } \\
\text { than Girls }\end{array}$ & $\begin{array}{c}\text { Boys Have Greater } \\
\text { Losses in Peer } \\
\text { Resources than Girls. }\end{array}$ \\
\hline Test Type & $\begin{array}{c}\text { T-tests in fall and } \\
\text { spring }\end{array}$ & $\begin{array}{c}\text { Repeated } \\
\text { measures ANOVA }\end{array}$ \\
\hline Peer Group Engagement & ++ & ++ \\
& $T$-tests in fall & \\
\hline Peer Group Size & ++ & \\
Same-sex Members in Group & ++ & \\
(\%) & & \\
Friendships & & \\
Reciprocated & ++ & \\
Self-reported & ++ & \\
Peer-reported & $n s$ & \\
Friendship Quality & $n s$ & \\
Peer Resource Average & ++ & \\
\hline
\end{tabular}

Note: ++ supported, + partially supported, $n s$ not supported. 


\section{BOYS' ENGAGEMENT AND INTERPERSONAL RESOURCES IN SIXTH GRADE}

Summary of Gender Disparities in Peer Resources. Gender disparities were

found for all peer network resources, except the number of peer-reported friendships. In

fall, boys had smaller and more heterogenous networks and fewer self-reported and reciprocated friendships. Moreover, compared to girls, boys' peer groups were lower in engagement at both time points, and showed differential losses over the school year.

\section{Research Question Two: Interpersonal Resources that Buffer Boys' Declines in}

\section{Engagement}

\section{Research Question Two: Part One}

Part One of the second research questions was: Compared to boys with lower levels of interpersonal resources, do boys with more resources show higher levels of engagement in school at the beginning and the end of sixth grade, and do boys with more resources show smaller declines in engagement over sixth grade? It was hypothesized that boys with higher resources will have higher levels of engagement in the fall and spring and will also show smaller losses in engagement.

Descriptive Statistics. Correlations between boys' engagement and their interpersonal resources are shown in Table 14. As expected, the intercorrelations among dimensions of parenting were relatively high, ranging from .36 to .56 ; as were the intercorrelations among dimensions of teaching, which ranged from .80 to .82 . Correlations between corresponding dimensions of parents and teachers were also relatively high, ranging from .33 to .57 . Correlations between relatedness dimensions 


\section{BOYS' ENGAGEMENT AND INTERPERSONAL RESOURCES IN SIXTH GRADE}

varied from .16 to .47 . Among peer resources, number of reciprocated friendships correlated with self-reported $(r=.56)$ and peer-reported $(r=.65)$ friendships. Lastly, percent of same-sex peer group members strongly correlated with network size $(r=.65)$ and moderately correlated with peer group engagement $(r=.21)$.

Boys' fall, and spring engagement were strongly correlated $(r=.73, p<.01)$. Overall, correlations of individual parent and teacher variables with engagement were stronger than individual peer variables. Each parent and teacher provision positively correlated with fall and spring engagement. Interestingly, the correlations of parent and teacher involvement with engagement were similar in strength (Fall: $r=.35, r=.31 ; p<$ .01 , respectively; Spring: $r=.38, r=.36 ; p<.01$ ), however, the correlation between engagement and teacher structure (fall: $r=.44$; spring: $r=.48 ; p<.01$ ) seemed to be stronger than with parent structure (fall: $r=.26$; spring: $r=.28 ; p<.01$ ).

The relatedness variables all positively correlated with fall and spring engagement, except for friend relatedness with spring engagement. Paternal relatedness seemed to have the stronger correlations with engagement than maternal relatedness (Fall: $r=.30, \mathrm{p}<.01, r=.18, p<.05$, respectively; Spring: $r=.38, \mathrm{p}<.01, r=.17 ; p<$ $.05)$.

For peer variables, peer group engagement, as well as the number of reciprocated and self-reported friends all moderately correlated with engagement in both fall $(r=.40, r=$ $.42 r=.31$, respectively, $p<.01)$ and spring $(r=.36, r=.37, r=.31 ; p<.01)$. Peer group 


\section{BOYS' ENGAGEMENT AND INTERPERSONAL RESOURCES IN SIXTH GRADE}

size, percent of same-sex peer group members, and friendship quality significantly correlated with engagement in spring ( $r=.17, r=.15, r=.27$, respectively), but not in fall. Percent of close and closest lost friends did not significantly correlate with engagement in either fall ( $r=-.12, r=-.03$, respectively) or spring $(r=.11, r=-.10)$. 
BOYS' ENGAGEMENT AND INTERPERSONAL RESOURCES IN SIXTH GRADE

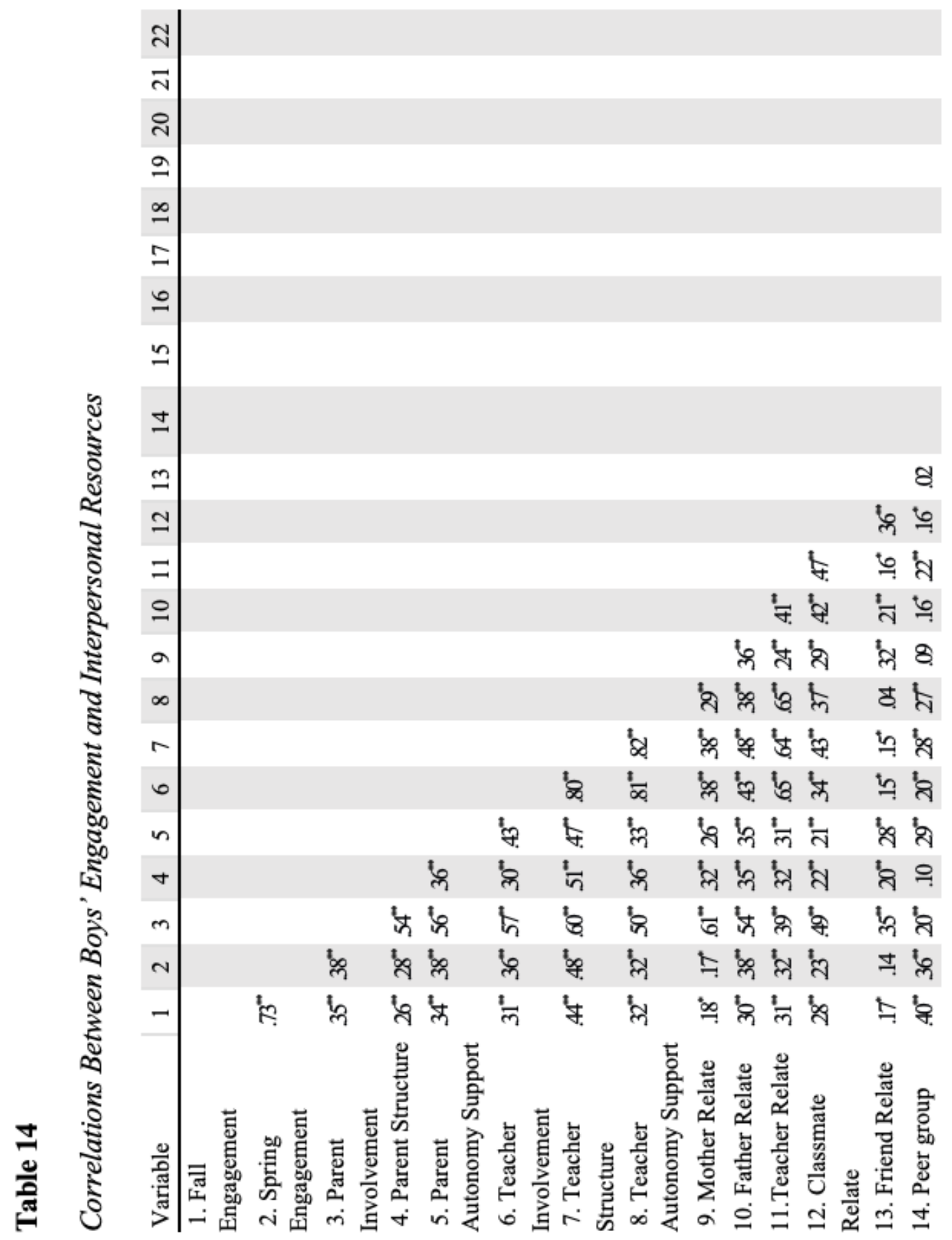




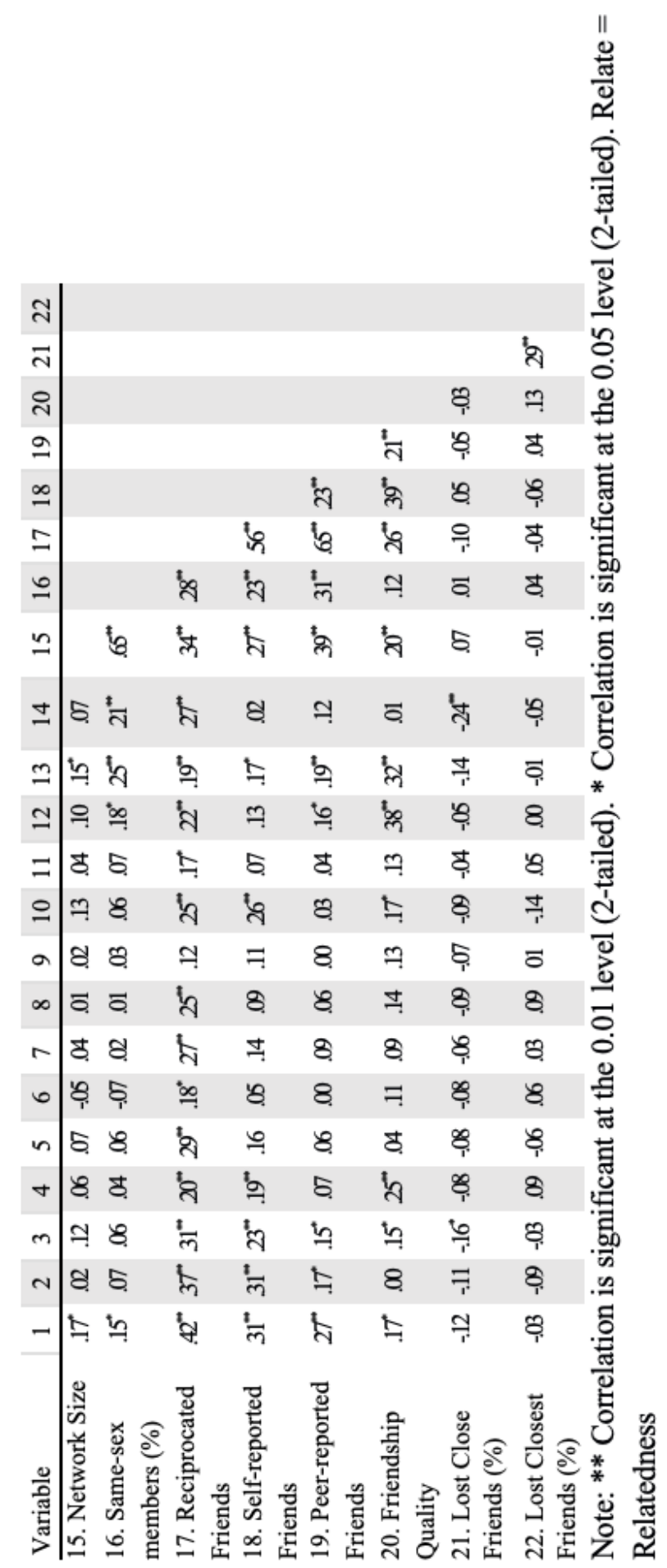




\section{BOYS' ENGAGEMENT AND INTERPERSONAL RESOURCES IN SIXTH GRADE}

Correlations between boys' parent, teacher, and peer composites are shown in

Table 15. All composite variables were positively correlated with fall and spring

engagement $(p<.01)$. Positive correlations at the .01 level were found between each composite variable, except the peer composite which correlated with combined teacher and parent involvement at the .05 level $(r=.18)$ and did not significantly correlate with averaged teacher provisions $(r=.14, n s)$.

\section{Table 15}

Correlations Between Boys’ Academic Engagement and Composites of Parent, Teacher, and Peer Resources

\begin{tabular}{|c|c|c|c|c|c|c|c|c|c|}
\hline Variable & 1 & 2 & 3 & 4 & 5 & 6 & 7 & 8 & 9 \\
\hline 1. $\quad$ Fall Engagement & & & & & & & & & \\
\hline 2. Spring Engagement & $.73^{* *}$ & & & & & & & & \\
\hline 3. Parent Average & $.39^{* *}$ & $.43^{* *}$ & & & & & & & \\
\hline 4. Teacher Average & $.38^{* *}$ & $.41^{* *}$ & $.60^{* *}$ & & & & & & \\
\hline 5. $\mathrm{T} \& \mathrm{P}$ Involvement & $.35^{* *}$ & $.37^{* *}$ & $.76^{* *}$ & $.80^{* *}$ & & & & & \\
\hline 6. T \& P Structure & $.40^{* *}$ & $.44^{* *}$ & $.81^{* *}$ & $.78^{* *}$ & $.68^{* *}$ & & & & \\
\hline $\begin{array}{l}\text { 7. T \& P Autonomy } \\
\text { Support }\end{array}$ & $.41^{* *}$ & $.43^{* *}$ & $.78^{* *}$ & $.85^{* *}$ & $.74^{* *}$ & $.72 * *$ & & & \\
\hline 8. Relatedness Average & $.37^{* *}$ & $.37^{* *}$ & $.64^{* *}$ & $.61^{* *}$ & $.68^{* *}$ & $.60 * *$ & $.57^{* *}$ & & \\
\hline 9. Peer Average & $.42^{* *}$ & $.29^{* *}$ & $.28^{* *}$ & .14 & $.18^{*}$ & $.23^{* *}$ & $.21^{* *}$ & $.29^{* *}$ & \\
\hline
\end{tabular}

Note: $\mathrm{T}=$ Teacher, $\mathrm{P}=$ Parent. ${ }^{* *}$. Correlation is significant at the 0.01 level (2-tailed). * Correlation is significant at the 0.05 level (2-tailed).

Tests were conducted for each interpersonal resource variable (parent and teacher involvement, structure, and autonomy support, and peer variables; average peer group engagement and network size, number of same-sex group members, number of reciprocated, self-reported, and peer-reported friendships, friendship quality, and number 


\section{BOYS' ENGAGEMENT AND INTERPERSONAL RESOURCES IN SIXTH GRADE}

and percentage of close and closest lost friends). In addition, all interpersonal resource variables were averaged to construct a composite score of parent, teacher, and peer resources for each boy. Independent-samples t-tests were conducted to test the hypothesis that boys with higher resources will have higher levels of teacher-reported engagement in the fall and spring. Of boys, the top tenth and twentieth percentile groups for each resource were those with higher $(20 \%)$ and the highest (10\%) levels of resources, compared to boys with lower resources, representing the remaining boys. The distributions of some resources called for different cutoffs to better align with the fit of the data. Rationale for alternative percentile groups is provided when utilized.

Repeated measures ANOVA were used to test the hypothesis that, compared to boys with low resources, boys with higher resources will show smaller declines in engagement across the sixth-grade year. First, the results of each interpersonal resource variable will be presented separately. Then, analyses on parent, teacher, and peer composite scores will be presented. Overall, the hypotheses were partially supported (See Table 16, 17, and 18 for summaries).

Relationship Quality with Parents. Parent Involvement: Boys with the Highest Levels of Parent Involvement (top 10\%). Results of an independent-samples t-test indicated that, compared to boys with lower levels of parent involvement in the beginning of the school year, boys with the highest levels of parent involvement did not differ in levels of teacher-rated student engagement in the fall (high: $M=3.14, S D=.53$; low: $M=$ 


\section{BOYS' ENGAGEMENT AND INTERPERSONAL RESOURCES IN SIXTH GRADE}

$2.93, S D=.64, t=1.36, n s)$ and spring of the sixth-grade year (high: $M=3.17, S D=.53$;

low: $M=2.90, S D=.65, t=1.76, n s)$.

A repeated measures ANOVA showed that student engagement did not change significantly over the school year for both groups, Wilks' Lambda $=1.00, F(1,191)=.00$, $n s$, and the two groups of low and high boys did not change differently, Wilks' Lambda= $1.00, F(1,191)=.34, n s$. The analyses do not support the research hypothesis that boys higher in parent involvement experienced lower losses in overall engagement than boys with lower levels of parent involvement across sixth grade.

Boys with High Levels of Parent Involvement (top 20\%). Results of an independent-samples t-test indicated that, compared to boys with lower levels of parent involvement in the beginning of the school year, boys with higher levels of parent involvement had higher levels of student engagement in the spring (high: $M=3.19, S D=$ .53 ; low: $M=2.86, S D=.65, t=2.81, p<.01, C I, .10, .56, \mathrm{~d}=.52)$, but not in the fall (high: $M=3.13, S D=.67$; low: $M=2.91, S D=.61, t=1.88, n s$ ). A repeated measures ANOVA, however, confirmed that student engagement did not change significantly over the school year for boys with lower and higher levels of parent involvement at the beginning of the school year, Wilks' Lambda $=1.00, F(1,191)=.01, n s$, nor did lower and higher boys change differently, Wilks' Lambda $=.99, F(1,191)=1.68, n s$. Overall, although all mean level trends were in the expected direction, suggesting lower losses for boys with higher levels of parent involvement at the beginning of the school year, the 


\section{BOYS' ENGAGEMENT AND INTERPERSONAL RESOURCES IN SIXTH GRADE}

analyses do not support the hypothesis that these boys experienced lower losses in engagement across the school year than boys with lower levels of parent involvement.

\section{Parent Structure. Boys with Highest Levels of Parent Structure (top 10\%).}

Results of an independent-samples t-test indicated that, compared to boys with lower levels of parent structure in the beginning of the school year, boys with the highest levels of parent structure did not significantly differ in their engagement in the beginning of the school year (high: $M=3.17, S D=.55$; low: $M=2.92, S D=.63, t=1.81, n s$ ), however, they were found to have higher levels of engagement at the end of sixth grade (high: $M=$ 3.19, $S D=.48$; low: $M=2.89, S D=.66, t=2.21, p<.05, C I, .03, .58, d=.48)$.

A repeated measures ANOVA showed that boys' engagement did not change significantly over the school year for the two groups, Wilks' Lambda $=1.00, F(1,191)=$ $.03, n s$, and low and high boys did not change differently, Wilks' Lambda $=.998, F(1$, $191)=.35, n s$. The analyses do not support the research hypothesis that these boys experienced lower losses in overall engagement than boys with lower levels of parent structure across sixth grade.

Boys with High Levels of Parent Structure (top 20\%). Results of an independentsamples t-test showed that compared to boys with lower levels of parent structure in the beginning of the school year, boys with higher levels had significantly higher levels of student engagement in the fall (high: $M=3.22, S D=.52$; low: $M=2.90, S D=.64, t=$ $2.61, p<.05, C I, .08, .56, d=.51$ ) and spring of sixth grade (high: $M=3.21, S D=.48$; 


\section{BOYS' ENGAGEMENT AND INTERPERSONAL RESOURCES IN SIXTH GRADE}

low: $M=2.87, S D=.66, t=3.42, p<.01, C I, .14, .54, d=.54$, equality of variances not assumed). Nevertheless, a repeated measures ANOVA showed that student engagement did not change significantly over the school year for these two groups, Wilks' Lambda= $1.00, F(1,191)=.24, n s$, nor did low and high boys change differently, Wilks' Lambda= $1.00, F(1,191)=.08, n s$. The analyses do not support the hypothesis that these boys experienced lower losses in engagement than boys with lower levels of parent structure across sixth grade. Likely, the standard deviations were just too high compared to the mean level differences. Note that an argument that the sample size was too small does not really make a good point because the sample consists of (nearly) all boys in a small town. The results may have turned out significant only if two or more school systems would be analyzed.

\section{Parent Autonomy Support: Boys with Highest Levels of Parent Autonomy}

Support (top 10\%). This was the variable for which I had the strongest expectations because very high levels of parental autonomy support may indicate a child doing well. Results of an independent-samples t-test indicated that, compared to boys with lower levels of parent autonomy support in the beginning of the school year, boys with the highest levels of parent autonomy support showed significantly higher levels of student engagement in the fall (high: $M=3.30, S D=.75$; low: $M=2.91, S D=.60, t=2.81, p<$ $.01, C I, .12, .67, d=.64$ ), as well as spring of the sixth-grade year (high: $M=3.34, S D=$ .67 ; low: $M=2.87, S D=.62, t=3.32, p=.001, C I, .19, .75, d=.75)$. Nevertheless, a 


\section{BOYS' ENGAGEMENT AND INTERPERSONAL RESOURCES IN SIXTH GRADE}

repeated measures ANOVA showed that student engagement did not change significantly over the school year for boys, Wilks' Lambda $=1.00, F(1,191)=.00, n s$, nor did low and high boys change differently, Wilks' Lambda $=1.00, F(1,191)=.55, n s$. Although the mean level trends were in the expected direction suggesting lower losses for boys with the highest levels of parent autonomy support at the beginning of the school year, the analyses do not support the research hypothesis that these boys experienced lower losses in overall engagement than boys with lower levels of parent autonomy support across sixth grade.

Boys with High Levels of Parent Autonomy Support (top 20\%). Results of an independent-samples t-test indicated that, compared to boys with lower levels of parent autonomy support in the beginning of the school year, boys with higher levels showed significantly higher levels of student engagement in the fall (high group: $M=3.29, S D=$ .65 ; low: $M=2.88, S D=.60 ; t=3.72, p<.001, C I, .19, .63, d=.68)$ and spring (high: $M$ $=3.28, S D=.63 ;$ low: $M=2.84, S D=.62, t=3.84, p<.001, C I, .21, .66, d=.70)$ of the sixth-grade year. A repeated measures ANOVA, however, showed that overall student engagement did not change significantly across the school year, Wilks' Lambda $=1.00$, $F(1,191)=.31, n s$, and that low and high boys did not change differently, Wilks' Lambda $=1.00, F(1,191)=.07, n s$. The analyses do not support the research hypothesis that these boys experienced lower losses in overall engagement than boys with lower levels of parent autonomy support across sixth grade. 


\section{BOYS' ENGAGEMENT AND INTERPERSONAL RESOURCES IN SIXTH GRADE}

Composite of Parent Resources (top 10\% of Average Parent Provisions). Results of an independent-samples t-test indicated that, compared to boys with lower averages of parent resources (parent structure, autonomy support, and involvement) in the beginning

of the school year, boys with the highest averages of parent resources had higher levels of student engagement in the Fall (high: $M=3.30, S D=.63$, low: $M=2.92, S D=.62, t=$ $2.45, p<.05, C I, .07, .68$, with a moderate effect size; $d=.61$ ) and spring of sixth grade (high: $M=3.28, S D=.60$; low: $M=2.89, \mathrm{~S} D=.64, t=2.49, p<.05, C I, .08, .72$, with a moderate effect size; $d=.62)$.

A repeated measures ANOVA showed that student engagement did not significantly change across the school year for boys with low and high averages of parent resources at the beginning of the school year (Wilks' Lambda $=1.00, F(1,191)=.19, n s$ ) nor did they have lower losses in engagement than boys with lower averages of parent resources $($ Wilks'Lambda $=.99, F(1,191)=1.27, n s)$. The analyses do not support the hypothesis.

Composite of Parent Resources (top 20\% of Average Parent Provisions). Results of an independent-samples t-test indicated that, compared to boys with lower averages of parent resources (parent structure, autonomy support, and involvement) in the beginning of the school year, boys with higher averages of parent resources had higher levels of student engagement in the fall (high: $M=3.22, S D=.67$; low: $M=2.89, S D=.60, t=$ $2.99, p<.01, C I, .11, .55$, with a moderate effect size; $d=.54$ ) and spring of sixth grade 


\section{BOYS' ENGAGEMENT AND INTERPERSONAL RESOURCES IN SIXTH GRADE}

(high: $M=3.27, S D=.52$; low: $M=2.84, S D=.65, t=3.80, p<.001, C I, .21, .65$, with a moderate effect size; $d=.69$ ).

A repeated measures ANOVA showed that student engagement did not significantly change across the school year for boys with low and high averages of parent resources at the beginning of the school year, Wilks' Lambda $=1.00, F(1,191)=.00, n s$, nor did these groups change differently, Wilks' Lambda $=.99, F(1,191)=1.27$, ns. Mean level trends were in the expected direction, suggesting increases in engagement for boys with higher averages of parent resources and losses for boys with lower averages of parent resources across sixth grade. The analyses, however, do not support the hypothesis.

\section{Summary of Engagement Differences Between Boys Higher and Lower in}

Parent Provisions. Overall, for the 20/80 group comparisons, evidence was found that mean levels of engagement differed between most groups in fall and spring, but no evidence was found for group differences in how engagement changed across the year. In terms of composite parent provisions, boys with higher levels also had higher levels of engagement at the beginning and end of the school year. This pattern held for each dimension separately, with the exception of parent involvement in fall. In sum, boys higher (top 20\%) in parent structure, autonomy support, and composite parent resources showed higher levels of engagement in fall and spring compared to the rest of the sample, but groups did not differ in how their engagement changed over the school year. For the 


\section{BOYS' ENGAGEMENT AND INTERPERSONAL RESOURCES IN SIXTH GRADE}

10/90 group comparisons, patterns of findings were similar but not as consistent; with this split, no mean differences between groups were found for parent involvement in either fall or spring, or for parent structure in fall.

\section{Relationship Quality with Teachers. Teacher Involvement: Boys with the}

Highest Levels of Teacher Involvement (top 10\%). Results of an independent-samples ttest indicated that, compared to boys with lower levels of teacher involvement in the beginning of the school year, boys with the highest levels of teacher involvement had higher levels of teacher-rated student engagement in the spring (high: group $M=3.28, S D$ $=.59$; low: $M=2.89, S D=.64, t=2.61, p=.01, C I, .10, .70, d=.63)$, but not in fall (high: $M=3.11, S D=.66$; low: $M=2.94, S D=.62, t=1.15, n s$ ). The mean level trends were in the expected direction suggesting gains for boys with the highest levels of teacher involvement at the beginning of the school year. A repeated measures ANOVA showed that student engagement did not change significantly over the school year for both groups, Wilks' Lambda $=.99, F(1,191)=1.15, n s$, however, low and high boys changed differently, Wilks' Lambda $=.98, F(1,191)=4.10, p<.05$, with a small effect size; $\eta^{2}=$ .02. The analyses support the research hypothesis that boys with the highest levels of teacher involvement experienced lower losses of engagement (or had stable engagement) than boys with lower levels of teacher involvement across sixth grade.

Boys with High Levels of Teacher Involvement (top 20\%). Results of an independent-samples t-test indicated that, compared to boys with lower levels of teacher 


\section{BOYS' ENGAGEMENT AND INTERPERSONAL RESOURCES IN SIXTH GRADE}

involvement in the beginning of the school year, boys with higher levels of teacher involvement had higher levels of student engagement in the fall (high: $M=3.29, S D=$ .58 ; low: $M=2.87, S D=.61, t=3.92, p<.001, C I, .21, .64, d=.70)$ and spring of sixth grade (high: $M=3.30, S D=.56$; low: $M=2.83, S D=.63, t=4.25, p<.001, C I, .25, .69$, $d=.76)$ A repeated measures ANOVA showed that student engagement did not change significantly over the school year, Wilks' Lambda $=1.00, F(1,191)=.18, n s$, nor did low and high boys change differently, Wilks' Lambda $=1.00, F(1,191)=.28, n s$. The analyses do not support the research hypothesis that these boys experienced smaller losses in overall engagement.

\section{Teacher Structure: Boys with the Highest Levels of Teacher Structure (top}

10\%). Results of an independent-samples t-test indicated that, compared to boys with lower levels of teacher structure in the beginning of the school year, boys with the highest levels of teacher structure were significantly more engaged in the fall (high: $M=3.38, S D$ $=.67$; low: $M=2.91, S D=.61, t=3.20, p<.01, C I, .18, .77, d=.77)$ and spring of the sixth-grade year (high: $M=3.37, S D=.53$; low: $M=2.87, S D=.64, \mathrm{t}=3.28, p=.001$, $C I, .20, .80, d=.79)$. A repeated measures ANOVA showed that student engagement did not change significantly over the school year, Wilks' Lambda $=1.00, F(1,191)=.14, n s$, nor did low and high boys change differently, Wilks' Lambda $=1.00, F(1,191)=.05, n s$. The analyses do not support the research hypothesis that boys with the highest levels of teacher structure experienced lower losses in overall engagement across sixth grade. 


\section{BOYS' ENGAGEMENT AND INTERPERSONAL RESOURCES IN SIXTH GRADE}

Boys with High Levels of Teacher Structure (top 20\%). Results of an

independent-samples t-test indicated that, compared to boys with lower levels of teacher structure in the beginning of the school year, boys with higher levels of teacher structure had higher levels of student engagement in the fall (high: $M=3.36, S D=.61$; low: $M=$ 2.86, $S D=.60, t=4.50, p<.001, C I, .28, .72, d=.83$ ) and spring of sixth grade (high: $M$ $=3.34, S D=.54$; low: $M=2.83, S D=.63, t=4.53, p<.001, C I, .29, .74, d=.84)$.

A repeated measures ANOVA showed that student engagement did not change significantly over the school year, Wilks' Lambda $=1.00, F(1,191)=.37$, ns, nor did low and high boys change differently, Wilks' Lambda $=1.00, F(1,191)=.03$, ns. In sum, losses for boys with high levels of teacher structure were similar to those for boys with lower levels. The hypothesis was not supported.

\section{Teacher Autonomy Support: Boys with Highest Levels of Teacher Autonomy} Support (top 10\%). Results of an independent-samples t-test indicated that, compared to boys with lower levels of teacher autonomy support in the beginning of the school year, boys with the highest levels of teacher autonomy support had higher levels of student engagement in fall (high: $M=3.22, S D=.66$; low: $M=2.92, S D=.62, t=2.07, p<.05$, $C I, .13, .58, d=.48$ ) and spring (high: $M=3.23, S D=.57$; low: $M=2.89, S D=.64, t=$ $2.37, p<.01, C I, .06, .64, d=.55)$ of the sixth-grade year. A repeated measures ANOVA showed that student engagement did not change significantly over the school, Wilks' Lambda $=1.00, F(1,191)=.04, n s$, nor did low and high boys change differently, Wilks' 


\section{BOYS' ENGAGEMENT AND INTERPERSONAL RESOURCES IN SIXTH GRADE}

Lambda $=1.00, F(1,191)=.23, n s$. The analyses do not support the research hypothesis that these boys experienced lower losses in overall engagement than boys with lower levels of teacher autonomy support across sixth grade.

Boys with High Levels of Teacher Autonomy Support (top 20\%). Results of an independent-samples t-test indicated that, compared to boys with lower levels of teacher autonomy support in the beginning of the school year, boys with high levels of teacher autonomy support still showed higher levels of student engagement in the fall (high: $M=$ 3.26, $S D=.56$; low: $M=2.88, S D=.62, t=3.41, p<.001, C I, .16, .60, d=.62)$ and spring of sixth grade (high: $M=3.22, S D=.55$; low: $M=2.85, S D=.65, t=3.20, p<$ $.01, C I, .14, .59, d=.58)$. A repeated measurement showed that student engagement did not change significantly over the school year, Wilks' Lambda $=1.00, F(1,191)=.69, n s$, nor did low and high boys change differently, Wilks' Lambda $=1.00, F(1,191)=.03, n s$. The analyses do not support the research hypothesis that these boys experienced lower losses in overall engagement than boys with lower levels of teacher autonomy support across sixth grade. In sum, teacher autonomy support, as a resource, did not make a difference for engagement change.

\section{Composite of Teacher Resources (top 10\% of Average Teacher Provisions).}

Results of an independent-samples t-test indicated that, compared to boys with lower averages of teacher resources (teacher structure, autonomy support, and involvement) in the beginning of the school year, boys with the highest averages of teacher resources had 


\section{BOYS' ENGAGEMENT AND INTERPERSONAL RESOURCES IN SIXTH GRADE}

higher levels of student engagement in the fall (high: $M=3.26, S D=.69$; low: $M=2.92$, $S D=.61, t=2.30, p<.05, C I, .05, .63$, with a moderate effect size; $d=.54)$ and spring of sixth grade (high: $M=3.33, S D=.60$; low: $M=2.88, S D=.63, t=3.08, p<.01, C I, .16$, .75 , with a moderate effect size; $d=.73$ ).

A repeated measurement showed that student engagement did not significantly change across the school year for boys with low and high averages of teacher resources at the beginning of the school year, Wilks' Lambda $=1.00, F(1,191)=.09, n s$. The mean level trends were in the expected direction, suggesting gains in engagement for boys with the highest averages of teacher resources. These boys did not change differently in engagement compared to boys with lower averages of teacher resources (Wilks' Lambda $=.99, F(1,191)=1.20, n s)$. The analyses do not support the hypothesis.

\section{Composite of Teacher Resources (top 20\% of Average Teacher Provisions).}

Results of an independent-samples t-test indicated that, compared to boys with lower averages of teacher resources (teacher structure, autonomy support, and involvement) in the beginning of the school year, boys with higher averages of teacher resources had higher levels of student engagement in the fall (high: $M=3.31, S D=.56$; low: $M=2.87$, $S D=.62, t=4.07, p<.001, C I, .23, .66$, with a moderately high effect size; $d=.73)$ and spring of sixth grade (high: $M=3.23, S D=.60$; low: $M=2.85, S D=.65, t=3.44, p<$ $.001, C I, .16, .61$, with a moderate effect size; $d=.62$ ). 


\section{BOYS' ENGAGEMENT AND INTERPERSONAL RESOURCES IN SIXTH GRADE}

A repeated measurement showed that student engagement did not significantly change across the school year for boys with low and high averages of teacher resources at the beginning of the school year, Wilks' Lambda $=.99, F(1,191)=1.29, n s$, nor did these groups change differently, Wilks' Lambda $=1.00, F(1,191)=.43, n s$. The analyses do not support the hypothesis that these boys experienced lower losses in overall engagement than boys with lower averages of teacher resources.

\section{Summary of Engagement Differences Between Boys Higher and Lower in}

Teacher Provisions. Overall, boys with higher teacher provisions in the beginning of the school year showed higher levels of engagement in fall and spring, compared to the rest of the sample, but did not differ in how their engagement patterns across the school year. Separately, each provision showed a similar pattern. Group differences in the 10/90 showed similar patterns, with two exceptions. Boys with the highest levels of teacher involvement began the school year with engagement levels similar to the rest of their male peers but showed different patterns of engagement change across sixth grade. Mean level trends suggest gains in engagement for boys with the highest levels of teacher involvement and losses for boys with lower levels. When examining the groups separately, a follow-up analyses indicated significant gains in engagement for boys with the highest levels of teacher involvement (Wilkes' Lambda $=.75, F(1,18)=5.95, p<$ $.05)$. 


\section{BOYS' ENGAGEMENT AND INTERPERSONAL RESOURCES IN SIXTH GRADE Combined Adults Relationship Quality. Composite of Teacher \& Parent}

Involvement: Boys with the Highest Level of Adult Involvement (top 10\%). Follow-up analyses averaging parent and teacher involvement confirms that boys with the highest level of adult involvement at the beginning of the school year had higher levels of student engagement in fall and spring of the sixth-grade year. Results of an independent-samples t-test indicated that, compared to boys with lower averages of teacher and parent involvement in the beginning of the school year, boys with the highest averages had significantly higher levels of engagement in the beginning (high: $M=3.27, S D=.56$; low: $M=2.92, S D=.63, t=2.36, p<.05, C I, .06, .65, d=.57$ ) and end of the sixth-grade year (high: $M=3.43, S D=.48$; low: $M=2.87, S D=.64, t=3.72, p<.001, C I, .26, .86, d$ $=.90)$.

A repeated measurement showed that engagement did not change significantly over the school year for boys with low and high parent and teacher involvement averages at the beginning of the school year, Wilks' Lambda $=1.00, F(1,191)=.86, n s$, nor did these groups change differently in engagement across the school year, Wilks' Lambda= $.98, F(1,191)=3.42, n s$. Although the mean level trends were in the expected direction, suggesting lower losses for boys with the highest levels of adult involvement in the beginning of the school year, the analyses do not support the research hypothesis that these boys experienced lower losses in overall engagement than boys with lower levels of adult involvement across sixth grade. 


\section{BOYS' ENGAGEMENT AND INTERPERSONAL RESOURCES IN SIXTH GRADE}

Boys with High Levels of Adult Involvement (top 20\%). Results of an

independent-samples t-test indicated that, compared to boys with lower averages of teacher and parent involvement in the beginning of the school year, boys with higher averages had significantly higher levels of engagement in the fall (high: $M=3.29, S D=$ .59 ; low: $M=2.87, S D=.61, t=3.85, p<.001, C I, .21, .64, d=.70)$ and spring of the sixth-grade year (high: $M=3.29, S D=.64$, low: $M=2.83, S D=.64, t=4.05, p<.001$, $C I, .23, .28, d=.73)$

A repeated measurement showed that engagement did not change significantly over the school year for boys with low and high parent and teacher involvement averages at the beginning of the school year, Wilks' Lambda $=1.00, F(1,191)=.26, n s$, nor did these groups change differently in engagement across the school year, Wilks' Lambda= $1.00, F(1,191)=.13, n s$. The analyses do not support the research hypothesis that boys with higher levels of parent and teacher involvement averages at the beginning of the school year experienced lower declines in overall individual engagement than boys with lower levels of parent and teacher involvement averages. Interestingly, mean level trends were not in the expected direction for boys with high levels of involvement; their engagement declined while the other boys' engagement remained stable across the school year. Further, the top 10 and $20 \%$ groups differed in mean level trends; the boys with the highest levels of adult involvement increased in engagement, whereas boys with high levels experienced losses in engagement. 


\section{BOYS' ENGAGEMENT AND INTERPERSONAL RESOURCES IN SIXTH GRADE}

Composite of Teacher \& Parent Structure: Boys with the Highest Level of Adult

Structure (top 10\%). Follow-up analyses averaging parent and teacher structure confirms that boys with the highest averages of adult structure at the beginning of the school year had higher levels of student engagement in fall and spring of the sixth-grade year. Results of an independent-samples t-test indicated that, compared to boys with lower averages of teacher and parent structure in the beginning of the school year, boys with the highest averages had significantly higher levels of engagement in the beginning (high: $M=3.37$, $S D=.54$; low: $M=2.91, S D=.62, t=3.09, p<.01, C I, .17, .75, d=.75)$ and end of the sixth-grade year (high: $M=3.32, S D=.51$; low: $M=2.88, S D=.64, t=2.91, p<.01, C I$, $.14, .75, d=.70)$.

A repeated measurement showed that engagement did not change significantly over the school year for boys with low and high adult structure averages at the beginning of the school year, Wilks' Lambda $=1.00, F(1,191)=.42, n s$, nor did these groups change differently in engagement across the school year, Wilks' Lambda $=1.00, F(1$, $191)=.02, n s$. The analyses do not support the research hypothesis that these boys experienced lower losses in overall engagement than boys with lower averages of adult structure across sixth grade.

Composite of Teacher \& Parent Structure: Boys with High Levels of Adult Structure (top 20\%). Follow-up analyses averaging parent and teacher structure confirms that boys with high averages of adult structure at the beginning of the school year had 


\section{BOYS' ENGAGEMENT AND INTERPERSONAL RESOURCES IN SIXTH GRADE}

higher levels of student engagement in fall and spring of the sixth-grade year. Results of an independent-samples t-test indicated that, compared to boys with lower averages of teacher and parent structure in the beginning of the school year, boys with the high averages had significantly higher levels of engagement in the beginning (high: $M=3.27$, $S D=.61 ;$ low: $M=2.88, S D=.62, t=3.53, p<.001, C I, .17, .61, d=.64)$ and end of the sixth-grade year (high: $M=3.26, S D=.52$; low: $M=2.84, S D=.65, t=3.76, p<.001$, $C I, .20, .65, d=.68)$.

A repeated measurement showed that engagement did not change significantly over the school year for boys with low and high adult structure averages at the beginning of the school year, Wilks' Lambda $=1.00, F(1,191)=.25, n s$, nor did these groups change differently in engagement across the school year, Wilks' Lambda $=1.00, F(1$, $191)=.16, n s$. The analyses do not support the research hypothesis that these boys experienced lower losses in overall engagement than boys with lower levels of adult structure across sixth grade.

\section{Composite of Teacher \& Parent Autonomy Support: Boys with the Highest} Level of Adult Autonomy Support (top 10\%). Follow-up analyses averaging parent and teacher autonomy support confirm that boys with the highest averages of adult autonomy support at the beginning of the school year had higher levels of student engagement in fall and spring of the sixth-grade year. Results of an independent-samples t-test indicated that, compared to boys with lower averages of teacher and parent autonomy support in 


\section{BOYS' ENGAGEMENT AND INTERPERSONAL RESOURCES IN SIXTH GRADE}

the beginning of the school year, boys with the highest averages had significantly higher levels of engagement in the beginning (high: $M=3.39, S D=.65$; low: $M=2.90, S D=$ $.61, t=3.34, p=.001, C I, .20, .77, d=.79$ ) and end of the sixth-grade year (high: $M=$ $3.38, S D=.59 ;$ low: $M=2.87, S D=.63, t=3.40, p<.001, C I, .21, .80, d=.80)$.

A repeated measurement showed that engagement did not change significantly over the school year for boys with low and high autonomy support averages at the beginning of the school year, Wilks' Lambda $=1.00, F(1,191)=.17, n s$, nor did these groups change differently in engagement across the school year, Wilks' Lambda $=1.00$, $F(1,191)=.04, n s$. The analyses do not support the research hypothesis that these boys experienced lower losses in overall engagement than boys with lower averages of adult autonomy support across sixth grade.

\section{Composite of Teacher \& Parent Autonomy Support: Boys with High Levels of}

Adult Autonomy Support (top 20\%). Follow-up analyses averaging parent and teacher autonomy support confirms that boys with high averages of adult autonomy support at the beginning of the school year had higher levels of student engagement in fall and spring of the sixth-grade year. Results of an independent-samples t-test indicated that, compared to boys with lower averages of teacher and parent autonomy support in the beginning of the school year, boys with higher averages had significantly higher levels of engagement in the beginning (high: $M=3.26, S D=.69$; low: $M=2.88, S D=.59, t=$ 


\section{BOYS' ENGAGEMENT AND INTERPERSONAL RESOURCES IN SIXTH GRADE}

$3.41, p<.001, C I, .16, .60, d=.62$ ) and end of the sixth-grade year (high: $M=3.27, S D=$ .57 ; low: $M=2.84, S D=.64, t=3.80, p<.001, C I, .21, .65, d=.69)$.

A repeated measurement showed that engagement did not change significantly over the school year for boys with low and high autonomy support averages at the beginning of the school year, Wilks' Lambda $=1.00, F(1,191)=.13, n s$, nor did these groups change differently in engagement across the school year, Wilks' Lambda $=1.00$, $F(1,191)=.37, n s$. The analyses do not support the research hypothesis that these boys experienced lower losses in overall engagement than boys with lower averages of adult autonomy support across sixth grade (See Table 16).

\section{Table 16}

Summary of Support for the Hypotheses: Higher Levels of Parent and Teacher Provisions may Buffer Boys' Losses in Academic Engagement

\begin{tabular}{|c|c|c|c|c|}
\hline \multirow[t]{2}{*}{ Expectations: } & \multicolumn{2}{|c|}{ Top 20\% } & \multicolumn{2}{|c|}{ Top $10 \%$} \\
\hline & $\begin{array}{l}\text { Boys with } \\
\text { High } \\
\text { Provisions are } \\
\text { Higher in } \\
\text { Engagement } \\
\text { than Boys } \\
\text { with Lower } \\
\text { Provisions }\end{array}$ & $\begin{array}{l}\text { Boys with High } \\
\text { Provisions } \\
\text { Change More } \\
\text { Positively in } \\
\text { Engagement } \\
\text { than Boys with } \\
\text { Lower } \\
\text { Provisions }\end{array}$ & $\begin{array}{l}\text { Boys with } \\
\text { Highest } \\
\text { Provisions are } \\
\text { Higher in } \\
\text { Engagement } \\
\text { than Boys } \\
\text { with Lower } \\
\text { Provisions }\end{array}$ & $\begin{array}{c}\text { Boys with } \\
\text { Highest } \\
\text { Provisions } \\
\text { Change More } \\
\text { Positively in } \\
\text { Engagement } \\
\text { than Boys with } \\
\text { Lower } \\
\text { Provisions }\end{array}$ \\
\hline Test Type & $T$-test & $\begin{array}{l}\text { Repeated } \\
\text { measures } \\
A N O V A\end{array}$ & $T$-test & $\begin{array}{l}\text { Repeated } \\
\text { measures } \\
A N O V A\end{array}$ \\
\hline
\end{tabular}

Provisions

from: 
BOYS' ENGAGEMENT AND INTERPERSONAL RESOURCES IN SIXTH GRADE

\begin{tabular}{|c|c|c|c|c|}
\hline \multirow[t]{2}{*}{ Expectations: } & \multicolumn{2}{|c|}{ Top 20\% } & \multicolumn{2}{|c|}{ Top $10 \%$} \\
\hline & $\begin{array}{l}\text { Boys with } \\
\text { High } \\
\text { Provisions are } \\
\text { Higher in } \\
\text { Engagement } \\
\text { than Boys } \\
\text { with Lower } \\
\text { Provisions }\end{array}$ & $\begin{array}{l}\text { Boys with High } \\
\text { Provisions } \\
\text { Change More } \\
\text { Positively in } \\
\text { Engagement } \\
\text { than Boys with } \\
\text { Lower } \\
\text { Provisions }\end{array}$ & $\begin{array}{l}\text { Boys with } \\
\text { Highest } \\
\text { Provisions are } \\
\text { Higher in } \\
\text { Engagement } \\
\text { than Boys } \\
\text { with Lower } \\
\text { Provisions }\end{array}$ & $\begin{array}{c}\text { Boys with } \\
\text { Highest } \\
\text { Provisions } \\
\text { Change More } \\
\text { Positively in } \\
\text { Engagement } \\
\text { than Boys with } \\
\text { Lower } \\
\text { Provisions }\end{array}$ \\
\hline Test Type & $T$-test & $\begin{array}{c}\text { Repeated } \\
\text { measures } \\
A N O V A\end{array}$ & $T$-test & $\begin{array}{c}\text { Repeated } \\
\text { measures } \\
\text { ANOVA }\end{array}$ \\
\hline Parent & + & $n s$ & $n s$ & $n s$ \\
\hline $\begin{array}{l}\text { Involvement } \\
\text { Structure }\end{array}$ & ++ & $n s$ & + & $n s$ \\
\hline $\begin{array}{l}\text { Autonomy } \\
\text { Support }\end{array}$ & ++ & $n s$ & ++ & $n s$ \\
\hline $\begin{array}{l}\text { Parent } \\
\text { Average }\end{array}$ & ++ & $n s$ & ++ & $n s$ \\
\hline Teacher & & & & \\
\hline Involvement & ++ & $n s$ & + & ++ \\
\hline Structure & ++ & $n s$ & ++ & $n s$ \\
\hline $\begin{array}{l}\text { Autonomy } \\
\text { Support }\end{array}$ & ++ & $n s$ & ++ & $n s$ \\
\hline $\begin{array}{l}\text { Teacher } \\
\text { Average }\end{array}$ & ++ & $n s$ & ++ & $n s$ \\
\hline $\begin{array}{l}\text { Combined } \\
\text { Adults }\end{array}$ & & & & \\
\hline Involvement & ++ & $n s$ & ++ & $n s$ \\
\hline Structure & ++ & $n s$ & ++ & $n s$ \\
\hline Autonomy & ++ & $n s$ & ++ & $n s$ \\
\hline
\end{tabular}


BOYS' ENGAGEMENT AND INTERPERSONAL RESOURCES IN SIXTH GRADE

\begin{tabular}{|c|c|c|c|c|}
\hline \multirow[t]{2}{*}{ Expectations: } & \multicolumn{2}{|c|}{ Top 20\% } & \multicolumn{2}{|c|}{ Top $10 \%$} \\
\hline & $\begin{array}{l}\text { Boys with } \\
\text { High } \\
\text { Provisions are } \\
\text { Higher in } \\
\text { Engagement } \\
\text { than Boys } \\
\text { with Lower } \\
\text { Provisions }\end{array}$ & $\begin{array}{l}\text { Boys with High } \\
\text { Provisions } \\
\text { Change More } \\
\text { Positively in } \\
\text { Engagement } \\
\text { than Boys with } \\
\text { Lower } \\
\text { Provisions }\end{array}$ & $\begin{array}{l}\text { Boys with } \\
\text { Highest } \\
\text { Provisions are } \\
\text { Higher in } \\
\text { Engagement } \\
\text { than Boys } \\
\text { with Lower } \\
\text { Provisions }\end{array}$ & $\begin{array}{c}\text { Boys with } \\
\text { Highest } \\
\text { Provisions } \\
\text { Change More } \\
\text { Positively in } \\
\text { Engagement } \\
\text { than Boys with } \\
\text { Lower } \\
\text { Provisions }\end{array}$ \\
\hline Test Type & $T$-test & $\begin{array}{c}\text { Repeated } \\
\text { measures } \\
A N O V A\end{array}$ & $T$-test & $\begin{array}{c}\text { Repeated } \\
\text { measures } \\
A N O V A\end{array}$ \\
\hline & & & & \\
\hline
\end{tabular}

Note: + + supported, + partially supported, $n s$ not supported.

Summary of Engagement Differences Between Boys Higher and Lower in

Adult Provisions. Boys with higher levels of overall combined parent and teacher provisions showed higher levels of engagement at the beginning and end of the school year but did not differ in how their engagement changed across the year. These patterns were similar for both the 20/80 and 10/90 groups and similar when examining each provision separately.

Relatedness to Parents, Teacher, Classmates, and Friends. For the analyses of relatedness, cutoff percentages were based on inspection of the frequency distributions. The goal was to use comparison groups that were different enough (e.g., there was a gap in the ranking of mean values at the specific point). The top $50 \%$ are boys with approximately 3.75 or greater (out of 4.00 ) in relatedness. 


\section{BOYS' ENGAGEMENT AND INTERPERSONAL RESOURCES IN SIXTH GRADE}

Maternal Relatedness (top 50\%). Results of an independent-samples t-test indicated that, compared to boys with lower levels of maternal relatedness in the beginning of the school year, boys with higher levels of maternal relatedness did not differ in levels of student engagement in the fall (high: $M=3.03, S D=.64$; low: $M=$ $2.87, S D=.61, t=1.78, n s)$, or spring of the sixth-grade year (high: $M=2.98, S D=.61$; low: $M=2.86, S D=.68, t=1.32, n s)$.

A repeated measurement showed that student engagement did not change significantly over the school year for boys with low and high levels of maternal relatedness at the beginning of the school year, Wilks' Lambda $=1.00, F(1,191)=.77$, $n s$, nor did low and high boys change differently, Wilks' Lambda $=1.00, F(1,191)=.32$, $n s$. The analyses do not support the research hypothesis that these boys experienced greater losses in overall engagement than boys with lower levels of maternal relatedness across sixth grade.

Paternal Relatedness (top 50\%). Results of an independent-samples t-test indicated that, compared to boys with lower levels of paternal relatedness in the beginning of the school year, boys with higher levels of paternal relatedness had higher levels of student engagement in fall (high: $M=3.09, S D=.66$; low: $M=2.79, S D=.54, t$ $=3.48, p<.001, C I, .13, .48, d=.50$ ), and spring of the sixth-grade year (high: $M=3.13$, $S D=.59$; low: $M=2.68, S D=.63, t=5.06, p<.001, C I, .27, .62, d=.73)$. 


\section{BOYS' ENGAGEMENT AND INTERPERSONAL RESOURCES IN SIXTH GRADE}

A repeated measurement showed that student engagement did not change

significantly over the school year for boys with low and high levels of paternal

relatedness in the beginning of the school year, Wilks' Lambda $=.99, F(1,191)=1.23$, $n s$, however, low and high boys changed differently, Wilks' Lambda $=.98, F(1,191)=$ $4.18, p<.05$, with small effect size, $\eta^{2}=.02$. Boys with higher levels of paternal relatedness experienced gains in student engagement, whereas boys with lower levels showed engagement loss across sixth grade. The analyses support the research hypothesis.

Teacher Relatedness (top 50\%). Results of an independent-samples t-test indicated that, compared to boys with lower levels of teacher relatedness in the beginning of the school year, boys with higher levels of teacher relatedness had higher levels of student engagement in the fall (high: $M=3.14, S D=.63$; low: $M=2.71, S D=.53, t=$ $4.96, p<.001, C I, .26, .60, d=.72$ ), and spring of the sixth-grade year (high: $M=3.11$, $S D=.59$; low: $M=2.67, S D=.63, t=5.04, p<.001, C I, .27, .62, d=.73)$.

A repeated measurement showed that student engagement did not change significantly over the school year for boys with low and high levels of teacher relatedness in the beginning of the school year, Wilks' Lambda $=1.00, F(1,191)=.90, n s$, nor did low and high boys changed differently, Wilks' Lambda $=1.00, F(1,191)=.06, n s$. The analyses do not support the research hypothesis that these boys experienced lower losses 


\section{BOYS' ENGAGEMENT AND INTERPERSONAL RESOURCES IN SIXTH GRADE}

in overall engagement than boys with lower levels of teacher relatedness across sixth grade.

Classmate Relatedness (top 50\%). Results of an independent-samples t-test indicated that, compared to boys with lower levels of classmate relatedness in the beginning of the school year, boys with higher levels of classmate relatedness had higher levels of student engagement in the fall (high: $M=3.08, S D=.63$; low: $M=2.81, S D=$ $.60, t=2.98, p<.001, C I, .09, .44, d=.43$ ), and spring of the sixth-grade year (high: $M=$ 3.04, $S D=.62$; low: $M=2.78, S D=.64, t=2.91, p<.001, C I, .09, .45, d=.42)$.

A repeated measurement showed that student engagement did not change significantly over the school year for boys with low and high levels of classmate relatedness in the beginning of the school year, Wilks' Lambda $=1.00, F(1,191)=.84$, $n s$, nor did low and high boys changed differently, Wilks' Lambda $=1.00, F(1,191)=$ $.00, n s$. The analyses do not support the research hypothesis that these boys experienced lower losses in overall engagement than boys with lower levels of classmate relatedness across sixth grade.

Friend Relatedness (top 50\%). Results of an independent-samples t-test indicated that, compared to boys with lower levels of friend relatedness in the beginning of the school year, boys with higher levels of friend relatedness had higher levels of student engagement in the fall (high: $M=3.08, S D=.62$; low: $M=2.83, S D=.62, t=2.82, p<$ 


\section{BOYS' ENGAGEMENT AND INTERPERSONAL RESOURCES IN SIXTH GRADE}

$.001, C I, .08, .43, d=.41$ ), but not in spring of the sixth-grade year (high: $M=3.00, S D=$ $.63 ;$ low: $M=2.85, S D=.65, t=1.68, n s)$.

A repeated measurement showed that student engagement did not change significantly over the school year for boys with low and high levels of friend relatedness in the beginning of the school year, Wilks' Lambda $=1.00, F(1,191)=.93, n s$, nor did low and high boys change differently, Wilks' Lambda $=1.00, F(1,191)=2.03$, ns. Although the mean level trends were not in the expected direction; boys with lower levels of friend relatedness remained stable in engagement across the school year while boys with higher levels experienced small losses in engagement across the sixth-grade year. The analyses do not support the research hypothesis.

Composite of Parent, Teacher, Classmate, and Friend Relatedness: Boys with

High Levels of Overall Relatedness (top 50\%). Follow-up analyses averaging parent, teacher, classmate, and friend relatedness confirms that boys with high averages of overall relatedness at the beginning of the school year had higher levels of student engagement in fall and spring of the sixth-grade year. Results of an independent-samples t-test indicated that, compared to boys with lower averages of overall relatedness in the beginning of the school year, boys with higher averages had significantly higher levels of engagement in the beginning (high: $M=3.16, S D=.64$; low: $M=2.81, S D=.58, t=$ $3.89, p<.001, C I, .17, .52, d=.57$ ) and end of the sixth-grade year (high: $M=3.15, S D=$ .58 ; low: $M=2.77, S D=.64, t=4.25, p<.001, C I, .21, .56, d=.62)$. 


\section{BOYS' ENGAGEMENT AND INTERPERSONAL RESOURCES IN SIXTH GRADE}

A repeated measurement showed that engagement did not change significantly

over the school year for boys with low and high overall relatedness at the beginning of the school year, Wilks' Lambda $=1.00, F(1,191)=.64, n s$, nor did these groups change differently in engagement across the school year, Wilks' Lambda $=1.00, F(1,191)=.32$, $n s$. The analyses do not support the research hypothesis that these boys experienced lower losses in overall engagement than boys with lower averages of overall relatedness across sixth grade (See Table 17)

\section{Table 17}

Summary of Support: Higher Levels of Relatedness with Parents, Teacher, Classmates, and Friends may Buffer Boys' Losses in Academic Engagement

\begin{tabular}{lcc}
\hline Expectations: & \multicolumn{2}{c}{ Median Split (Top 50\%) } \\
& Boys with High & Boys with High \\
& $\begin{array}{c}\text { Relatedness are Higher } \\
\text { in Engagement than } \\
\text { Boys with Lower } \\
\text { Relatedness }\end{array}$ & $\begin{array}{c}\text { Relatedness Change } \\
\text { More Positively in } \\
\text { Engagement than Boys } \\
\text { with Lower Relatedness }\end{array}$ \\
& & Repeated \\
& T-test & Measures ANOVA \\
\hline Test Type & & $n s$ \\
& & ++ \\
Relatedness to: & $n s$ & $n s$ \\
Mother & ++ & $n s$ \\
Father & ++ & $n s$ \\
Teacher & ++ & $n s$ \\
Classmates & + & \\
Friends & ++ & \\
Relatedness Average & & \\
\hline
\end{tabular}

Note: + + supported, + partially supported, $n s$ not supported. 


\section{BOYS' ENGAGEMENT AND INTERPERSONAL RESOURCES IN SIXTH GRADE Summary of Engagement Differences Between Boys Higher and Lower in}

Relatedness. Patterns were generally consistent for boys higher in levels of relatedness to others (the upper 50\%) showing higher levels of engagement in both fall and spring, with two exceptions: Groups who differed in their relatedness to mothers did not differ in engagement; and groups who differed in their relatedness to friends did not differ in engagement at the spring time point (although they did in fall). In terms of engagement change, boys with higher levels of relatedness did not differ from boys with lower levels, except for relatedness to fathers. Boys higher in relatedness to their father differed from boys with lower levels in how their engagement changed across the school year. When examining the groups separately, a follow-up analyses indicated significant losses in engagement for boys with lower levels of paternal relatedness (Wilkes' Lambda $=.95$, $\mathrm{F}(1,87)=5.00, \mathrm{p}<.05)$, but not for boys with higher levels, suggesting that paternal relatedness may act as a buffer against declines in engagement across the sixth-grade year.

Peer Network Resources. Peer Group Engagement (top 10\%). Results of an independent-samples t-test indicated that, compared to boys whose peer networks are low in engagement in the beginning of the school year, boys with peer groups with high average levels of teacher-reported engagement had higher levels of individual engagement in the fall (high: $M=3.51, S D=.64$; low: $M=2.90, S D=.60, t=4.12, p<$ 


\section{BOYS' ENGAGEMENT AND INTERPERSONAL RESOURCES IN SIXTH GRADE}

$.001, C I, .32, .91, d=1.02$ ) and spring of the sixth-grade year (high: $M=3.37, S D=.64$;

low: $M=2.88, S D=.63, t=3.14, p<.01, C I, .18, .80, d=.78)$.

A repeated measurement showed that individual student engagement did not change significantly over the school year for boys with low and high peer engagement averages at the beginning of the school year, Wilks' Lambda $=1.00, F(1,191)=2.05, n s$, nor did these groups change differently in engagement across the school year, Wilks' Lambda $=.99, F(1,191)=1.21, n s$. Although the mean level trends were in the expected direction, suggesting losses for boys with higher peer group engagement, the analyses do not support the hypothesis

that these boys experienced lower losses in overall engagement than boys with lower levels of peer group engagement across sixth grade. Follow-up analyses showed comparable results at the $20 \%$ cut-off (See Appendix B).

Peer Group Size (top 10\%). Results of an independent-samples t-test indicated that, compared to boys with a low number of peer group members (seven or less) in the beginning of the school year, boys with a higher number of peers in their network (eight or more) did not differ in levels of engagement in the fall (high: $M=3.15, S D=.63$; low: $M=2.93, S D=.63, t=1.41, n s)$, or spring of the sixth-grade year (high: $M=2.97, S D=$ .83 ; low: $M=2.92, S D=.62, t=.28, n s$, equal variances not assumed).

A repeated measurement showed that engagement did not change significantly over the school year for boys with low and high numbers of peers in their network at the 


\section{BOYS' ENGAGEMENT AND INTERPERSONAL RESOURCES IN SIXTH GRADE}

beginning of the school year, Wilks' Lambda $=1.00, F(1,191)=2.85, n s$, nor did these groups change differently in engagement across the school year, Wilks' Lambda $=.99$, $F(1,191)=2.00, n s$. The analyses do not support the hypothesis that these boys experienced lower losses in overall engagement than boys with a smaller network size. Follow-up analyses showed comparable results at the 20\% cut-off (See Appendix B).

Number of Same-Sex Group Members. Results of an independent-samples t-test indicated that, compared to boys with peer groups comprised of only same sex members in the beginning of the school year, boys with peer groups that also include girls did not differ in levels of engagement in the fall (with girls: $M=2.86, S D=.55$; without girls: $M$ $=3.02, S D=.67, t=1.73, n s$, equal variances not assumed), or spring of the sixth-grade year (with girls: $M=2.89, S D=.63$; without girls: $M=2.95, S D=.65, t=.62, n s$ ).

A repeated measurement showed that engagement did not change significantly over the school year for boys with or without girls in their network at the beginning of the school year, Wilks' Lambda $=1.00, F(1,191)=.40, n s$, nor did these groups change differently in engagement across the school year, Wilks' Lambda $=.99, F(1,191)=1.89$, $n s$. The mean level trends were not in the expected direction, suggesting losses for boys with heterogeneous networks. The analyses do not support the research hypothesis.

Reciprocated Friendships (top 10\%). Results of an independent-samples t-test indicated that, compared to boys with lower numbers of reciprocal friends (three or less) in the beginning of the school year, boys with a higher number of reciprocal friends (four 


\section{BOYS' ENGAGEMENT AND INTERPERSONAL RESOURCES IN SIXTH GRADE}

or more) had higher levels of engagement in the fall (high: $M=3.52, S D=.50$; low: $M=$ 2.88, $S D=.61, t=4.86, p<.001, C I, .36, .90, d=1.08)$ and spring of the sixth-grade year (high: $M=3.40, S D=.62$; low: $M=2.86, S D=.62, t=3.92, p<.001, C I, .27, .81, d$ $=.87)$.

A repeated measurement showed that engagement did not change significantly over the school year for boys with low and high numbers of reciprocal friendships at the beginning of the school year, Wilks' Lambda $=.99, F(1,191)=1.78, n s$, nor did these groups change differently in engagement across the school year, Wilks' Lambda $=1.00$, $F(1,191)=.93, n s$. The analyses do not support the hypothesis that these boys experienced lower losses in overall engagement than boys with small numbers of reciprocal friends. Follow-up analyses showed comparable results at the $30 \%$ cutoff; the frequency of the distribution made it impossible to distinguish between $10 \%$ and $20 \%$ (See Appendix B).

Self-Reported Friendships (top 10\%). Results of an independent-samples t-test indicated that, compared to boys with lower numbers of self-reported friends (11 or less) in the beginning of the school year, boys with higher numbers of self-reported friends (12 or more) had higher levels of engagement in the spring (high: $M=3.21, S D=.60$; low: $M$ $=2.89, S D=.64, t=2.04, p<.05, C I, .01, .62, d=.49)$, but not in fall of the sixth-grade year (high: $M=3.21, S D=.73$; low: $M=2.93, S D=.61, t=1.91, p=.058, C I, .01, .59, d$ $=.46 ;$ although approaching significance) . 


\section{BOYS' ENGAGEMENT AND INTERPERSONAL RESOURCES IN SIXTH GRADE}

A repeated measurement showed that engagement did not change significantly

over the school year for boys with low and high numbers of self-reported friendships at the beginning of the school year, Wilks' Lambda $=1.00, F(1,191)=1.27, n s$, nor did these groups change differently in engagement across the school year, Wilks' Lambda= $1.00, F(1,191)=.058, n s$. The analyses do not support the hypothesis that these boys experienced lower losses in overall engagement than boys with smaller numbers of selfreported friendships. Follow-up analyses at the $20 \%$ cutoff were comparable except that boys with higher numbers of self-reported friendships showed higher engagement in spring (See Appendix B).

Peer-Reported Friendships (top 10\%). Results of an independent-samples t-test indicated that, compared to boys with lower numbers of peers who reported them as friends (10 or less) in the beginning of the school year, boys with a higher number of peers who reported them as friends ( 11 or more) did not differ in levels of engagement in the fall (high: $M=3.17, S D=.61$; low: $M=2.93, S D=.63 ; t=.16, n s$ ), or spring of the sixth-grade year (high: $M=3.03, S D=.55$; low: $M=2.91, S D=.65, t=.71, n s$ ). Further analyses at the $20 \%$ cutoff showed higher engagement in fall and spring for boys who had eight or fewer peer-reported friends (See Appendix B). Upon further inspection, boys in the top $10 \%$ had 11 or more peer-reported friends, suggesting that having more friends may not help academic engagement. 


\section{BOYS' ENGAGEMENT AND INTERPERSONAL RESOURCES IN SIXTH GRADE}

A repeated measurement showed that engagement did not change significantly over the school year for boys with low and high numbers of peers who reported them as friends at the beginning of the school year, Wilks' Lambda $=1.00, F(1,191)=2.11, n s$, nor did these groups change differently in engagement across the school year, Wilks' Lambda $=.99, F(1,191)=1.26, n s$. The analyses do not support the hypothesis that these boys experienced lower losses in overall engagement than boys with smaller numbers of peer-reported friends.

Quality of Friendships (top 40\%). A 40\% cutoff was necessary due to the distribution of the frequency data; 76 boys had identical scores at the $60 \%$ percentile. Results of an independent-samples t-test indicated that, compared to boys with lower averages of friendship quality in the beginning of the school year, boys with higher averages did not significantly differ in levels of engagement in the fall (high: $M=3.04$, $S D=.59 ;$ low: $M=2.90, S D=.65, t=1.48, n s$ ) nor spring of the sixth-grade year (high: $M=2.98, S D=.67 ;$ low: $M=2.89, S D=.63, t=.971, n s)$.

A repeated measurement showed that engagement did not change significantly over the school year for boys with low and high friendship quality averages at the beginning of the school year, Wilks' Lambda $=.99, F(1,191)=1.08, n s$, nor did these groups change differently in engagement across the school year, Wilks' Lambda $=1.00$, $F(1,191)=.42, n s$. The analyses do not support the hypothesis that these boys 


\section{BOYS' ENGAGEMENT AND INTERPERSONAL RESOURCES IN SIXTH GRADE}

experienced lower losses in overall engagement than boys with lower levels of friendship quality.

Percent of Close Friends Lost (Boys with Lower Losses; Lost Less than 50\%). Results of an independent-samples t-test indicated that, compared to boys who reported losing a greater percentage of their close friends across the school year, boys who reported lower losses of friends had higher levels of student engagement in the fall (low loss: $M=3.15, S D=.65$; high loss: $M=2.89, S D=.61, t=2.54, p<.05$, with a moderate effect size; $d=.42$ ), and spring of the sixth-grade year (low loss: $M=3.08, S D=.61$; high loss: $M=2.87, S D=.65, t=2.00, p<.05$, with a small effect size; $d=.33$ ). Follow-up analyses tested differences between groups at the thirty and forty percent cut-off; no differences were found (See Appendix B).

A repeated measurement showed that student engagement did not change significantly over the school year for boys with high and low losses of friends, Wilks' Lambda $=.99, F(1,191)=1.24, n s$, nor did boys change differently, Wilks' Lambda $=$ $1.00, F(1,191)=.40, n s$. The analyses do not support the hypothesis that these boys experienced lower losses in overall engagement than boys with higher friendship losses.

Percent of Closest Friends Lost (Boys with Lower Losses; Lost Less than 50\%). Results of an independent-samples t-test indicated that boys with lower and higher percentages of closest lost friends did not differ in student engagement in the fall (low loss: $M=2.96, S D=.65$; high loss: $M=2.95, S D=.56 t=.03, n s)$, nor spring of the 


\section{BOYS' ENGAGEMENT AND INTERPERSONAL RESOURCES IN SIXTH GRADE}

sixth-grade year (low loss: $M=2.95, S D=.63$; high loss: $M=2.87, S D=.65, t=.97, n s$.

Follow-up analyses tested differences between groups at the twenty-five percent cut-off; no differences were found (see appendix).

A repeated measurement showed that student engagement did not change significantly over the school year for boys with high or low losses of closest friends, Wilks' Lambda $=1.00, F(1,191)=2.36, n s$, nor did boys change differently, Wilks' Lambda $=.99, F(1,191)=1.71, n s$. Although the mean level trends were in the expected direction, suggesting losses for boys with lower losses of closest friends, the analyses do not support the hypothesis that these boys experienced lower losses in overall engagement than boys with higher friendship losses of their closest friends.

Composite of Peer Resources (Boys with the Highest Averaged Peer Resources;

top 10\%). Results of an independent-samples t-test indicated that, compared to boys with lower levels of averaged peer resources in the beginning of the school year (peer group engagement, peer group size, percentage of same-sex group members, number of reciprocated, self-reported, and peer-reported friends, friendship quality, percentage of lost friends and lost closest friends), boys with higher levels of averaged peer resources had higher levels of student engagement in the fall (high: $M=3.48, S D=.59$; low: $M=$ $2.89, S D=.61, t=4.13, p<.001, C I, .31, .87$, with a large effect size; $d=.98)$ and spring of sixth-grade (high: $M=3.30, S D=.59$; low: $M=2.88, S D=.64, t=2.83, p<.01, C I$, $.13, .72$, with a moderate effect size; .67). 


\section{BOYS' ENGAGEMENT AND INTERPERSONAL RESOURCES IN SIXTH GRADE}

A repeated measurement showed that student engagement did not significantly change across the school year for boys with low and high averages of peer resources at the beginning of the school year (Wilks' Lambda $=1.00, F(1,191)=3.14, n s$ ), nor did boys with high levels of this resource experience lower losses of engagement than boys with lower averages of peer resources, Wilks' Lambda $=.99, F(1,191)=2.31$, ns. The analyses do not support the hypothesis.

\section{Composite of Peer Resources (Boys with High Averaged Peer Resources; top}

20\%). Results of an independent-samples t-test indicated that, compared to boys with lower levels of averaged peer resources in the beginning of the school year (peer group engagement, peer group size, percentage of same-sex group members, number of reciprocated, self-reported, and peer-reported friends, friendship quality, percentage of lost friends and lost closest friends), boys with higher levels of averaged peer resources had higher levels of student engagement in the fall (high: $M=3.29, S D=.62$; low: $M=$ 2.87, $S D=.60, t=3.83, p<.001, C I, .20, .64$, with a moderately large effect size; $d=$ .69 ) and spring of sixth-grade (high: $M=3.20, S D=.64$; low: $M=2.86, S D=.63, t=$ $3.00, p<.01, C I, .12, .57$, with a moderate effect size; .55).

A repeated measurement showed that student engagement did not significantly change across the school year for boys with low and high averages of peer resources at the beginning of the school year, (Wilks' Lambda $=.99, F(1,191)=1.67, n s)$, nor did boys with higher levels experience lower losses of engagement than boys with lower 


\section{BOYS’ ENGAGEMENT AND INTERPERSONAL RESOURCES IN SIXTH GRADE}

averages of peer resources, Wilks' Lambda $=1.00, F(1,191)=.84, n s$. The analyses do not support the hypothesis (See Table 18).

\section{Table 18}

Summary of Support: Higher Levels of Peer Network Resources may Buffer Boys' Losses in Academic Engagement

\begin{tabular}{|c|c|c|}
\hline Expectations: & $\begin{array}{l}\text { Boys with High Peer } \\
\text { Resources are Higher } \\
\text { in Engagement than } \\
\text { Boys with Lower Peer } \\
\text { Resources }\end{array}$ & $\begin{array}{l}\text { Boys with High Peer Resources } \\
\text { Change More Positively in } \\
\text { Engagement than Boys with } \\
\text { Lower Peer Resources }\end{array}$ \\
\hline Test Type & $\begin{array}{c}T \text {-tests in fall and } \\
\text { spring }\end{array}$ & Repeated measures $A N O V A$ \\
\hline \multicolumn{3}{|l|}{ Engagement } \\
\hline \multicolumn{3}{|c|}{$T$-tests in fall } \\
\hline Peer Group Size & $n s$ & $n s$ \\
\hline Same-sex members (\%) & $n s$ & $n s$ \\
\hline \multicolumn{3}{|l|}{ Friendships } \\
\hline Reciprocated $* *$ & ++ & $n s$ \\
\hline Self-reported $* *$ & + & $n s$ \\
\hline Peer-reported $*(* *)$ & $n s$ & $n s$ \\
\hline Friendship Quality*** & $n s$ & $n s$ \\
\hline Close Friends Lost $\% * * * *$ & ++ & $n s$ \\
\hline Closest Friends Lost $\% * * * *$ & $n s$ & $n s$ \\
\hline Peer Resource Average ** & ++ & $n s$ \\
\hline
\end{tabular}

Note: + + supported, + partially supported, $n s$ not supported.

Note: *Significant at the $20 \%$ cutoff; ** top $10 \%$, *** top $40 \%$, **** top $50 \%$ 


\section{BOYS' ENGAGEMENT AND INTERPERSONAL RESOURCES IN SIXTH GRADE Summary of Engagement Differences Between Boys Higher and Lower in}

Peer Resources. When considered together, boys' peer resources appeared to play a role in levels of engagement, but not in changes in engagement over the school year. As expected, boys with the highest levels of peer group engagement showed higher levels of individual engagement in fall and spring of the sixth-grade year than did the rest of the sample. Other peer resources, namely peer group and friendship indicators, showed varied results. Boys did not differ in their engagement according to their peer group size nor the homogeneity of their peer groups. In terms of friendships, boys with the highest number of reciprocated friendships showed higher levels of engagement in fall and spring. No support was found for self- or peer-reported friendships or friendship quality. Of the friendships lost across the year, boys who lost less than half of their close friends showed higher levels of engagement in fall and spring, however, no support was found for closest friends lost.

\section{Research Question Two: Part Two}

Part Two of the second research question was: What levels of interpersonal resources are needed to buffer boys' declines in engagement? It was hypothesized that boys who do not show a loss in engagement will experience higher levels of many of the interpersonal resources examined and will also experience an overall higher level of resources, compared to boys who show losses in engagement. Independent-samples ttests were conducted to test the hypothesis that boys with stable, or no losses, in teacher- 


\section{BOYS' ENGAGEMENT AND INTERPERSONAL RESOURCES IN SIXTH GRADE}

rated academic engagement $(N=72)$ across the school year will have higher

interpersonal resources at the beginning and end of sixth grade, compared to boys who show declines in engagement or who remain low in engagement $(N=121)$. Those in the bottom third in engagement at the beginning and end of the school year were considered to have remained low. Repeated measures ANOVA were used to test the hypothesis that, compared to boys with losses in engagement, boys who remain stable in their engagement will experience smaller declines in interpersonal resources across the school year. The hypotheses were partially supported. See Table 19 for a summary.

Relationship Quality with Parents. Parent Involvement. Results of an

independent-samples t-test indicated that boys who experienced losses in engagement and boys with stable engagement across the school year did not significantly differ in parent involvement in the fall (no loss: $M=3.14, S D=.46$; loss: $M=3.04, S D=.54, t=1.33$, $n s$ ) nor spring (no loss: $M=3.26, S D=.52$; loss: $M=3.12, S D=.49, t=1.90, n s$; although reaching significance; $p=.059$ ) of the sixth-grade year.

A repeated measurement showed that parent involvement increased across the school year for boys with losses and no losses in engagement, $M=3.07$ to $M=3.17$, Wilks' Lambda $=.95, F(1,191)=9.65, p<.01, \eta^{2}=.05$, however the groups did not change differently, Wilks' Lambda $=1.00, F(1,191)=.40, n s$. The analyses do not support the hypothesis that boys with stable engagement experience smaller declines in parent involvement. 


\section{BOYS' ENGAGEMENT AND INTERPERSONAL RESOURCES IN SIXTH GRADE}

Parent Structure. Results of an independent-samples t-test indicated that, compared to boys who experienced losses in engagement across the school year, boys with stable engagement had higher levels of parent structure in the fall (no loss: $M=3.05$, $S D=.41 ;$ loss: $M=2.91, S D=.42, t=2.30, p<.05, C I, .02, .26, d=.34$ ) and spring (no loss: $M=2.96, S D=.49 ;$ loss: $M=2.71, S D=.41, t=3.74, p<.001, C I, .12, .37, d=$ $.56)$ of the sixth-grade year.

A repeated measurement showed that parent structure declined across the school year for boys with losses and no losses in engagement across the school year, $M=2.96$ to 2.81, Wilks' Lambda $=.90, F(1,191)=20.96, p<.001, \eta^{2}=.10$. Although mean level trends were in the expected direction, suggesting losses for boys with stable engagement across sixth grade, these boys did not experience smaller declines in parent structure than boys who had engagement loss, Wilks' Lambda $=.99, F(1,191)=2.68$, ns. The analyses do not support the hypothesis.

Parent Autonomy Support. Results of an independent-samples t-test indicated that, compared to boys who experienced losses in engagement across the school year, boys with stable engagement had higher levels of parent autonomy support in the fall (no loss:, $M=3.14, S D=.40 ;$ loss: $M=2.98, S D=.47, t=2.44, p<.05, C I, .03, .29, d=$ .36 ), but not in spring (no loss: $M=3.02, S D=.48$; loss: $M=2.89, S D=.52, t=1.77, n s$ ) of the sixth-grade year. 


\section{BOYS’ ENGAGEMENT AND INTERPERSONAL RESOURCES IN SIXTH GRADE}

A repeated measurement showed that parent autonomy support declined across the school year for boys with losses and no losses in engagement across the school year $\left(M=3.04\right.$ to $M=2.93$, Wilks' Lambda $\left.=.96, F(1,191)=8.74, p<.01, \eta^{2}=.04\right)$, however, the groups did not change differently, Wilks' Lambda $=1.00, \mathrm{~F}(1,191)=.16$, $n s$. The analyses do not support the hypothesis.

Composite of Parent Resources. Results of an independent-samples t-test indicated that, compared to boys who experienced losses in engagement across the school year, boys with stable engagement had higher averages of parent resources (parent structure, autonomy support, and involvement) the fall (no loss: $M=3.11, S D=.34$; loss: $M=2.97, S D=.39, t=2.45, p<.05, C I, .03, .24$, with a small effect size; $d=.36)$ and spring of sixth-grade (no loss: $M=3.08, S D=.42$; loss: $M=2.91, S D=.37, t=2.98, p<$ $.01, C I, .06, .29$, with a small effect size; $d=.44)$.

A repeated measurement showed that averaged parent resources declined across the school year for boys with losses and no losses in engagement across the school year $\left(M=3.02\right.$ to $M=2.97$, Wilks' Lambda $\left.=.97, F(1,191)=5.28, p<.05, \eta^{2}=.03\right)$, however, these groups did not change differently, Wilks' Lambda $=1.00, F(1,191)=.77$, $n s$. The analyses do not support the hypothesis.

\section{Summary of Differences in Parent Provisions Between Boys with Stable}

\section{Engagement and Boys with Losses in Engagement. Boys with relatively high and} stable engagement across the school year had higher levels of parent provisions than boys 


\section{BOYS' ENGAGEMENT AND INTERPERSONAL RESOURCES IN SIXTH GRADE}

who remained low in engagement or experienced losses, except for parent involvement. In terms of parent structure, boys with stable engagement had higher levels in fall and spring than boys with engagement loss. For autonomy support, in the beginning of the school year, boys with stable engagement reported having higher levels of this parent autonomy provision than boys with losses, however these differences were no longer apparent by the end of the school year. Counter to predictions, boys who remained low or experienced declines in engagement did not show greater losses in any parent provision across the school year, compared to boys with stable engagement.

Relationship Quality with Teachers. Teacher Involvement. Results of an independent-samples t-test indicated that boys who experienced losses in engagement and boys with stable engagement across the school year did not significantly differ in teacher involvement in the fall (no loss: $M=2.88, S D=.47$; loss: $M=2.74, S D=.52, t=1.89$, $n s$ ) nor spring (no loss: $M=2.80, S D=.50$; loss: $M=2.70, S D=.46, t=1.42, n s$ ) of the sixth-grade year.

A repeated measurement showed that teacher involvement lessened across the school year for boys with losses and no losses in engagement $(M=2.79$ to $M=2.74$, Wilks' Lambda $\left.=.96, F(1,191)=7.24, p<.01, \eta^{2}=.04\right)$, however, the groups did not change differently, Wilks' Lambda $=1.00, F(1,191)=.85, n s$. The analyses do not support the hypothesis that boys with stable engagement experience smaller declines in teacher involvement. 


\section{BOYS' ENGAGEMENT AND INTERPERSONAL RESOURCES IN SIXTH GRADE}

Teacher Structure. Results of an independent-samples t-test indicated that, compared to boys who experienced losses in engagement across the school year, boys with stable engagement had higher levels of teacher structure in the fall (no loss: $M=$ $2.98, S D=.41 ;$ loss: $M=2.82, S D=.46, t=2.38, p<.05, C I, .03, .29, d=.36)$, but not spring (no loss: $M=2.87, S D=.45 ;$ loss: $M=2.76, S D=.39, t=1.76, n s$ ) of the sixthgrade year.

A repeated measurement showed that teacher structure declined across the school year for boys with losses and no losses in engagement across the school year $(M=$ 2.88 to 2.80, Wilks' Lambda $\left.=.94, F(1,191)=11.96, p<.001, \eta^{2}=.06\right)$, however, these groups did not change differently, Wilks' Lambda $=1.00, F(1,191)=1.00, n s$. The analyses do not support the hypothesis.

Teacher Autonomy Support. Results of an independent-samples t-test indicated that boys who experienced losses in engagement and boys with stable engagement across the school year did not significantly differ in teacher autonomy support in the fall (no loss:, $M=2.75, S D=.45$; loss: $M=2.70, S D=.50, t=.66, n s$ ) nor spring (no loss: $M=$ $2.65, S D=.50 ;$ loss: $M=2.61, S D=.40, t=.61, n s)$ of the sixth-grade year.

A repeated measurement showed that teacher autonomy support declined across the school year for boys with losses and no losses in engagement across the school year $\left(M=2.72\right.$ to $M=2.62$, Wilks' Lambda $\left.=.95, F(1,191)=9.51, p<.01, \eta^{2}=.05\right)$, 


\section{BOYS' ENGAGEMENT AND INTERPERSONAL RESOURCES IN SIXTH GRADE}

however, these groups did not change differently, Wilks' Lambda $=1.00, \mathrm{~F}(1,191)=.01$, $n s$. The analyses do not support the hypothesis.

Composite of Teacher Resources. Results of an independent-samples t-test indicated that, that boys who experienced losses in engagement and boys with stable engagement across the school year did not significantly differ in averages of teacher resources (teacher structure, autonomy support, and involvement) in the fall (no loss: $M=$ $2.87, S D=.41 ;$ loss: $M=2.75, S D=.46, t=1.74, n s$ ) nor spring of sixth grade (no loss: $M=2.78, S D=.45 ;$ loss: $M=2.69, S D=.37, t=1.39, n s)$.

A repeated measurement showed that averaged teacher resources declined across the school year for boys with losses and no losses in engagement across the school year $\left(M=2.80\right.$ to $M=2.72$, Wilks' Lambda $\left.=.93, F(1,191)=14.48, p<.001, \eta^{2}=.07\right)$, however, the groups did not change differently, Wilks' Lambda $=1.00, F(1,191)=.58$, $n s$. The analyses do not support the hypothesis.

\section{Summary of Differences in Teacher Provisions Between Boys with Stable}

Engagement and Boys with Losses in Engagement. In general, teacher provisions were not different between boys with relatively high and stable engagement versus boys with low engagement or who experiences declines. The only teacher provision that surfaced as a potential buffer against declines in engagement was structure. Boys with stable engagement showed higher levels of teacher structure in the beginning of the school year. 


\section{BOYS’ ENGAGEMENT AND INTERPERSONAL RESOURCES IN SIXTH GRADE}

Like parent provisions, groups did not differ in the extent to which teacher provisions changed across the school year.

\section{Composites of Adult Provisions. Composite of Teacher and Parent}

Involvement. Results of an independent-samples t-test indicated that, that boys who experienced losses in engagement and boys with stable engagement across the school year did not significantly differ in averages of teacher and parent involvement in the fall (no loss: $M=2.99, S D=.44$; loss: $M=2.88, S D=.45, t=1.60, n s$ ) nor spring of sixth grade (no loss: $M=3.03, S D=.46$; loss: $M=2.91, S D=.41, t=1.88, n s$ ).

A repeated measurement showed that averaged adult involvement increased across the school year for boys with losses and no losses in engagement across the school year $\left(M=2.92\right.$ to $M=2.95$, Wilks' Lambda $\left.=.98, F(1,191)=4.05, p<.05, \eta^{2}=.02\right)$, however, the groups did not change differently, Wilks' Lambda $=1.00, F(1,191)=.17$, $n s$. The analyses do not support the hypothesis.

Composite of Teacher and Parent Structure. Results of an independent-samples t-test indicated that, compared to boys who experienced losses in engagement across the school year, boys with stable engagement had higher levels of teacher and parent structure in the fall (no loss: $M=3.02, S D=.37$; loss: $M=2.87, S D=.37, t=2.71, p<$ $.01, C I, .04, .26, d=.40$ ), and spring (no loss: $M=2.91, S D=.41 ;$ loss: $M=2.74, S D=$ $.34, t=3.20, p<.01, C I, .07, .29, \mathrm{~d}=.48)$ of the sixth-grade year. 


\section{BOYS’ ENGAGEMENT AND INTERPERSONAL RESOURCES IN SIXTH GRADE}

A repeated measurement showed that adult structure declined across the school

year for boys with losses and no losses in engagement across the school year $(M=2.92$ to 2.80, Wilks' Lambda $\left.=.87, F(1,191)=27.68, p<.001, \eta^{2}=.13\right)$, however, the groups did not change differently, Wilks' Lambda $=1.00, F(1,191)=.39$, ns. The analyses do not support the hypothesis.

Composite of Teacher and Parent Autonomy Support. Results of an independent-samples t-test indicated that boys who experienced losses in engagement and boys with stable engagement across the school year did not significantly differ in averages of teacher and parent autonomy support in the fall (no loss: $M=2.94, S D=.35$; loss: $M=2.84, S D=.39, t=1.86, n s)$ nor spring of sixth grade (no loss: $M=2.83, S D=$ $.45 ;$ loss: $M=2.75, S D=.41, t=1.38, n s)$.

A repeated measurement showed that averaged adult autonomy support lessened across the school year for boys with losses and no losses in engagement across the school year $\left(M=2.88\right.$ to $M=2.78$, Wilks' Lambda $\left.=.93, F(1,191)=14.06, p<.001, \eta^{2}=.07\right)$, however, these group did not change differently, Wilks' Lambda $=1.00, F(1,191)=.11$, $n s$. The analyses do not support the hypothesis (See Table 19). 


\section{BOYS’ ENGAGEMENT AND INTERPERSONAL RESOURCES IN SIXTH GRADE}

\section{Table 19}

Summary of Support: Identifying Provisions most Powerful in Explaining Boys with Stable (or gains in) Academic Engagement in Sixth Grade

\begin{tabular}{|c|c|c|}
\hline Expectations: & $\begin{array}{c}\text { Boys with Stable } \\
\text { Engagement are Higher in } \\
\text { Adult Provisions than Boys } \\
\text { with Engagement Loss (or } \\
\text { who remain low) }\end{array}$ & $\begin{array}{l}\text { Boys with Stable Engagement } \\
\text { Change More Positively in } \\
\text { Adult Provisions than Boys } \\
\text { with Engagement Loss (or who } \\
\text { remain low) }\end{array}$ \\
\hline Test Type & $T$-tests in fall and spring & Repeated measures $A N O V A$ \\
\hline \multicolumn{3}{|l|}{ Provisions from: } \\
\hline \multicolumn{3}{|l|}{ Parent } \\
\hline Involvement & $n s$ & $n s$ \\
\hline Structure & ++ & $n s$ \\
\hline Autonomy Support & + & $n s$ \\
\hline Parent Average & ++ & $n s$ \\
\hline \multicolumn{3}{|l|}{ Teacher } \\
\hline Involvement & $n s$ & $n s$ \\
\hline Structure & + & $n s$ \\
\hline Autonomy Support & $n s$ & $n s$ \\
\hline Teacher Average & $n s$ & $n s$ \\
\hline \multicolumn{3}{|c|}{ Combined Parent and Teacher } \\
\hline Involvement & $n s$ & $n s$ \\
\hline Structure & ++ & $n s$ \\
\hline Autonomy Support & $n s$ & $n s$ \\
\hline
\end{tabular}

Note: + + supported, + partially supported, $n s$ not supported. 


\section{BOYS' ENGAGEMENT AND INTERPERSONAL RESOURCES IN SIXTH GRADE \\ Summary of Differences in Adult Provisions Between Boys with Stable}

Engagement and Boys with Losses in Engagement. Combining parent and teacher provisions provided a second set of analyses indicating that boys with relatively high and stable engagement experience higher levels of adult structure at both the beginning and end of the school year relative to boys whose engagement declined. No differences were found between the groups in adult involvement or autonomy support, nor in the way that adult provisions changed across the school year.

\section{Relatedness to Parents, Teacher, Classmates, and Friends. Maternal}

Relatedness. Results of an independent-samples t-test indicated that boys who experienced losses in engagement and boys with stable engagement across the school year did not significantly differ in maternal relatedness in the fall (no loss: $M=3.43$; loss: $M=3.48, S D=.66, S D=.62, t=.52, n s$ ) nor spring of sixth grade (no loss: $M=3.47, S D$ $=.66 ;$ loss: $M=3.36, S D=.71, t=.16, n s)$.

A repeated measurement showed that maternal relatedness did not change across the school year for boys with losses and no losses in engagement across the school year, Wilks' Lambda $=1.00, F(1,191)=1.24, n s$, however, the groups changed differently, Wilks' Lambda $=.98, F(1,191)=4.34, p<.05, \eta^{2}=.02$. Boys with stable engagement experienced increases in maternal relatedness ( $M=3.43$ to $M=3.47$ ), whereas boys with losses in engagement declined in maternal relatedness across the sixth-grade year. 


\section{BOYS' ENGAGEMENT AND INTERPERSONAL RESOURCES IN SIXTH GRADE}

Paternal Relatedness. Results of an independent-samples t-test indicated that, compared to boys who experienced losses in engagement across the school year, boys with stable engagement had higher levels of paternal relatedness in the spring (no loss: $M$ $=3.53, S D=.59$; loss: $M=3.25, S D=.74, t=2.90, p<.01, C I, .09, .47, d=.41$; equal variances not assumed), but not fall (no loss: $M=3.47, S D=.59$; loss: $M=3.28, S D=$ $.77, t=1.79, n s)$ of the sixth-grade year.

A repeated measurement showed that paternal relatedness did not change across the school year for boys with losses and no losses in engagement across the school year, Wilks' Lambda $=1.00, F(1,191)=.03$, ns. Mean level trends suggested that boys with stable engagement increased in paternal relatedness $(M=3.47$ to 3.53$)$, however, the groups did not change differently, Wilks' Lambda $=1.00, F(1,191)=.95, n s$. The hypothesis was not supported.

Teacher Relatedness. Results of an independent-samples t-test indicated that, compared to boys who experienced losses in engagement across the school year, boys with stable engagement had higher levels of teacher relatedness in the fall (no loss: $M=$ $3.08, S D=.55 ;$ loss: $M=2.87, S D=.69, t=2.19, p<.05, C I, .02, .40, d=.33)$, but not spring (no loss: $M=2.94, S D=.64$; loss: $M=2.81, S D=.67, t=1.27, n s$ ) of the sixthgrade year.

A repeated measurement showed that teacher relatedness lessened across the school year for boys with losses and no losses in engagement across the school year $(M=$ 


\section{BOYS' ENGAGEMENT AND INTERPERSONAL RESOURCES IN SIXTH GRADE}

2.95 to $M=2.86$, Wilks' Lambda $\left.=.98, F(1,191)=4.25, p<.05, \eta^{2}=.02\right)$, however, the group did not change differently, Wilks' Lambda $=1.00, F(1,191)=.78, n s$. The analyses do not support the hypothesis.

Classmate Relatedness. Results of an independent-samples t-test indicated that boys who experienced losses in engagement and boys with stable engagement across the school year did not significantly differ in classmate relatedness in the fall (no loss: $M=$ $3.16, S D=.79 ;$ loss: $M=3.19, S D=.68, t=.21, n s)$ nor spring (no loss: $M=3.09, S D=$ $.79 ;$ loss: $M=3.08, S D=.72 t=.03, n s)$ of the sixth-grade year.

A repeated measurement showed that classmate relatedness did not change across the school year for boys with losses and no losses in engagement across the school year (Wilks' Lambda $=.99, F(1,191)=2.57, n s)$, nor did the groups change differently, Wilks' Lambda $=1.00, F(1,191)=.05, n s$. The analyses do not support the hypothesis.

Friend Relatedness. Results of an independent-samples t-test indicated that boys who experienced losses in engagement and boys with stable engagement across the school year did not significantly differ in friend relatedness in the fall (no loss: $M=3.45$, $S D=.56 ;$ loss: $M=3.41, S D=.65, t=.44, n s)$ nor spring $($ no loss: $M=3.50, S D=.53$; loss: $M=3.43, S D=.59, t=.86, n s)$ of the sixth-grade year.

A repeated measurement showed that friend relatedness did not change across the school year for boys with losses and no losses in engagement across the school year, 


\section{BOYS' ENGAGEMENT AND INTERPERSONAL RESOURCES IN SIXTH GRADE}

(Wilks' Lambda $=1.00, F(1,191)=.48, n s)$, nor did the groups change differently, Wilks' Lambda $=1.00, F(1,191)=.05, n s$. The analyses do not support the hypothesis.

\section{Composite of Relatedness to Parents, Teachers, Classmates, and Friends.}

Results of an independent-samples t-test indicated that boys who experienced losses in engagement and boys with stable engagement across the school year did not significantly differ in averaged relatedness (parents, teachers, classmates, and friends) in the fall (no loss: $M=3.32, S D=.43$; loss: $M=3.25, S D=.47, t=1.08, n s$ ) nor spring (no loss: $M=$ 3.30, $S D=.41$; loss: $M=3.18, S D=.51, t=1.70, n s)$ of the sixth-grade year.

A repeated measurement showed that averaged relatedness did not change across the school year for boys with losses and no losses in engagement across the school year, Wilks' Lambda $=.99, F(1,191)=2.01, n s$. Although mean level trends were in the expected direction, suggesting losses for boys with stable engagement, these boys did not experience smaller losses in averaged relatedness than boys with engagement loss, Wilks' Lambda $=1.00, F(1,191)=.72, n s$. The analyses do not support the hypothesis (See Table 20). 


\section{BOYS' ENGAGEMENT AND INTERPERSONAL RESOURCES IN SIXTH GRADE}

\section{Table 20}

Summary of Support: Identifying Types of Relatedness most Powerful in Explaining Boys with Stable (or gains in) Academic Engagement in Sixth Grade

\begin{tabular}{|c|c|c|}
\hline Expectations: & $\begin{array}{l}\text { Boys with Stable } \\
\text { Engagement are } \\
\text { Higher in } \\
\text { Relatedness than } \\
\text { Boys with } \\
\text { Engagement Loss } \\
\text { (or who remain } \\
\text { low) }\end{array}$ & $\begin{array}{c}\text { Boys with Stable } \\
\text { Engagement Change } \\
\text { More Positively in } \\
\text { Relatedness than Boys } \\
\text { with Engagement Loss (or } \\
\text { who remain low) }\end{array}$ \\
\hline Test Type & $T$-test & $\begin{array}{c}\text { Repeated measures } \\
\text { ANOVA }\end{array}$ \\
\hline \multicolumn{3}{|l|}{ Relatedness to: } \\
\hline Mother & $n s$ & ++ \\
\hline Father & + & $n s$ \\
\hline Teacher & + & $n s$ \\
\hline Classmates & $n s$ & $n s$ \\
\hline Friends & $n s$ & $n s$ \\
\hline Relatedness Average & $n s$ & $n s$ \\
\hline
\end{tabular}

Note: + + supported, + partially supported, $n s$ not supported.

\section{Summary of Differences in Relatedness Between Boys with Stable}

Engagement and Boys with Losses in Engagement. Partial support was found for the

hypothesis that boys with relatively high and stable engagement experienced higher levels of relatedness to others. Boys with stable engagement showed higher levels of paternal relatedness in spring and teacher relatedness in fall. Changes in only one provision differentiated boys with different patterns of engagement, namely, maternal relatedness. When examining the groups separately, a follow-up analyses indicated 


\section{BOYS' ENGAGEMENT AND INTERPERSONAL RESOURCES IN SIXTH GRADE}

significant losses in maternal relatedness for boys who remained low or showed declines in engagement across the school year (Wilkes' Lambda $=.95, F(1,120)=5.77, p<.05)$.

Peer Network Resources. Peer Group Engagement. Results of an independentsamples t-test indicated that, compared to boys who experienced losses in engagement across the school year, boys with stable engagement levels significantly differed in their average peer group engagement in the spring (no loss: $M=3.39, S D=.44$; loss: $M=$ 2.64, $S D=.59, t=10.08, p<.001, C I, .60, .89, d=1.40$; equal variance not assumed), but not in fall (no loss: $M=3.02, S D=.37$; loss: $M=3.04, S D=.40, t=.41, n s$.) of the sixth-grade year.

A repeated measurement showed that peer group engagement did not change for both groups of boys (Wilks' Lambda $=1.00, F(1,191)=.12, n s$ ), however, boys with no losses (or gains) in individual engagement experienced marked gains in their average peer group engagement, (Wilks' Lambda $\left.=.64, F(1,191)=107.64, p<.001, \eta^{2}=.36\right)$ across sixth grade.

Peer Group Size. Results of an independent-samples t-test indicated that, compared to boys who experienced losses in engagement across the school year, boys with stable engagement levels had smaller peer group networks in the fall (no loss: $M=$ $3.19, S D=3.43 ;$ loss: $M=4.38, S D=3.52, t=2.38, p<.05, C I .20,2.18$, with a small effect size; $d=.34)$. Mean level trends, however, were not in the expected direction in that boys with stable engagement levels had smaller network sizes than compared to boys 


\section{BOYS' ENGAGEMENT AND INTERPERSONAL RESOURCES IN SIXTH GRADE}

who declined in engagement. The analysis does not support the research hypothesis that boys with stable or increased levels of engagement across the school year, or who show no declines in engagement, have a greater number of peers in their peer group network than boys with engagement loss.

Number of Same-Sex Group Members. Results of an independent-samples t-test indicated that boys who experienced losses in engagement and boys with stable engagement levels did not differ in the percentage of same-sex network members in the fall (no loss: $M=.62, S D=.47$; loss: $M=.72, S D=.44, t=1.56, n s$, equal variances not assumed). The analysis does not support the research hypothesis that boys with stable or increased levels of engagement across the school year, or who show no declines in engagement, have a lower percentage of same-sex network members in the fall, at the beginning of the school year, as compared to boys who experienced losses in engagement.

Reciprocated Friendships. Results of an independent-samples t-test indicated that boys who experienced losses in engagement and boys with stable engagement levels did not differ in the number of reciprocated friendships in the fall (no loss: $M=2.10, S D=$ 1.99; loss: $M=2.22, S D=1.95, t=.39, n s)$. The analysis does not support the research hypothesis that boys with stable or increased levels of engagement across the school year, or who show no declines in engagement, have a greater number of reciprocated friendships at the beginning of the school year than boys who had losses in engagement. 


\section{BOYS' ENGAGEMENT AND INTERPERSONAL RESOURCES IN SIXTH GRADE}

Self-Reported Friendships. Results of an independent-samples t-test indicated

that boys who experienced losses in engagement and boys with stable engagement levels did not differ in the number of self-reported friendships in the fall (no loss: $M=7.78, S D$ $=4.08 ;$ loss: $M=7.43, S D=4.02, t=.61, n s)$. The analysis does not support the research hypothesis that boys with stable or increased levels of engagement across the school year, or who show no declines in engagement, have a greater number of self-reported friendships at the beginning of the school year than boys who had losses in engagement.

Peer-Reported Friendships. Results of an independent-samples t-test indicated that boys who experienced losses in engagement and boys with stable engagement levels did not differ in the number of peers who reported them as friends in the fall (no loss: $M$ $=5.19, S D=4.07 ;$ loss: $M=5.98, S D=4.01, t=1.36, n s)$. The analysis does not support the research hypothesis that boys with stable or increased levels of engagement across the school year, or who show no declines in engagement, have a greater number of peerreported friendships at the beginning of the school year than boys who had losses in engagement.

Quality of Friendships. Results of an independent-samples t-test indicated that boys who experienced losses in engagement and boys with stable engagement levels did not differ in the quality of their friendships in the fall (no loss: $M=2.44, S D=.65$; loss: $M=2.59, S D=.44, t=1.86, n s$, equal variances not assumed). Mean levels were not in the expected direction, suggesting lower levels of friendship quality for boys with stable 


\section{BOYS' ENGAGEMENT AND INTERPERSONAL RESOURCES IN SIXTH GRADE}

levels of engagement. The analysis does not support the research hypothesis that boys with stable or increased levels of engagement across the school year, or who show no declines in engagement, have higher levels of friendship quality at the beginning of the school year than boys who had losses in engagement.

Percentage of Close Friends Lost. Results of an independent-samples t-test indicated that boys who experienced losses in engagement and boys with stable engagement levels did not differ in the percentage of friends lost across the school year (no loss: $M=.54, S D=.20$; loss: $M=.55, S D=.18, t=.52, n s$ ). The analysis does not support the research hypothesis that boys with stable or increased levels of engagement across the school year, or who show no declines in engagement, have lower percentages of friends lost across sixth grade.

Percentage of Closest Friends Lost. Results of an independent-samples t-test indicated that, compared to boys who experienced losses in engagement across the school year, boys with stable engagement levels had lower percentages of lost closest friends across the school year (no loss: $M=.23, S D=.26$; loss: $M=.31, S D=.28, t=1.98, p<$ $.05, C I, .00, .15$, with a small effect size; $d=.29$ ). The analysis supports the research hypothesis that boys with stable or increased levels of engagement across the school year, or who show no declines in engagement, have lower percentages of closest friends lost across the school year, as compared to boys who experienced losses in engagement. 


\section{BOYS' ENGAGEMENT AND INTERPERSONAL RESOURCES IN SIXTH GRADE}

Composite of Peer Network Resources. Results of an independent-samples t-test indicated that boys who experienced losses in engagement and boys with stable engagement levels did not differ in averaged peer network resources (peer group engagement, peer group size, percentage of same-sex group members, number of reciprocated, self-reported, and peer-reported friends, friendship quality, percentage of lost friends and lost closest friends) at the beginning of the school year (no loss: $M=$ 2.52, $S D=.38 ;$ loss: $M=2.53, S D=.41, t=.12, n s ;$ see Table 21$)$.

\section{Table 21}

Summary of Support: Identifying Types of Peer Network Resources most Powerful in Explaining Boys with Stable (or gains in) Academic Engagement in Sixth Grade

\begin{tabular}{lcc}
\hline Expectations: & $\begin{array}{c}\text { Boys with Stable } \\
\text { Engagement are } \\
\text { Higher in Peer } \\
\text { Resources than } \\
\text { Boys with } \\
\text { Engagement Loss } \\
\text { (or remain low) }\end{array}$ & $\begin{array}{c}\text { Boys with Stable } \\
\text { Engagement Change } \\
\text { More Positively in } \\
\text { Peer Resources than } \\
\text { Boys with } \\
\text { Engagement Loss } \\
\text { (or remain low) }\end{array}$ \\
& $\begin{array}{c}\text { T-tests in fall and } \\
\text { spring }\end{array}$ & $\begin{array}{c}\text { Repeated } \\
\text { measures ANOVA }\end{array}$ \\
\hline Test Type & + & ++ \\
Peer Group Engagement & -tests in fall & \\
& ++ & \\
Peer Group Size & $n s$ & \\
Same-sex Members in Group $(\%)$ & $n s$ & \\
Friendships & $n s$ & \\
Reciprocated & $n s$ & \\
Self-reported & $n s$ & \\
Peer-reported & $n s$ & \\
Friendship Quality & & \\
Close Friends Lost \% & &
\end{tabular}




\section{BOYS’ ENGAGEMENT AND INTERPERSONAL RESOURCES IN SIXTH GRADE}

Closest Friends Lost \%

Peer Resource Average
$++$

$n s$

Note: + + supported, + partially supported, $n s$ not supported.

Note: ${ }^{\text {a }}$ Boys with stable engagement had smaller peer networks.

\section{Summary of Differences in Peer Resources Between Boys with Stable}

Engagement and Boys with Losses in Engagement. Two peer resources seemed to act as protective factors for losses in boys' engagement; clearest evidence was found peer group engagement. Compared to boys who showed losses in engagement, boys with relatively high and stable engagement across the school year had peer groups who showed higher engagement in spring (but not in fall). These two groups also differed in the way their peer group's engagement changed over the year. When examining the groups separately, a follow-up analyses indicated significant gains in peer group engagement for boys with stable engagement (Wilkes' Lambda $=.60, F(1,71)=46.64, p$ $<.001)$, and significant losses for boys who remained low or showed declines in engagement across the school year (Wilkes' Lambda $=.63, F(1,120)=71.10, p<.001)$. In terms of peer group size, boys with stable engagement had smaller peer groups than boys with low or losses in engagement. Boys with different patterns of engagement did not appear to differ in percent of same-sex peer group members, reported friendships, or friendship quality. However, boys in the stable engagement group reported experiencing fewer losses in their closest friendships. 


\section{BOYS' ENGAGEMENT AND INTERPERSONAL RESOURCES IN SIXTH GRADE \\ Chapter 6. Discussion}

The main goal of this study was to explore ways boys can be supported during their first year in middle school. The study was guided by Connell and Wellborn's (1991) model of context supports for student engagement and aims to apply the model to examine the motivational pathways of boys. During and after the transition to middle school, there are normative declines in student engagement, and previous research suggests that such declines may be steeper for boys. Research has increasingly highlighted the challenges boys are facing in school and this study aims to explore the interpersonal resources, namely, provisions of support from parents, teachers, and peers, that may buffer boys from these losses and promote their motivational resilience.

Following a summary of the current study's main findings, strengths and limitations, implications, and avenues for future research are discussed.

\section{Summary of the Findings}

This study focused on two main questions: Do boys show lower mean levels and steeper declines in teacher-reported engagement and self-reported interpersonal resources across the first year of middle school? And can interpersonal resources from parents, teachers, and peers protect boys from such declines? Overall, the answer to these questions was "yes" and "no," in that partial support was found for all study hypotheses.

For the sample as a whole, correlations between engagement and interpersonal resources were consistent with motivational theories: Students who were rated by teachers as more 


\section{BOYS' ENGAGEMENT AND INTERPERSONAL RESOURCES IN SIXTH GRADE}

engaged in fall and spring also reported experiencing higher involvement, structure, and autonomy support from both parents and teachers as well as higher relatedness to all social partners; they also belonged to more engaged peer groups, had larger peer networks composed of a higher percentage of same sex peers, and (based on several indices) more friends.

\section{Gender Disparities in Engagement}

The first part of Research Question One used repeated measures ANOVAs to examine whether gender disparities in engagement were present at the beginning and end of sixth grade, and whether boys showed steeper losses in engagement across the year. In general, evidence was found for gender differences in mean levels but not in losses. In fact, contrary to previous research, normative declines in engagement were not found for boys or for girls. Despite its relative stability, however, gender disparities were documented indicating that boys were less engaged at both time points. Of special interest were exploratory analyses examining behavioral and emotional dimensions of engagement separately. Mirroring the pattern for overall engagement, boys were less behaviorally and emotionally engaged at both time points. However, unlike overall engagement, these dimensions showed gender differences in their patterns of change. Girls' behavioral engagement increased while their emotional engagement remained stable, whereas boys did not experience gains in behavioral engagement and showed significant losses in emotional engagement. 


\section{BOYS' ENGAGEMENT AND INTERPERSONAL RESOURCES IN SIXTH GRADE}

Taken together, even in this high-functioning sample, it appears that boys are less engaged than girls during the first year of middle school, and they lose emotional engagement as the year progresses. At the same time, the absence of normative declines in overall engagement, although good news for the students in this sample, did make it more difficult to identify interpersonal resources that could buffer losses. Findings from this study suggest that it may be more fruitful in future studies to examine behavioral and emotional dimensions of engagement separately.

\section{Gender Disparities in Interpersonal Resources}

The second part of this research question investigated whether there are gender disparities in students' interpersonal resources at the beginning and end of sixth grade, and if boys show greater declines in these provisions over sixth grade. As expected, gender disparities were present for most parent, teacher, and peer resources showing lower levels for boys at one or both time points. However, little evidence was found of gender differences in losses of resources; instead, all students experienced losses in most parent and teacher provisions, except for parent involvement.

Adult Provisions. Patterns of gender differences varied depending on the adult and on the specific dimension. Overall, just as teacher provisions were more highly intercorrelated, gender differences were also more consistent for teacher provisions: Teacher involvement, structure, and composite provisions showed gender disparities at both fall and spring; for parents, these same provisions showed gender disparities at only one time 


\section{BOYS' ENGAGEMENT AND INTERPERSONAL RESOURCES IN SIXTH GRADE}

point. For both adults, autonomy support showed no gender differences at either time point. Teacher provisions were also more consistent in change over time. Although there were no gender disparities, both boys and girls reported losses in all three teacher provisions as the year progressed. Patterns of change in parent provisions were more differentiated: Involvement increased and autonomy support decreased for both boys and girls; and, in the only finding indicating gender differences in patterns of change, boys experienced greater losses in parent structure. Taken together, although little evidence suggests greater declines for boys, all students reported losses in most parent and teacher provisions over sixth grade. Hence, the pattern of results paints a picture in which boys have lower levels of these resources than girls, while also experiencing losses in most adult provisions, including greater losses in adult structure.

Peer Resources. Gender disparities were also found for most peer resources, with only a few exceptions. Compared to girls, boys' peer groups were smaller, more homogenous, and less engaged. Moreover, boys' peer group engagement also showed losses across the school year. Boys did not differ from girls in number of peer-nominated friends or friendship quality, but they had fewer reciprocated and self-reported friendships. This combination indicates that boys have less to access to higher engaged peer groups, and to peer groups who maintain their engagement across sixth grade; and they also report fewer friendships. 


\section{BOYS' ENGAGEMENT AND INTERPERSONAL RESOURCES IN SIXTH GRADE}

Relatedness. No gender differences were found in mean levels or in losses in relatedness to most social partners, and students had relatively high absolute values in levels of this resource. The one exception was teacher relatedness. Although boys and girls had comparable levels of this resource, both experienced losses in teacher relatedness over the school year mirroring the pattern in which teacher provisions declined for all students. Interestingly, despite losses in parent structure and autonomy support, parent relatedness did not decline, which may be connected to the previous finding showing gains in parent involvement across the school year.

\section{Interpersonal Resources that May Support Boys' Engagement}

Research Question Two focused on whether interpersonal resources could protect boys from losses in engagement. Overall, patterns of findings suggested that certain resources could support engagement at concurrent time points, but (as might be expected given that no declines in overall engagement were found) fewer protective effects were uncovered. However, despite this analytical problem, a few select resources were identified. In general, patterns of correlations between boys' engagement and resources were promising and similar to the group as a whole, however correlations between engagement and indicators of peer resources were somewhat less consistent at the spring timepoint. These correlations suggest that most interpersonal resources showed promised as potential buffers for boys, but some peer indicators may not be a resource for engagement. 


\section{BOYS' ENGAGEMENT AND INTERPERSONAL RESOURCES IN SIXTH GRADE}

\section{Comparing the Engagement of Boys with Higher versus Lower Interpersonal}

Resources. Two analytic strategies were used to identify resources that support boys' concurrent engagement and protect them from losses. The first created subgroups of boys higher and lower in interpersonal provisions and then examined whether they also differed in engagement. Repeated measures ANOVAs indicated that boys with higher levels of overall combined parent and teacher provisions showed higher levels of engagement at the beginning and end of the school year but did not differ in changes in engagement across the year. These patterns were similar for both the 20/80 and 10/90 groups, and held for most resources. For the 20/80 group. the only exception was parent involvement in fall, whereas for the 10/90 group, tests of three other parent provisions did not reach significance at particular time points.

Only one resource was identified that buffered losses in engagement for boys, and it was found in the 10/90 comparison. Boys with the very highest levels of teacher involvement (top 10\%) were similar to the rest of the sample at the beginning of the school year, but then showed significant gains compared to boys lower in this resource who experienced losses. In sum, although differences in engagement change were not detected between boys with higher and lower levels of adult resources, boys with higher levels of most adult provisions did show higher levels of engagement at the beginning and end of the school year. Moreover, it seems that very high levels of teacher 


\section{BOYS' ENGAGEMENT AND INTERPERSONAL RESOURCES IN SIXTH GRADE}

involvement (top 10\%) can be nominated as a protective factor and a resource in optimizing boys' levels of engagement.

Relatedness. A similar pattern was found for most aspects of relatedness: Compared to boys with lower levels, boys with higher resources were also higher in engagement at each time point, but did not differ in engagement losses. The few exceptions to this pattern were instructive. Interestingly, differential patterns were found for relatedness to mother versus father. Although no engagement differences were found between boys higher and lower in maternal relatedness, boys who reported higher relatedness to fathers did show higher levels of engagement at both time points. Relatedness to fathers was also the one resource that seemed to buffer boys' losses in engagement. Boys higher in this resource maintained their engagement over the school year, whereas boys who were lower registered losses. This suggests that relatedness to father may serve as a protective factor and resource in supporting boys' engagement. Given the differential patterns for parental relatedness, it may be interesting in future studies to separate the dimensions of parent provisions (i.e., involvement, structure, and autonomy support) to examine potential differences between mother and father provisions of support.

Peer Resources. Overall, fewer differences in engagement were found for boys higher versus lower in peer resources, and none were found in how engagement changed over the school year. For some peer resources, boys with the highest levels (top 10\%) 


\section{BOYS' ENGAGEMENT AND INTERPERSONAL RESOURCES IN SIXTH GRADE}

showed higher levels of engagement at both timepoints than boys in the rest of the sample. As expected, these included peer engagement, reciprocated (and to some extent self-reported) friendships as well as percent of close friends lost. Boys were more likely to show significantly higher engagement in fall and spring when they experienced the highest levels of peer group engagement, reciprocated friendships, and the lowest percentage of close friends lost. Comparisons of groups who differed in the other resources (network size, homogeneity, number of peer-reported friends, friendship quality, or percentage of closest friends lost) did not reveal mean level differences in engagement at either time point, or in changes in engagement across the school year.

\section{Comparing the Interpersonal Resources of Boys who Gained versus Lost}

Engagement. The second strategy used to identify resources that support boys'

concurrent engagement and protect them from losses examined whether there were mean level differences in interpersonal provisions between boys with relatively high and stable engagement across the school year compared to those who remained low in engagement or experienced losses. Overall, this strategy was much more successful in identifying interpersonal resources that may buffer boys engagement, perhaps because the "at-risk" subgroup combined boys who lost engagement with those whose engagement started and stayed low (i.e., who never had high levels of engagement to begin with, and so did not have anything to lose). 


\section{BOYS' ENGAGEMENT AND INTERPERSONAL RESOURCES IN SIXTH GRADE}

Parent Provisions. In general, repeated measures ANOVAs showed that boys with relatively high and stable engagement had higher parent provisions (i.e., higher structure, autonomy support, and composite provisions) than boys with low and stable engagement or those who showed declines in engagement (even though groups did differ in the extent to which they lost parental resources). The one exception was parent involvement: Engagement subgroups did not differ in parental involvement at either timepoint. Findings for this parent resource have some similarities with patterns found for parent involvement using the first strategy. In the first strategy, boys with higher parent involvement (top 20\%) showed higher engagement in spring, but not in fall, and the 10/90 group showed no differences in engagement at either timepoint. The overall gains in parent involvement over the school year, found for boys (and girls), may have made it difficult to detect it as a factor in engagement, or it may be that parent involvement does not serve as a stand-alone resource in protecting boys against declines in engagement or supporting boys' optimal levels of engagement. The former explanation seems more likely, given that the latter possibility is not consistent with correlational patterns found for boys, in which parental involvement shows robust connections with boys' engagement at both timepoints, connections at least as high as the other parent provisions. Taken together, findings indicate that boys with relatively high and stable engagement can be differentiated from boys with low and stable engagement in that the former group experienced higher levels of parent structure and autonomy support, 


\section{BOYS' ENGAGEMENT AND INTERPERSONAL RESOURCES IN SIXTH GRADE}

suggesting that these may be important resources in supporting boys' engagement. This prospect is a bit worrying, given that all students experience losses in these provisions across the school year. Interestingly however, engagement subgroups did differ in the extent to which they lost these (or any) parental resources.

Teacher provisions. For teacher provisions, few significant differences were detected. Boys relatively high and stable in engagement did not show higher levels nor did they show smaller declines in these resources than boys who remained low or experienced losses in engagement. The single exception was for teacher structure: The subgroup high in engagement also experienced higher levels of teacher structure in the fall. Taken together, these findings suggest that only teacher structure, which was generally declining for boys (and girls) over sixth grade, might help to support and buffer boys' engagement over the school year. However, this the protective effect of teacher structure was no longer present by spring.

Relatedness. Partial support was found for the hypothesis that boys with relatively high and stable engagement experienced higher levels of relatedness to others, namely, relatedness to fathers in spring and to teacher in fall. Subgroups also differed in the losses in maternal relatedness they experienced: Boys low and stable in engagement or who showed engagement loss also reported greater losses in relatedness to mothers across the school year. Taken together, findings suggests that relatedness to fathers and teachers 


\section{BOYS' ENGAGEMENT AND INTERPERSONAL RESOURCES IN SIXTH GRADE}

may act as (somewhat inconsistent) protective factors for boys' engagement, and that maintaining high levels of relatedness to mothers may serve in this role as well.

Peer Resources. In terms of peer resources, there is evidence showing that peer group engagement is an important protective factor against declines in boys' own engagement. Boys with relatively high and stable engagement had peer groups who showed higher engagement (at least at one time point) and experienced significant gains in their peer group engagement. Boys with high and stable engagement also had smaller peer groups and lost fewer closest friends than the rest of the sample. Boys with different patterns of engagement did not differ in percent of same-sex group members, number of friendships, or friendship quality. Taken together, findings suggest that engaged peer groups and maintenance of closest friendships may support and buffer boys' engagement across the school year.

\section{Interpersonal Factors that Support and Protect Boys' Engagement Over Sixth Grade}

The primary goal of this study was to identify interpersonal factors that could support and protect boys' engagement during the first year of middle school. Taken as a whole, findings were promising but sobering. Multiple interpersonal resources showed promise as supportive or protective factors, but gender disparities were found in almost all of them, indicating boys were at a disadvantage. Moreover, many of these resources also declined over the school year, for boys as well as girls. Resources and relatedness to the three social partners (parents, teachers, and peers) showed somewhat different 


\section{BOYS' ENGAGEMENT AND INTERPERSONAL RESOURCES IN SIXTH GRADE}

patterns and so contributed different information to the search for factors that could support and protect boys.

\section{Parental Provisions and Relatedness to Mothers and Fathers. Parental}

resources, especially structure and autonomy support, which showed high and consistent connections to boys' engagement in both fall and spring, seemed to support concurrent levels of boys' engagement (as shown in analyses using strategy one) and also to differentiate boys with high and stable engagement from those low or losing engagement (in analyses using strategy two). However, compared to girls, boys reported lower levels of both of these resources (at one or both time points) and also registered losses in both over the school year, including greater losses than girls in parental structure. The only bright spot for parent provisions was found for parental involvement, which was also tightly connected to boys' engagement at both timepoints, and actually increased over the school year. However, involvement seemed to act as a protective factor only in spring (in comparisons of the 20/80 groups using strategy one) after higher levels were reached.

Little additional evidence was found (using strategy one or two) that parental involvement acted consistently as a protective factor for boys' engagement.

Relatedness to mothers and fathers seemed promising as potential protective factors because they were tightly connected to boys' engagement at both fall and spring, and they generally showed no gender differences in either mean level or changes over the school year. Nevertheless, evidence differed markedly (in analyses using both strategy 


\section{BOYS' ENGAGEMENT AND INTERPERSONAL RESOURCES IN SIXTH GRADE}

one and two) about their protective effects. For relatedness to mothers, boys with high

versus low levels of this resource did not differ in their engagement at either timepoint or in losses in engagement (strategy one) nor did boys whose engagement was high and stable differ in maternal relatedness at either time point from boys with low or declining engagement (strategy two). However, boys whose engagement was low or declining also showed losses in this resource over the school year whereas boys whose engagement was high and stable did not, suggesting that high and stable relatedness to mothers may protect boys from losses in engagement. Quite a different pattern was found for relatedness to fathers. Boys high in this resource showed higher engagement at both timepoints and maintained their engagement over the school year, whereas boys low in this resource registered engagement losses (strategy one). Moreover, boys with high and stable engagement also experienced higher levels of relatedness to fathers at the spring time point (strategy two). In sum, for boys, relatedness to fathers seemed to exert a generally protective effect, but for relatedness to mothers to exert such a buffering effect, it needed to be stable across the school year.

Teacher Provisions and Relatedness to Teachers. The picture for teacher provisions, which were also clearly connected to boys' engagement at both timepoints, was more consistent across dimensions. Groups of boys higher in teacher involvement, structure, or autonomy support were also likely to show higher levels of engagement at each time point. However, compared to girls, boys reported lower levels of teacher 


\section{BOYS' ENGAGEMENT AND INTERPERSONAL RESOURCES IN SIXTH GRADE}

involvement and structure at both timepoints, and all teacher provisions declined across the school year. Only two aspects of teacher provisions showed findings that seemed to indicate they might be able to buffer boys. Boys with the highest levels of teacher involvement (top 10\%) actually showed gains in engagement across the school year, compared to the rest of the boys, who showed losses. And boys with high and stable engagement reported higher levels of teacher structure in fall compared to boys with low or declining engagement. It is possible however, given that this finding obtained only in fall, that because of losses in this teacher resource, by spring its protective effects were also lost.

Relatedness to teachers, which was also closely connected to boys' engagement at both timepoints, seemed to act as a protective factor, in that it seemed to support concurrent levels of boys' engagement (as shown in analyses using strategy one) and also to differentiate boys with high and stable engagement from those low or losing engagement, at least in fall (in analyses using strategy two). Unfortunately, however, it was the only kind of relatedness that showed losses (for both boys and girls) over the school year. Given that losses across sixth grade were also found for every teacher provision and the teacher composite, perhaps losses in teacher relatedness are not surprising, but these losses may provide one explanation for why teacher relatedness lost its protective effects by spring. 


\section{BOYS' ENGAGEMENT AND INTERPERSONAL RESOURCES IN SIXTH GRADE}

Peer Resources and Relatedness to Classmates and Friends. Compared to

parents and teachers, peer resources were not as consistently connected to boys'

engagement, especially by the spring timepoint. However, peer group engagement and

number of friends were correlated with boys' engagement at both timepoints, and boys

who were high in these resources also showed higher levels of engagement at both time points (compared to the rest of the sample). At the same time, gender differences were found for both peer group engagement and some indices of friends, indicating that boys' peer groups were less engaged than those of girls, and they had fewer friends. Moreover, boys' peer groups also declined in engagement across the year. Nevertheless, (based on analyses using strategy two) this peer resource seemed to show a protective effect. Boys with high and stable engagement (compared to those low in or losing engagement) were more likely to belong to more engaged peer groups and those peer groups were more likely to see increases in engagement over the year. This suggests that membership in an engaged peer group may be a powerful protective factor for boys' own engagement. Surprisingly, friendship quality did not seem to buffer boys' engagement or its losses.

Relatedness to friends and classmates seemed to play somewhat different roles in supporting and protecting boys' engagement. Relatedness to classmates, a correlate of boys' engagement at both time points, also supported concurrent engagement (using strategy one) but did not buffer changes in engagement (strategy one or two). Relatedness to friends, on the other hand, like friendship quality was correlated with boys' 


\section{BOYS' ENGAGEMENT AND INTERPERSONAL RESOURCES IN SIXTH GRADE}

engagement only in fall, and boys high in this resource were also more engaged (strategy one) but also only in fall. Despite the many positive consequences typically found for high quality friendships and high relatedness to friends, these interpersonal resources could not consistently support or buffer boys' engagement, especially as the year progressed. Although disappointing in the search for protective factors, the lack of connection was in some ways heartening, in that it suggested that even boys low in engagement could have high quality friendship relationships and experience high relatedness to friends.

\section{Strengths and Limitations of the Study}

The aim of this study is to examine the influences of interpersonal resources on academic engagement in an entire population of students. While a sample of this nature is one central strength of the study, it is important to identify possible limitations of the sample, methodology, and research design used in the current study.

\section{Sample and Generalizability}

One potential limitation of the study is the extent to which the findings can be generalized to a diverse population. The sample used in this study is part of a larger longitudinal dataset comprised of participants who resided in a town where $90 \%$ were Caucasian or of European American descent (Kindermann, 2007). Although the sample of participants is ethnically homogenous, the sample represents the entire population of public-school students, in this age group, in the town, lending itself to making some 


\section{BOYS' ENGAGEMENT AND INTERPERSONAL RESOURCES IN SIXTH GRADE}

generalizations based on this sample in a rural town. In a similar vein, a question of generalizability may arise because the sample comes from a rural town. Kindermann (2007) notes that two earlier studies in suburban elementary schools, with average engagement levels of 3.0 and 3.2, respectively, (Kindermann, 1993; Sage \& Kindermann, 1999) and one study with adolescents in an inner-city school, with an average engagement of 2.60, (Kindermann, McCollam, \& Gibson, 1996) shows comparable effects of peer selection and socialization. Therefore, the findings may be generalizable to larger towns or other school systems.

\section{Methods and Measures}

Socio-Cognitive Mapping (SCM), a method used in the current study to assess student's peer affiliations, is a preferred method that relies on observational data reported by peers, rather than only students' perceptions of their individual peer groups. A limitation of this method is that it focuses on students who are known to frequently "hang around" with one another, and thus does not assess other types of peer relationships, such as dyadic friendships. Nevertheless, this study also includes measures of close friendships as potential resources, making this an added strength of this study.

Student engagement is assessed by teacher reports as a way of avoiding reporting bias and over-reporting of academic engagement compared to student self-reports. While this is a strength of the study, teacher reports can also be a limited measure based on the type of engagement being reported. For example, teachers may not know, through 


\section{BOYS' ENGAGEMENT AND INTERPERSONAL RESOURCES IN SIXTH GRADE}

observations of students, how emotionally engaged a student may be in the classroom, thus, may not be able to accurately report on this dimension of engagement. A strength of this study, however, is the use of multiple data sources; students report on peer affiliations and interpersonal resources and teachers report on engagement.

As is typical for large-scale studies (the data are about an entire town), missing data are a problem which can affect the analyses. Missing data was estimated through Expectation Maximization (EM). This method assumes that data is missing at random (MAR). MAR allows for missingness of one variable to depend on other observed variables and avoids underestimation of standard errors, a limitation of other techniques. Compared to Multiple Imputation, the Maximum Likelihood method has several advantages to handling missing data, such as, efficiency with few data sets (Dempster, Laird, \& Rubin, 1977; Rubin, 1987), the results are the same with the same data set, it requires fewer methodological decisions, and all is done with one model avoiding the potential incompatibility between the imputation and analysis model (Allison, 2012).

\section{Research Design}

A strength of this study is its longitudinal design across a school year. The use of two time points, both at the beginning and end of the year, makes it possible to see change over time. Rather than a correlational study design that only includes one-time point, the design of the current study allows for an examination of a student's interpersonal resources as a potential causal source of predicting engagement change. 


\section{BOYS' ENGAGEMENT AND INTERPERSONAL RESOURCES IN SIXTH GRADE}

This study is, however, limited in longitudinal scope, presenting three limitations. First, using only two time points may not reflect fluctuation of engagement that may occur throughout the school year. Second, the absence of a time point at the end of the prior school year makes it difficult to understand the potential influence of the school transition that occurs from elementary to middle school. The design of this study is limited to the change of engagement across sixth grade only. This can lead to effects of regression to the mean. However, there are challenges in using data across school years, for example, students change teachers making it difficult to analyze student-reported teacher provisions. Parent provisions, however, may be assessed across middle school.

The use of t-tests and repeated measures ANOVA in this study helped identify mean level differences and change in engagement and provisions of support. The limitation, however, is that it is unknown how these provisions uniquely and collectively influence boys' engagement change. Further analyses that are multivariate in nature, such as MANOVA or regression analyses, can be performed in future analyses.

This study examined student engagement comprised of behavioral and emotional dimensions. Although these dimensions were split up in follow-up analyses for boys and girls, it is unknown how these dimensions singly fare between boys. Further analyses can test behavioral and emotional engagement apart to identify the provisions most important for each. 


\section{BOYS' ENGAGEMENT AND INTERPERSONAL RESOURCES IN SIXTH GRADE}

To examine engagement of boys highest in provisions, percentile cut-offs were used to create higher and lower groups. This was a helpful first step in understanding whether boys with greater resources have higher levels of engagement. It is unclear, however, how much resource is needed to prevent engagement declines. The use of cutoffs lead to a few perplexing results in the study. For example, boys with the highest levels of adult involvement (top 10\%) increased in engagement, whereas boys with high levels $(20 \%)$ experienced losses in engagement. An alternative way of creating high and low groups is to compare boys above and below the mean of the resource.

\section{Implications}

This study informs parents, teachers, and school administrators about the unique aspects of boys' social contexts that help them stay academically engaged in the classroom and to be successful in school. For parents, this research brings to light the elements of high-quality parent-child relationships that matter most for boys in supporting their academic success. This information can be a source of encouragement to parents to be involved in their child's schoolwork and engage in meaningful conversations with their child about his school experiences. The findings also emphasize to parents the importance of providing boys with structure at home that supports their academics (i.e., scheduled homework time, communicating clear academic expectations to the child, and giving the child choices when setting academic goals), and, above all, 


\section{BOYS' ENGAGEMENT AND INTERPERSONAL RESOURCES IN SIXTH GRADE}

highlights the crucial need to establish a warm and caring relationship with their child to promote engagement in school.

To promote boys' academic engagement, the findings of this study emphasize to teachers the importance of establishing high-quality relationships in the classroom, namely, through involvement, structure, and autonomy support. Of the provisions, providing structure in the classroom may be the most powerful buffer against boys' losses in engagement. Teachers provide structure by communicating clear expectations and consequences for behavior. It is also important that teachers give consistent feedback and are predictable in their responses to student behavior. Students also benefit when teachers offer help and support and are attuned to times when further instruction in needed before moving on to new material. The structure teachers provide helps students feel competent in carrying out the tasks asked of them.

This research spotlights boys' need to feel connected to teachers and peers at school to be ready to learn and engage in schoolwork. Rather than only viewing peers as a risk factor for school disaffection, positive and healthy peer relationships, as well as high levels of peer group engagement, may foster boys' individual engagement and act as a buffer against losses in engagement across the school year. Teachers can utilize this information to implement classroom practices and activities that build a strong sense of connection within boys' peer groups in the classroom and establish warm and caring relationships with their male students. 


\section{BOYS' ENGAGEMENT AND INTERPERSONAL RESOURCES IN SIXTH GRADE}

To support boys' engagement in school, this study can inform school

administrators about best practices in responding to student behavior. For example, stepping away from exclusionary and disciplinary practices of boys and redirecting the focus back toward high-quality teacher-student relationships may more effectively meet the needs of boys. This research encourages administrators to offer support to teachers in fostering warm and caring relationships with their students and work with teachers to develop innovative approaches that support boys' needs in the classroom and at school.

\section{Future Research}

There are several promising avenues of research to consider in identifying what boys need to be successful in school. For educational researchers, this study highlights the need to examine specific populations, namely boys, to uncover unmet needs that may be contributing to losses in academic engagement in the first year of middle school. Utilizing methods, such as profile analyses, may prove to be helpful in uncovering what boys need from parents, teachers, and peers to buffer losses. While this study compared the interpersonal provisions of boys who experience losses in engagement with those who remain stable, future research examining greater specified engagement profiles will help to identify distinguishing features of the most motivationally resilient boys (See Table 22). 


\section{BOYS’ ENGAGEMENT AND INTERPERSONAL RESOURCES IN SIXTH GRADE}

\section{Table 22}

\section{Boys' Engagement Profiles across Sixth Grade}

\begin{tabular}{lllll}
\hline Engagement Profile & Fall Engagement & Engagement Change & $\mathrm{N}$ & $\%$ \\
\hline Resilient & High/Low & $\begin{array}{l}\text { Remained high or high } \\
\text { gains }\end{array}$ & 54 & $28 \%$ \\
Thriving & Middle/Low & Gains & 26 & $14 \%$ \\
Average & High/Middle & Stable or minimal losses & 49 & $25 \%$ \\
Vulnerable & High/Middle/Low & High losses or remained low & 64 & $33 \%$ \\
\hline
\end{tabular}

Another direction is to expand the utilization of percentile cutoffs to conduct a person-centered analysis to study boys' provisions and engagement. The current study used the top ten and twenty percent of boys with highest provisions to create high and low comparison groups. Profiles can be expanded separating boys with the top $10 \%$ of provisions, the top 20 to $30 \%$, and boys in the lower and upper 50\%. Informed by existing research, combinations of provisions and engagement level can also be clustered together to create profiles.

Majority of peer studies focus on one type of peer group, such as peer group networks or close friendships, and less is known about how each may uniquely and cumulatively contribute to boys' change in engagement. To paint a more holistic picture of peer influences, future research can move in the direction of considering analyses that test the contributions of multiple forms of peer affiliations on academic outcomes. Collecting qualitative data regarding boys' friendships, may provide clarity of the 


\section{BOYS' ENGAGEMENT AND INTERPERSONAL RESOURCES IN SIXTH GRADE}

connection between peer affiliations, peer group engagement, close and intimate friendships, and academic engagement. No support was found in the current study linking boys' friendship quality to their engagement, which seems to misalign with Niobe Way's (2011) research connecting boys' loss of intimate friendships and academic losses. It may be that boys are more likely to describe the depth of their friendships in a qualitative format, such as interviews and focus groups, than by completing a survey in class.

While the current study aims to address challenges that boys face in middle school, it is equally imperative that girls' interpersonal resources and engagement are considered. Research questions posed in this study can, likewise, assess girls' engagement and provision profiles to identify the markers of resilient girls. From these findings, comparisons can be made between boys and girls regarding the kinds of resources that buffer engagement declines in sixth grade, as well as to pinpoint whether there are gender differences in interpersonal resources according to engagement profiles.

\section{Conclusion}

The challenges boys face in school may stem from a lack of certain interpersonal resources, therefore, understanding what boys need from parents, teachers, and peers is a crucial step in supporting their motivation and engagement in the classroom.

Experiencing exclusion from the classroom and other disciplinary consequences at school only further these challenges, impacting boys' long-term educational trajectories and development. Supporting boys' engagement is vital for their educational processes 


\section{BOYS' ENGAGEMENT AND INTERPERSONAL RESOURCES IN SIXTH GRADE}

beyond sixth grade, particularly for college preparation and completion. Also, when boys are engaged and successful in school, they will be better prepared for adulthood and the workplace. Said another way, school engagement will translate to work engagement (Upadyaya \& Salmelo-Aro, 2013). Parents and teachers, as well as resources from peers, can help meet boys' needs in school. This research brings to light interpersonal provisions that can sustain boys' motivation in school and support their academic success and positive life outcomes. 


\section{BOYS' ENGAGEMENT AND INTERPERSONAL RESOURCES IN SIXTH GRADE}

\section{References}

Alexander, K. L., Entwisle, D. R., \& Dauber, S. L. (1993). First-grade classroom behavior: Its short-and long-term consequences for school performance. Child development, 64(3), 801-814. https://doi.org/10.1111/j.1467-8624.1993.tb02944.x

Alexander, K., Entwisle, D., \& Horsey, C. (1997). From First Grade Forward: Early Foundations of High School Dropout. Sociology of Education, 70(2), 87-107. doi:10.2307/2673158

Allison, P. (2012). Handling missing data by maximum likelihood (Paper 312-2012; Statistics and Data Analysis section). In Proceedings of the SAS Global Forum 2012 Conference.

Anderman, L., \& Kaplan, A. (2008). Special issue: The role of interpersonal relationships in student motivation. Journal of Experimental Education, 76(2), 115-120.

Anderman, E. M., Maehr, M. L., \& Midgley, C. (1999). Declining motivation after the transition to middle school: Schools can make a difference. Journal of Research \& Development in Education, 32(3), 131-147.

Alspaugh, J. W. (2000). The Effect of Transition Grade to High School, Gender, and Grade Level Upon Dropout Rates. American Secondary Education, 29(1), 2-9. Retrieved January 6, 2020, from www.jstor.org/stable/41064411 


\section{BOYS' ENGAGEMENT AND INTERPERSONAL RESOURCES IN SIXTH GRADE}

Altermatt, E. R., \& Pomerantz, E. M. (2005). The implications of having high-achieving versus low-achieving friends: A longitudinal analysis. Social Development, 14(1), $61-81$

Amir, R., Saleha, A., Jelas, Z. M., \& Ahmad, A. R. Hutkemri.(2014). Students' engagement by age and gender: A cross-sectional study in Malaysia. Middle-East Journal of Science Research, 21(10), 1886-1892.

Anderman, E. M., \& Mueller, C. (2010). Middle school transitions and adolescent development. In J. L. Meece \& J. S. Eccles (Eds.), Handbook of research on schools, schooling, and human development, (pp. 198-215). New York:

Routledge.

Archambault, I., Janosz, M., Morizot, J., \& Pagani, L. (2009). Adolescent behavioral, affective, and cognitive engagement in school: Relationship to dropout. Journal of School Health, 79(9), 408-415.

Barger, M. M., Kim, E. M., Kuncel, N. R., \& Pomerantz, E. M. (2019). The relation between parents' involvement in children's schooling and children's adjustment: A meta-analysis. Psychological Bulletin, 145(9), 855-890.

Baroody, A. E., Rimm-Kaufman, S. E., Larsen, R. A., \& Curby, T. W. (2016). A multimethod approach for describing the contributions of student engagement on fifth grade students' social competence and achievement in mathematics. Learning and Individual Differences, 48, 54-60. 


\section{BOYS' ENGAGEMENT AND INTERPERSONAL RESOURCES IN SIXTH GRADE}

Baumeister, R. F., \& Leary, M. R. (1995). The need to belong: Desire for interpersonal attachments as a fundamental human motivation. Psychological Bulletin, 117(3), 497-529.

Belmont, M. J., Skinner, E. A., Wellborn, J. G., \& Connell, J. P. (1988). Teacher as social context (TASC): A measure of student perceptions of teacher provision of involvement, structure, and autonomy, support (Tech. Rep. No. 102). University of Rochester, Rochester, NY.

Bempechat, J., \& Shernoff, D. J. (2012). Parental influences on achievement motivation and student engagement. In S. Christenson, A. Reschly, \& C. Wylie (Eds.) Handbook of research on student engagement (pp. 315-342). New York: Springer Science.

Berndt, T. J. (2004). Children's friendships: Shifts over a half-century in perspectives on their development and their effects: Merrill-Palmer Quarterly, 50, 206-223.

Berndt, T. J. (2002). Friendship quality and social development. Current directions in psychological science, 11(1), 7-10.

Berndt, T. J., \& Keefe, K. (1995). Friends' influence on adolescents' adjustment to school. Child development, 66(5), 1312-1329.

Berndt, T. J., Laychak, A. E., \& Park, K. (1990). Friends' influence on adolescents' academic achievement motivation: An experimental study. Journal of Educational Psychology, 82(4), 664-670. 


\section{BOYS' ENGAGEMENT AND INTERPERSONAL RESOURCES IN SIXTH GRADE}

Brown, B. B., \& Dietz, E. L. (2009). Informal peer groups in middle childhood and adolescence. In K. H. Rubin, W. Bukowski, \& B. Laursen, Handbook of peer interactions, relationships, and groups (pp. 361-376). New York: Guilford.

Bukowski, W. M., \& Laursen, B., Rubin, K. H., (Eds.). (2019). Handbook of peer interactions, relationships, and groups. Guilford Press.

Bukowski, W. M., Motzoi, C., \& Meyer, F. (2009). Friendship as process, function, and outcome. In K. H. Rubin, W. M. Bukowski, \& B. Laursen, Handbook of peer interactions, relationships, and groups (pp. 217-231). New York: Guilford.

Cairns, R. B., \& Cairns, B. D. (1994). Lifelines and risks: Pathways of youth in our time. New York: Cambridge University Press.

Cairns, R. B., Perrin, J. E., \& Cairns, B. D. (1985). Social structure and social cognition in early adolescence: Affiliative patterns. The Journal of Early Adolescence, 5(3), 339-355.

Christenson, S. L., Reschly, A. L., \& Wylie, C. (Eds.). (2012). Handbook of research on student engagement. New York: Springer Science.

Connell, J. P. (1990). Context, self, and action: A motivational analysis of self-system processes across the life span. In D. Cicchetti \& M. Beeghly, The self in transition: Infancy to childhood, (pp. 61-97). Chicago and London: The University of Chicago Press. 


\section{BOYS' ENGAGEMENT AND INTERPERSONAL RESOURCES IN SIXTH GRADE}

Connell, J. P., Spencer, M. B., \& Aber, J. L. (1994). Educational risk and resilience in African- American youth: Context, self, action, and outcomes in school. Child Development, 65(2), 493-506.

Connell, J. P., \& Wellborn, J. G. (1991). Competence, autonomy, and relatedness: A motivational analysis of self-system processes. In M. R. Gunnar \& L. A. Sroufe (Eds.), The Minnesota symposia on child psychology, Vol. 23. Self-processes and development (pp. 43-77). Mahwah, NJ: Erlbaum.

Cooper, C. R., Chavira, G., \& Mena, D. D. (2005). From pipelines to partnerships: A synthesis of research on how diverse families, schools, and communities support children's pathways through school. Journal of Education for Students Placed at Risk, 10(4), 407-430.

Deci, E. L., \& Ryan, R. M. (2002). The paradox of achievement: The harder you push, the worse it gets. In J. Aronson (Ed.), Improving academic achievement (pp. 6187). New York: Academic Press.

Deci, E. L., \& Ryan, R. M. (2000). The" what" and" why" of goal pursuits: Human needs and the self-determination of behavior. Psychological inquiry, 11(4), 227-268.

Deci, E. L., \& Ryan, R. M. (1987). The support of autonomy and the control of behavior. Journal of personality and social psychology, 53(6), 1024-1037. 


\section{BOYS' ENGAGEMENT AND INTERPERSONAL RESOURCES IN SIXTH GRADE}

Dempster, A. P., Laird, N. M., \& Rubin, D. B. (1977). Maximum likelihood from incomplete data via the EM algorithm. Journal of the Royal Statistical Society: Series B (Methodological), 39(1), 1-22.

Dubow, E. F., Boxer, P., \& Huesmann, L. R. (2009). Long-term effects of parents' education on children's educational and occupational success: Mediation by family interactions, child aggression, and teenage aspirations. Merrill-Palmer quarterly (Wayne State University. Press), 55(3), 224-249.

Eccles, J. S., \& Midgley, C. (1989). Stage/environment fit: Developmentally appropriate classrooms for early adolescents. In R. E. Ames \& C. Ames (Eds.), Research on motivation in education (Vol. 3, pp. 139-186). New York: Academic Press.

Eccles, J. S., \& Roeser, R. W. (2011). Schools as developmental contexts during adolescence. Journal of Research on Adolescence, 21(1), 225-241.

Ekstrom, R. B., Goertz, M. E., Pollack, J. M., \& Rock, D. A. (1986). Who drops out of high school and why? Findings from a national study. In G. Natriello (Ed.), School Dropouts: Patterns and Policies (pp. 52-69). New York: Teachers College Press.

Farkas, M. S., \& Grolnick, W. S. (2010). Examining the components and concomitants of parental structure in the academic domain. Motivation and Emotion, 34(3), 266279. 


\section{BOYS' ENGAGEMENT AND INTERPERSONAL RESOURCES IN SIXTH GRADE}

Farkas, M. S., \& Grolnick, W. S. (2006). Toward a New Model of Parental Structure. Unpublished Manuscript.

Feldlaufer, H., Midgley, C., \& Eccles, J. S. (1988). Student, teacher, and observer perceptions of the classroom environment before and after the transition to junior high school. The Journal of Early Adolescence, 8(2), 133-156.

Finn, J. D., \& Cox, D. A. (1992). Participation and withdrawal among fourth-grade pupils. American Educational Research Journal, 29(1), 141-162.

Finn, J. D., \& Rock, D. A. (1997). Academic success among students at risk for school failure. Journal of Applied Psychology, 82, 221-234.

Finn, J. D., \& Zimmer, K. S. (2012). Student engagement: What is it? Why does it matter? In S. L. Christenson, A. L. Reschly, \& C. Wylie (Eds), Handbook of research on student engagement (pp. 97-131). New York: Springer Science.

Fredricks, J. A., Blumenfeld, P. C., \& Paris, A. H. (2004). School engagement: Potential of the concept, state of the evidence. Review of educational research, 74(1), 59109.

Fredricks, J. A., Reschly, A. L., \& Christenson, S. L. (Eds.). (2019). Handbook of student engagement interventions: Working with disengaged students. United Kingdom: Academic Press. 


\section{BOYS' ENGAGEMENT AND INTERPERSONAL RESOURCES IN SIXTH GRADE}

Furrer, C., \& Skinner, E. (2003). Sense of relatedness as a factor in children's academic engagement and performance. Journal of Educational Psychology, 95(1), 148162.

Gest, S. D., Farmer, T. W., Cairns, B. D., \& Xie, H. (2003). Identifying children's peer social networks in school classrooms: Links between peer reports and observed interactions. Social Development, 12(4), 513-529.

Gonzalez-DeHass, A. R., Willems, P. P., \& Holbein, M. F. D. (2005). Examining the relationship between parental involvement and student motivation. Educational Psychology Review, 17(2), 99-123.

Gregory, A., \& Korth, J. (2016). Teacher-student relationships and behavioral engagement in the classroom. In K. R. Wentzel \& G. B. Ramani (Eds.), Handbook of social influences in school contexts: Social-emotional, motivation, and cognitive outcomes, (pp. 178-191). New York: Routledge.

Grolnick, W. S. (2009). The role of parents in facilitating autonomous self-regulation for education. Theory and Research in Education, 7(2), 164-173.

Grolnick, W. S., Friendly, R. W., \& Bellas, V. M. (2009). Parenting and children's motivation at school. In K. R. Wentzel \& A. Wigfield (Eds.), Educational psychology handbook series. Handbook of motivation at school (pp. 279-300). New York: Routledge. 


\section{BOYS' ENGAGEMENT AND INTERPERSONAL RESOURCES IN SIXTH GRADE}

Grolnick, W. S., Gurland, S. T., DeCourcey, W., \& Jacob, K. (2002). Antecedents and consequences of mothers' autonomy support: An experimental investigation. Developmental psychology, 38(1), 143.

Grolnick, W. S., \& Ryan, R. M. (1989). Parent styles associated with children's selfregulation and competence in school. Journal of educational psychology, 81(2), 143.

Grolnick, W. S., Ryan, R. M., \& Deci, E. L. (1991). Inner resources for school achievement: Motivational mediators of children's perceptions of their parents. Journal of educational psychology, 83(4), 508.

Grolnick, W. S., \& Slowiaczek, M. L. (1994). Parents' involvement in children's schooling: A multidimensional conceptualization and motivational model. Child development, 65(1), 237-252.

Hamre, B. K., \& Pianta, R. C. (2001). Early teacher-child relationships and the trajectory of children's school outcomes through eighth grade. Child development, 72(2), 625-638.

Hospel, V., \& Galand, B. (2016). Are both classroom autonomy support and structure equally important for students' engagement? A multilevel analysis. Learning and Instruction, 41, 1-10.

Izzo, C. V., Weissberg, R. P., Kasprow, W. J., \& Fendrich, M. (1999). A longitudinal assessment of teacher perceptions of parent involvement in children's education 


\section{BOYS' ENGAGEMENT AND INTERPERSONAL RESOURCES IN SIXTH GRADE}

and school performance. American journal of community psychology, 27(6), 817839.

Jacobs, J. E., Lanza, S., Osgood, D. W., Eccles, J. S., \& Wigfield, A. (2002). Changes in children's self-competence and values: Gender and domain differences across grades one through twelve. Child development, 73(2), 509-527.

Janosz, M., Archambault, I., Morizot, J., \& Pagani, L. S. (2008). School engagement trajectories and their differential predictive relations to dropout. Journal of social issues, 64(1), 21-40.

Juvonen, J., Espinoza, G., \& Knifsend, C. (2012). The role of peer relationships in student academic and extracurricular engagement. In S. Christenson, A. Reschly, \& C. Wylie (Eds.), Handbook of research on student engagement (pp. 387-401). New York: Springer Science.

Juvonen, J., \& Knifsend, C. (2016). School-based peer relationships and achievement motivation. In K. R. Wentzel \& D. B. Miele (Eds.), Handbook of motivation at school (pp. 231-250). New York: Routledge.

Kindermann, T. A. (2016). Peer group influences on students' academic motivation. Handbook of social influences in school contexts: Social-emotional, motivation, and cognitive outcomes, (pp. 31-47). New York: Routledge. 


\section{BOYS' ENGAGEMENT AND INTERPERSONAL RESOURCES IN SIXTH GRADE}

Kindermann, T. A. (2007). Effects of naturally existing peer groups on changes in academic engagement in a cohort of sixth graders. Child Development, 78(4), 1186-1203.

Kindermann, T. A. "SoNet WORLD - 6th Grade Map: Peer Group Influences on School Motivation in a Cohort of 6th Graders in a Small Town." Google Sites, 2007, sites.google.com/view/sonet-world/home/6th-grade-map.

Kindermann, T. A. (1993). Natural peer groups as contexts for individual development: The case of children's motivation in school. Developmental psychology, 29(6), 970-977.

Kindermann, T. A., \& Gest, S. D. (2018). The peer group: Linking conceptualizations, theories, and methods. In W. Bukowski, B. Laursen, \& K. Rubin (Eds.), Handbook of peer interactions, relationships, relationships and groups ( $2^{\text {nd }}$ ed., pp. 84-105). New York: Guilford.

Kindermann, T. A., \& Gest, S. D. (2009). Assessment of the peer group: Identifying naturally occurring social networks and capturing their effects. In K. H. Rubin, W. Bukowski, \& B. Laursen (Eds.), Handbook of peer interactions, relationships, and groups (pp. 100-117). New York: Guilford.

Kindermann, T. A., McCollam, T. L., \& Gibson, E. (1996). Peer networks and students' classroom engagement during childhood and adolescence. In K. Wentzel \& J. 


\section{BOYS' ENGAGEMENT AND INTERPERSONAL RESOURCES IN SIXTH GRADE}

Juvonen (Eds.), Social motivation: Understanding children's school adjustment (pp. 279-312). Cambridge, England: Cambridge University Press.

Kindermann, T. A., \& Skinner, E. A. (2012). Will the real peer group please stand up? A" tensegrity" approach to examining the synergistic influences of peer groups and friendship networks on academic development. In A. M. Ryan \& G. W. Ladd (Eds.), Adolescence and education. Peer relationships and adjustment at school (pp. 51-77). Charlotte, NC: IAP Information Age Publishing.

King, R. B. (2016). Gender differences in motivation, engagement and achievement are related to students' perceptions of peer—but not of parent or teacher—attitudes toward school. Learning and Individual Differences, 52, 60-71.

Kingery, J. N., \& Erdley, C. A. (2007). Peer experiences as predictors of adjustment across the middle school transition. Education and treatment of children, 30(2), 73-88.

La Paro, K. M., Pianta, R. C., \& Stuhlman, M. (2004). The classroom assessment scoring system: Findings from the prekindergarten year. The elementary school journal, 104(5), 409-426.

Ladd, G. W., \& Dinella, L. M. (2009). Continuity and change in early school engagement:

Predictive of children's achievement trajectories from first to eighth grade? Journal of educational psychology, 101(1), 190. 


\section{BOYS' ENGAGEMENT AND INTERPERSONAL RESOURCES IN SIXTH GRADE}

Lam, S. F., Jimerson, S., Kikas, E., Cefai, C., Veiga, F. H., Nelson, B., ... \& Zollneritsch, J. (2012). Do girls and boys perceive themselves as equally engaged in school? The results of an international study from 12 countries. Journal of school psychology, 50(1), 77-94.

Larson, R. W. (2000). Toward a psychology of positive youth development. American psychologist, 55(1), 170.

Lee, V. E., \& Smith, J. B. (1993). Effects of school restructuring on the achievement and engagement of middle-grade students. Sociology of Education, 164-187.

Li, Y., \& Lerner, R. M. (2011). Trajectories of school engagement during adolescence: implications for grades, depression, delinquency, and substance use. Developmental psychology, 47(1), 233.

Lietaert, S., Roorda, D., Laevers, F., Verschueren, K., \& De Fraine, B. (2015). The gender gap in student engagement: The role of teachers' autonomy support, structure, and involvement. British Journal of Educational Psychology, 85(4), 498-518.

Martin, A. J., Anderson, J., Bobis, J., Way, J., \& Vellar, R. (2011). Switching on and switching off in mathematics: An ecological study of future intent and disengagement amongst middle school students. Journal of Educational Psychology, 104, 1-18. 


\section{BOYS' ENGAGEMENT AND INTERPERSONAL RESOURCES IN SIXTH GRADE}

Martin, A. J., \& Collie, R. J. (2016). The role of teacher-student relationships in unlocking students' academic potential: Exploring motivation, engagement, resilience, adaptability, goals, and instruction. In K. R. Wentzel \& G. B. Ramani (Eds.), Handbook of social influences in school contexts: Social-emotional, motivation, and cognitive outcomes, (pp. 158-177), New York: Routledge.

Martin, A. J., \& Dowson, M. (2009). Interpersonal relationships, motivation, engagement, and achievement: Yields for theory, current issues, and educational practice. Review of Educational Research, 79(1), 327-365.

McFarland, J., Hussar, B., Zhang, J., Wang, X., Wang, K., Hein, S., ... \& Barmer, A. (2019). The Condition of Education 2019. NCES 2019-144. National Center for Education Statistics.

Oelsner, J., Lippold, M. A., \& Greenberg, M. T. (2011). Factors influencing the development of school bonding among middle school students. The Journal of early adolescence, 31(3), 463-487.

Oregon Department of Education, Student Assessment. (2019). English language arts, by female and male: 2017-18. In Oregon Department of Education, Assessment Group Reports (Ed.). Retrieved from http://oregon.gov.

Park, S., Holloway, S. D., Arendtsz, A., Bempechat, J., \& Li, J. (2012). What makes students engaged in learning? A time-use study of within-and between-individual 


\section{BOYS' ENGAGEMENT AND INTERPERSONAL RESOURCES IN SIXTH GRADE}

predictors of emotional engagement in low-performing high schools. Journal of youth and adolescence, 41(3), 390-401.

Parker, J. G., \& Asher, S. R. (1987). Peer relations and later personal adjustment: Are low-accepted children at risk? Psychological Bulletin, 102(3), 357.

Pianta, R. C., Hamre, B. K., \& Allen, J. P. (2012). Teacher-student relationships and engagement: Conceptualizing, measuring, and improving the capacity of classroom interactions. In S. L. Christenson, A. L. Reschly, \& C. Wylie (Eds.), Handbook of research on student engagement (pp. 365-386). New York: Springer Science.

Pietarinen, J., Soini, T., \& Pyhältö, K. (2014). Students' emotional and cognitive engagement as the determinants of well-being and achievement in school. International Journal of Educational Research, 67, 40-51.

Pomerantz, E. M., Grolnick, W. S., \& Price, C. E. (2005). The Role of Parents in How Children Approach Achievement: A Dynamic Process Perspective. In A. J. Elliott \& C. S. Dweck (Eds.), Handbook of competence and motivation (pp. 259-278). New York: Guilford Press.

Pomerantz, E. M., \& Moorman, E. A. (2010). Parents' involvement in children's schooling. In J. L. Meece \& J. S. Eccles (Eds.), Handbook of research on schools, schooling, and human development (pp. 398-416). New York: Routledge. 


\section{BOYS' ENGAGEMENT AND INTERPERSONAL RESOURCES IN SIXTH GRADE}

Quin, D. (2017). Longitudinal and contextual associations between teacher-student relationships and student engagement: A systematic review. Review of Educational Research, 87(2), 345-387.

Rampey, B. D., Dion, G. S., \& Donahue, P. L. (2009). NAEP 2008: Trends in Academic Progress. NCES 2009-479. National Center for Education Statistics.

Reeve, J. (2012). A self-determination theory perspective on student engagement. In S. L. Christenson, A. L. Reschly, \& C. Wylie (Eds.), Handbook of research on student engagement (pp. 149-172). New York: Springer.

Reeve, J., Jang, H., Carrell, D., Jeon, S., \& Barch, J. (2004). Enhancing students' engagement by increasing teachers' autonomy support. Motivation and Emotion, $28,147-169$.

Rimm-Kaufman, S. E., Baroody, A. E., Larsen, R. A., Curby, T. W., \& Abry, T. (2015). To what extent do teacher-student interaction quality and student gender contribute to fifth graders' engagement in mathematics learning? Journal of Educational Psychology, 107(1), 170.

Ripski, M. B., \& Gregory, A. (2009). Unfair, unsafe, and unwelcome: Do high school students' perceptions of unfairness, hostility, and victimization in school predict engagement and achievement? Journal of School Violence, 8(4), 355-375.

Roorda, D. L., Koomen, H. M., Spilt, J. L., \& Oort, F. J. (2011). The influence of affective teacher-student relationships on students' school engagement and 


\section{BOYS' ENGAGEMENT AND INTERPERSONAL RESOURCES IN SIXTH GRADE}

achievement: A meta-analytic approach. Review of educational research, 81(4), 493-529.

Rowe, M. L., Ramani, G. B., \& Pomerantz, E. M. (2016). Parental involvement and children's motivation and achievement. In K. R. Wentzel \& D. B. Miele (Eds.), Handbook of Motivation at School (pp. 459-476). New York: Routledge.

Rubin, Donald B. 1987. Multiple Imputation for Nonresponse in Surveys. New York: Wiley.

Ryan, A. M. (2001). The peer group as a context for the development of young adolescent motivation and achievement. Child development, 72(4), 1135-1150.

Ryan, A. M., North, E. A., \& Ferguson, S. (2019). Peers and engagement. In J. A. Fredricks, A. L. Reschly, \& S. L. Christenson (Eds.). Handbook of Student Engagement Interventions (pp. 73-85). United Kingdom: Academic Press.

Ryan, A. M., \& Patrick, H. (2001). The classroom social environment and changes in adolescents' motivation and engagement during middle school. American educational research journal, 38(2), 437-460.

Ryan M., \& Shin, H. (2018). Peers, teachers, and academics. In W. Bukowski, B. Laursen, \& K. Rubin (Eds.), Handbook of peer interactions, relationships, and groups ( $2^{\text {nd }}$ ed., pp. 637-656). New York: Guilford. 


\section{BOYS' ENGAGEMENT AND INTERPERSONAL RESOURCES IN SIXTH GRADE}

Sage, N. A., \& Kindermann, T. A. (1999). Peer networks, behavior contingencies, and children's engagement in the classroom. Merrill-Palmer Quarterly (1982-), 143171.

Salmela-Aro, K., Moeller, J., Schneider, B., Spicer, J., \& Lavonen, J. (2016). Integrating the light and dark sides of student engagement using person-oriented and situation-specific approaches. Learning and Instruction, 43, 61-70.

Shin, H., \& Ryan, A. M. (2014). Early adolescent friendships and academic adjustment: Examining selection and influence processes with longitudinal social network analysis. Developmental Psychology, 50(11), 2462-2472.

Simmons, R. G., Burgeson, R., Carlton-Ford, S., \& Blyth, D. A. (1987). The impact of cumulative change in early adolescence. Child development, 1220-1234.

Simons-Morton, B., \& Chen, R. (2009). Peer and parent influences on school engagement among early adolescents. Youth \& Society, 41(1), 3-25.

Simons-Morton, B. G., \& Crump, A. D. (2003). Association of parental involvement and social competence with school adjustment and engagement among sixth graders. Journal of School Health, 73(3), 121-126.

Sirin, S. R., \& Rogers-Sirin, L. (2005). Components of school engagement among African American adolescents. Applied Developmental Science, 9(1), 5-13.

Skinner, E. A. (2016). Engagement and disaffection as central to processes of motivational resilience and development. In K. R. Wentzel \& G. B. Ramani 


\section{BOYS' ENGAGEMENT AND INTERPERSONAL RESOURCES IN SIXTH GRADE}

(Eds.), Handbook of social influences in school contexts: Social-emotional, motivation, and cognitive outcomes (pp. 13-30). New York: Routledge.

Skinner, E. A., \& Belmont, M. J. (1993). Motivation in the classroom: Reciprocal effects of teacher behavior and student engagement across the school year. Journal of educational psychology, 85(4), 571-581.

Skinner, E., Furrer, C., Marchand, G., \& Kindermann, T. (2008). Engagement and disaffection in the classroom: Part of a larger motivational dynamic? Journal of educational psychology, 100(4), 765-781.

Skinner, E., Johnson, S., \& Snyder, T. (2005). Six dimensions of parenting: A motivational model. Parenting: Science and practice, 5(2), 175-235. Retrieved from https://psycnet.apa.org/record/2005-05756-003

Skinner, E. A., Kindermann, T. A., Connell, J. P., \& Wellborn, J. G. (2009). Engagement and disaffection as organizational constructs in the dynamics of motivational development. In K. Wentzel \& A. Wigfield (Eds.), Handbook of motivation at school (pp. 223-245). Mahwah, NJ: Erlbaum.

Skinner, E. A., Kindermann, T. A., \& Furrer, C. J. (2009). A motivational perspective on engagement and disaffection: Conceptualization and assessment of children's behavioral and emotional participation in academic activities in the classroom. Educational and Psychological Measurement, 69(3), 493-525. 


\section{BOYS' ENGAGEMENT AND INTERPERSONAL RESOURCES IN SIXTH GRADE}

Skinner, E. A., \& Pitzer, J. R. (2012). Developmental dynamics of student engagement, coping, and everyday resilience. In S. L. Christenson, A. L. Reschly, \& C. Wylie (Eds.), Handbook of research on student engagement (pp. 21-44). New York: Springer Science.

Skinner, E. A., Wellborn, J. G., \& Connell, J. P. (1990). What it takes to do well in school and whether I've got it: A process model of perceived control and children's engagement and achievement in school. Journal of educational psychology, 82(1), 22.

Snyder, T., (2011). Parent and Teacher Influences on Children's Academic Motivation. Dissertations and Theses, Paper 105. Portland State University, Portland, OR.

Snyder, T. D., De Brey, C., \& Dillow, S. A. (2019). Digest of Education Statistics 2017, NCES 2018-070. National Center for Education Statistics.

Snyder, T. D., De Brey, C., \& Dillow, S. A. (2018). Digest of Education Statistics 2016, NCES 2017-094. National Center for Education Statistics.

Steinberg, L., Lamborn, S. D., Dornbusch, S. M., \& Darling, N. (1992). Impact of parenting practices on adolescent achievement: Authoritative parenting, school involvement, and encouragement to succeed. Child development, 63(5), 12661281. 


\section{BOYS' ENGAGEMENT AND INTERPERSONAL RESOURCES IN SIXTH GRADE}

Symonds, J., \& Galton, M. (2014). Moving to the next school at age 10-14 years: An international review of psychological development at school transition. Review of Education, 2(1), 1-27. doi:10.1002/rev3.3021.

Tyler, K. M., \& Boelter, C. M. (2008). Linking black middle school students' perceptions of teachers' expectations to academic engagement and efficacy. Negro Educational Review, 59(1), 27-44,125-126. Retrieved from http://stats.lib.pdx.edu/proxy.php?url=http://search.proquest.com/scholarlyjournals/linking-black-middle-school-studentsperceptions/docview/219037863/se-2?accountid=13265

Upadyaya, K., \& Salmela-Aro, K. (2013). Development of school engagement in association with academic success and well-being in varying social contexts: A review of empirical research. European Psychologist, 18(2), 136-147. Retrieved from http://dx.doi.org/10.1027/1016-9040/a000143

Van de Gaer, E., Pustjens, H., Van Damme, J., \& De Munter, A. (2009). School engagement and language achievement: A longitudinal study of gender differences across secondary school. Merrill-Palmer Quarterly (1982-), 373-405.

Vasquez, A. C., Patall, E. A., Fong, C. J., Corrigan, A. S., \& Pine, L. (2016). Parent autonomy support, academic achievement, and psychosocial functioning: A metaanalysis of research. Educational Psychology Review, 28(3), 605-644. 


\section{BOYS' ENGAGEMENT AND INTERPERSONAL RESOURCES IN SIXTH GRADE}

Virtanen, T. E., Lerkkanen, M. K., Poikkeus, A. M., \& Kuorelahti, M. (2015). The relationship between classroom quality and students' engagement in secondary school. Educational Psychology, 35(8), 963-983.

Von Eye, A. (1990). Introduction to configural frequency analysis: The search for types and antitypes in cross-classification. New York: Cambridge University Press.

Wang, M. T., \& Degol, J. L. (2016). School climate: A review of the construct, measurement, and impact on student outcomes. Educational Psychology Review, 28(2), 315-352.

Wang, M. T., Degol, J. L., \& Henry, D. A. (2019). An integrative development-insociocultural-context model for children's engagement in learning. American Psychologist, 74(9), 1086.

Wang, M. T., \& Eccles, J. S. (2012). Social support matters: Longitudinal effects of social support on three dimensions of school engagement from middle to high school. Child development, 83(3), 877-895.

Wang, M. T., Willett, J. B., \& Eccles, J. S. (2011). The assessment of school engagement: Examining dimensionality and measurement invariance by gender and race/ethnicity. Journal of School Psychology, 49(4), 465-480.

Warren, J. R., Hoffman, E., \& Andrew, M. (2014). Patterns and trends in grade retention rates in the United States, 1995-2010. Educational Researcher, 43(9), 433-443. 


\section{BOYS' ENGAGEMENT AND INTERPERSONAL RESOURCES IN SIXTH GRADE}

Way, N. (2011). Deep secrets: Boys' friendships and the crisis of connection. Cambridge, MA: Harvard University Press.

Wei, J., Pomerantz, E. M., Ng, F. F. Y., Yu, Y., Wang, M., \& Wang, Q. (2019). Why does parents' involvement in youth's learning vary across elementary, middle, and high school? Contemporary Educational Psychology, 56, 262-274.

Wellborn, J. (1992). Engaged and disaffected action: The conceptualization and measurement of motivation in the academic domain. Unpublished Dissertation, Department of Psychology, University of Rochester, Rochester, NY.

Wentzel, K. (2016). Teacher-student relationships. In K.R. Wentzel \& D.B. Miele (Eds.), Handbook of motivation in school 2nd edition (pp. 211-230). Routledge.

Wentzel, K. R. (2010). Students' relationships with teachers. In J. L. Meece \& J. S. Eccles (Eds.), Handbook of research on schools, schooling, and human development (pp. 75-91). New York: Routledge.

Wentzel, K. R. (2009). Peers and academic functioning at school. In K. H. Rubin, W. M. Bukowski, \& B. Laursen (Eds.), Social, emotional, and personality development in context. Handbook of peer interactions, relationships, and groups (p. 531547). New York: Guilford.

Wentzel, K. R., \& Miele, D. (Eds.) (2016). Handbook of motivation at school. Mahwah, NJ: Erlbaum. 


\section{BOYS' ENGAGEMENT AND INTERPERSONAL RESOURCES IN SIXTH GRADE}

Wentzel, K. R., \& Muenks, K. (2016). Peer influence on students’ motivation, academic achievement, and social behavior. In K. R. Wentzel \& G. B. Ramani (Eds.), Handbook of social influences in school contexts: Social-emotional, motivation, and cognitive outcomes (pp. 13-30). New York: Routledge.

Wentzel, K. R., \& Ramani, G. B. (Eds.) (2016). Handbook of social influences in school contexts: Social-emotional, motivation, and cognitive outcomes. New York: Routledge.

Wigfield, A., Byrnes, J. P., \& Eccles, J. S. (2006). Development During Early and Middle Adolescence. In A. Alexander \& P. H. Winne (Eds.), Handbook of educational psychology (pp. 87-113). Mahwah, NJ: Erlbaum.

Wigfield, A., \& Eccles, J. S. (1992). The development of achievement task values: A theoretical analysis. Developmental review, 12(3), 265-310.

Wigfield, A., Eccles, J. S., Fredricks, J. A., Simpkins, S., Roeser, R. W., \& Schiefele, U. (2015). Development of achievement motivation and engagement. In M. E. Lamb \& R. M. Lerner (Eds.), Handbook of child psychology and developmental science: Socioemotional processes (pp. 657-700). New York: John Wiley.

Woolley, M. E., \& Bowen, G. L. (2007). In the context of risk: Supportive adults and the school engagement of middle school students. Family relations, 56(1), 92-104. 
BOYS' ENGAGEMENT AND INTERPERSONAL RESOURCES IN SIXTH GRADE

Appendix A. Literature Review of Gender and Engagement

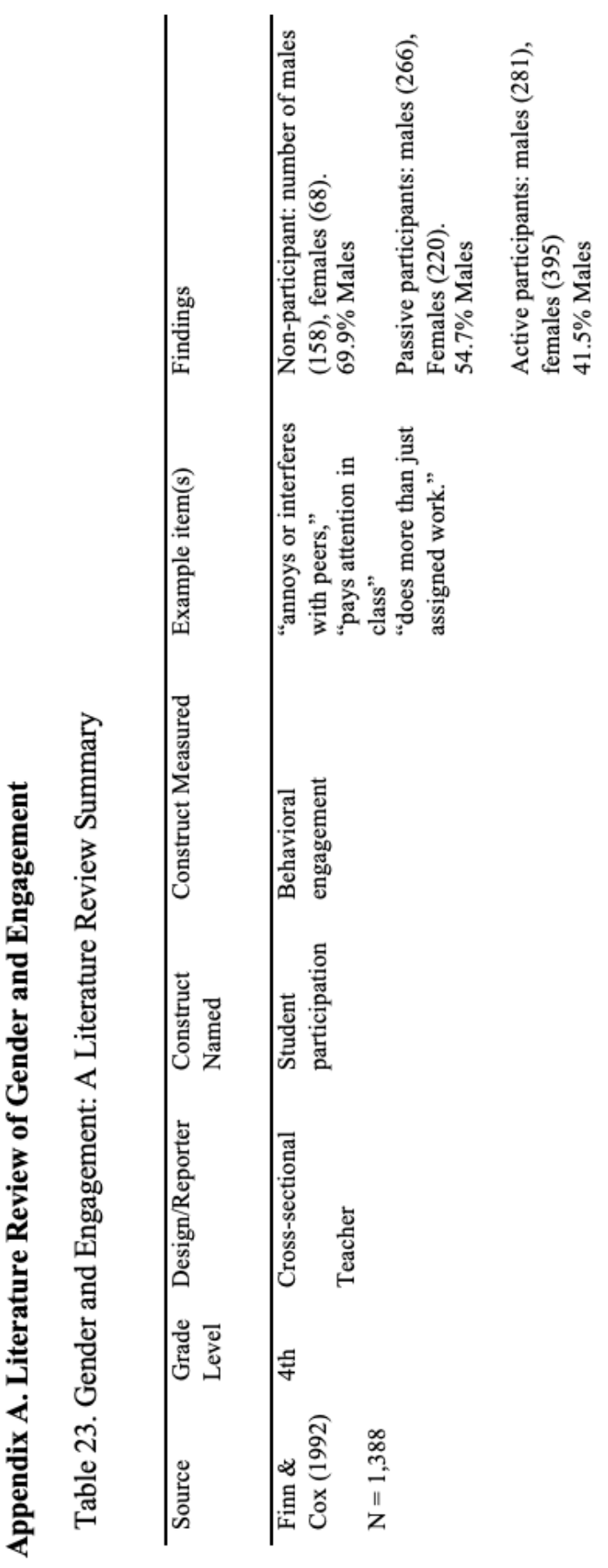




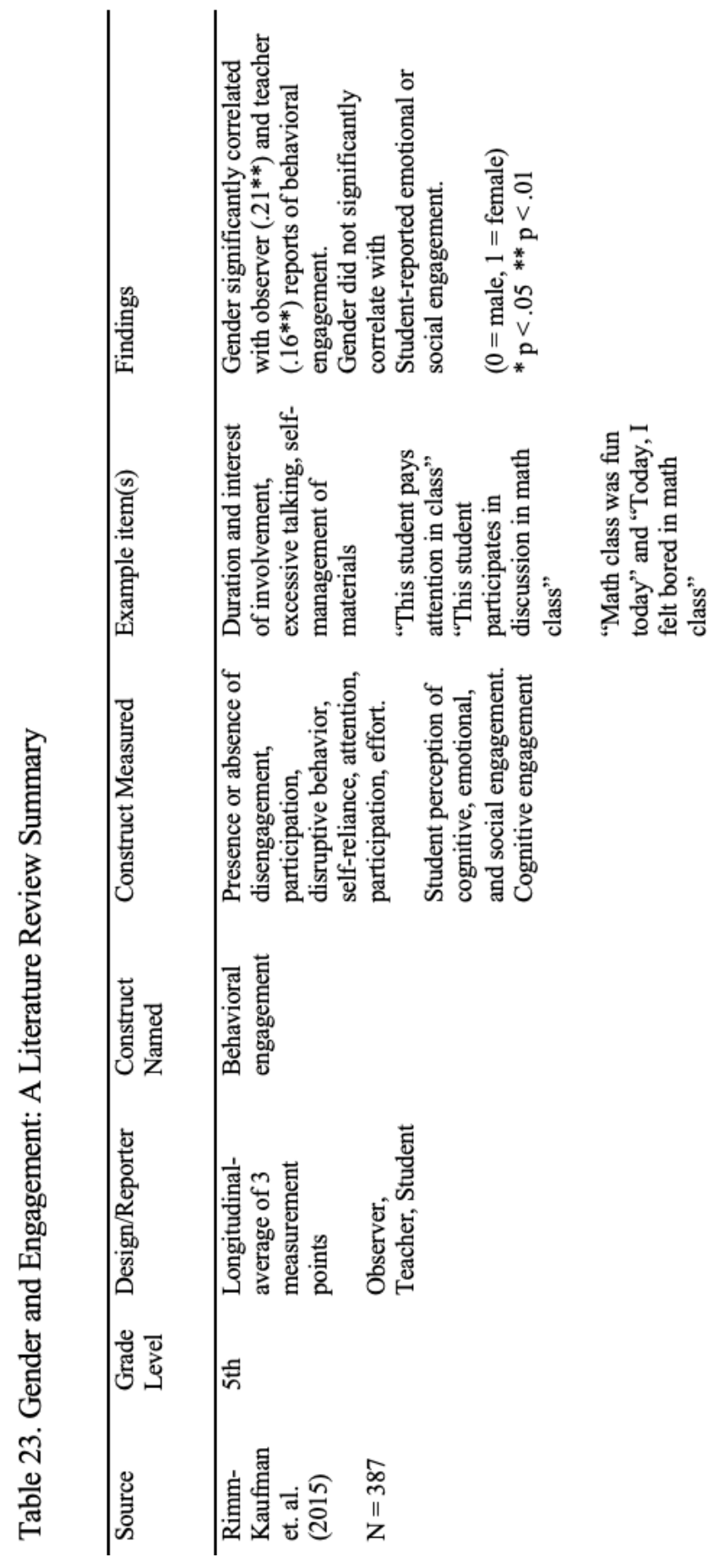




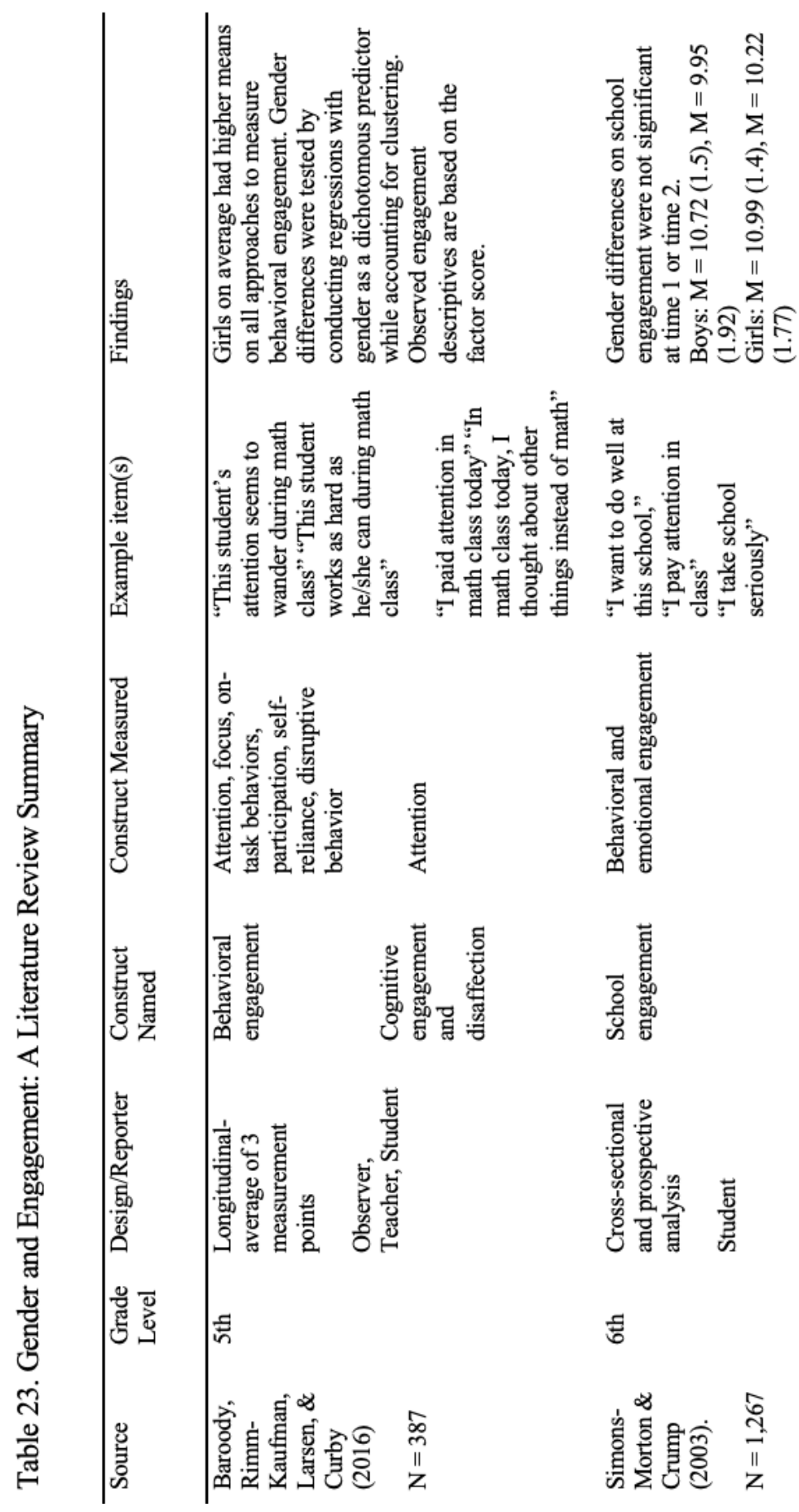




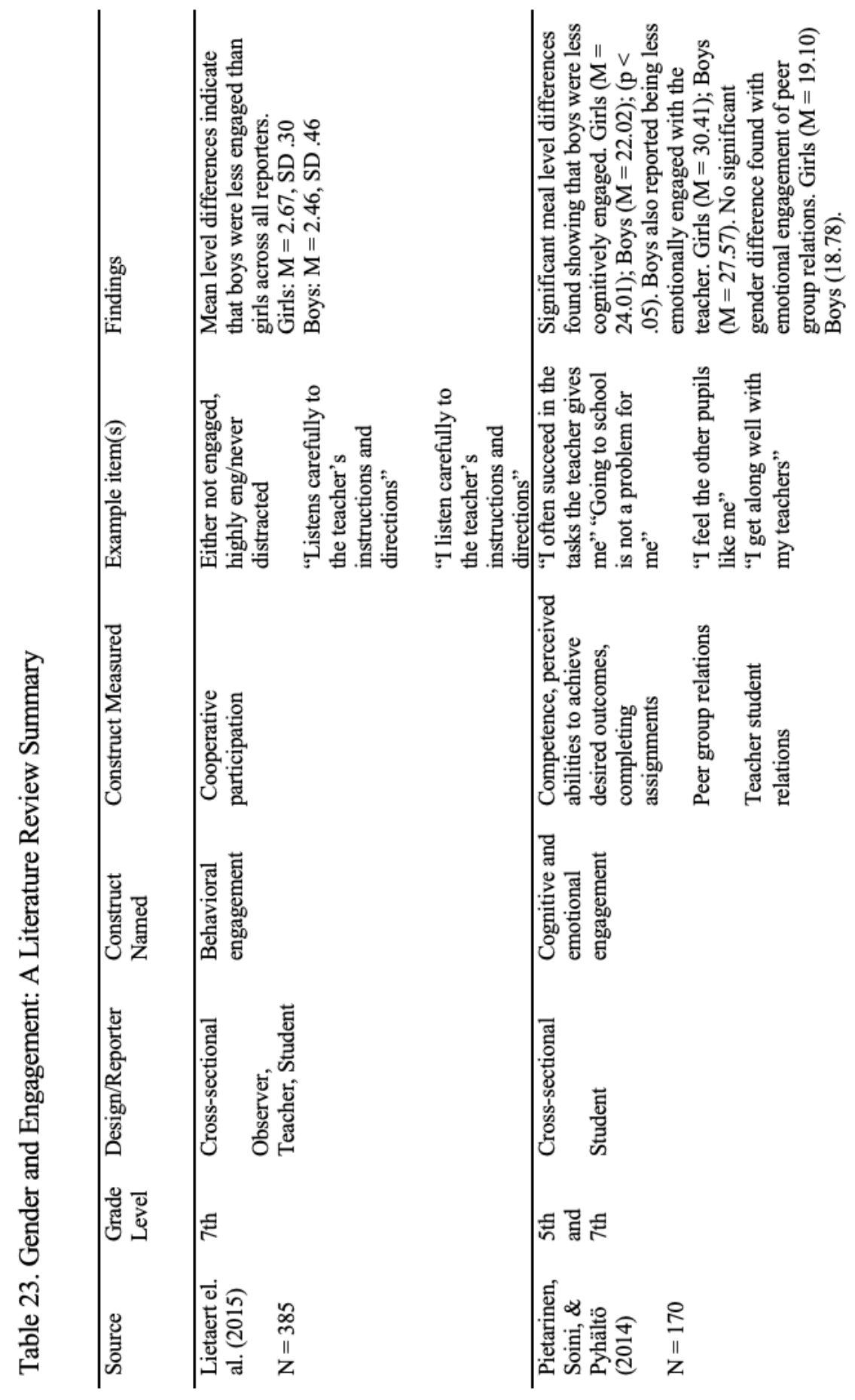




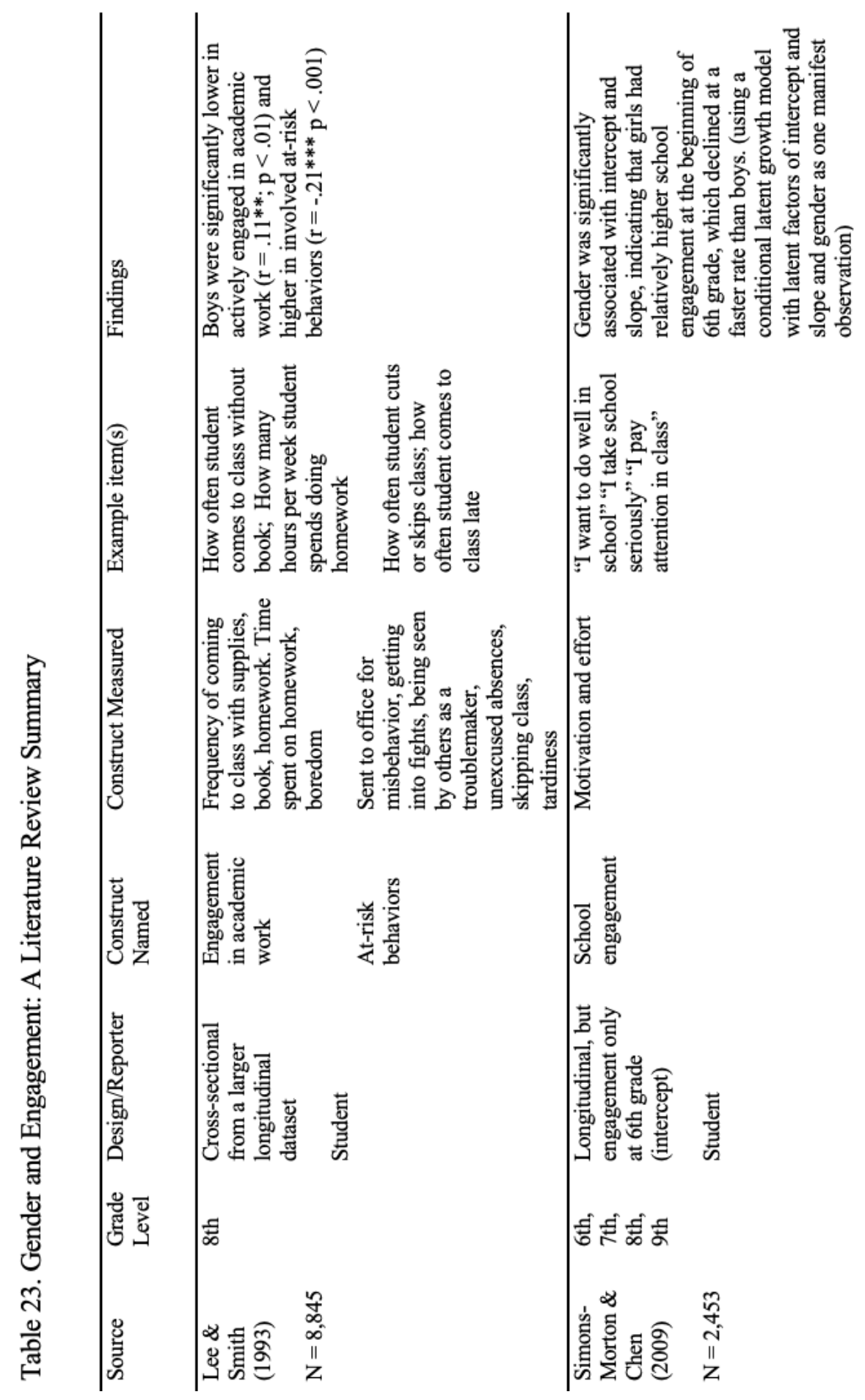




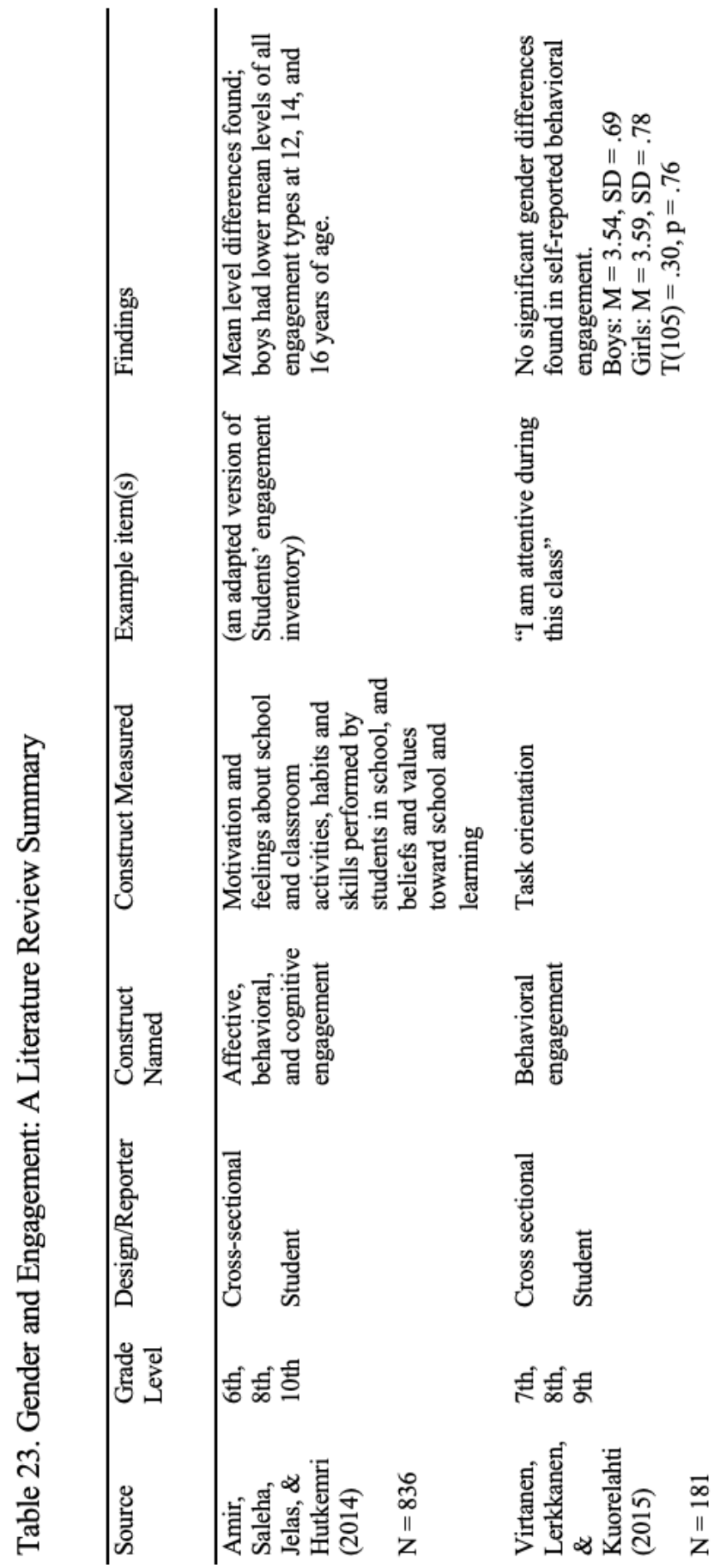




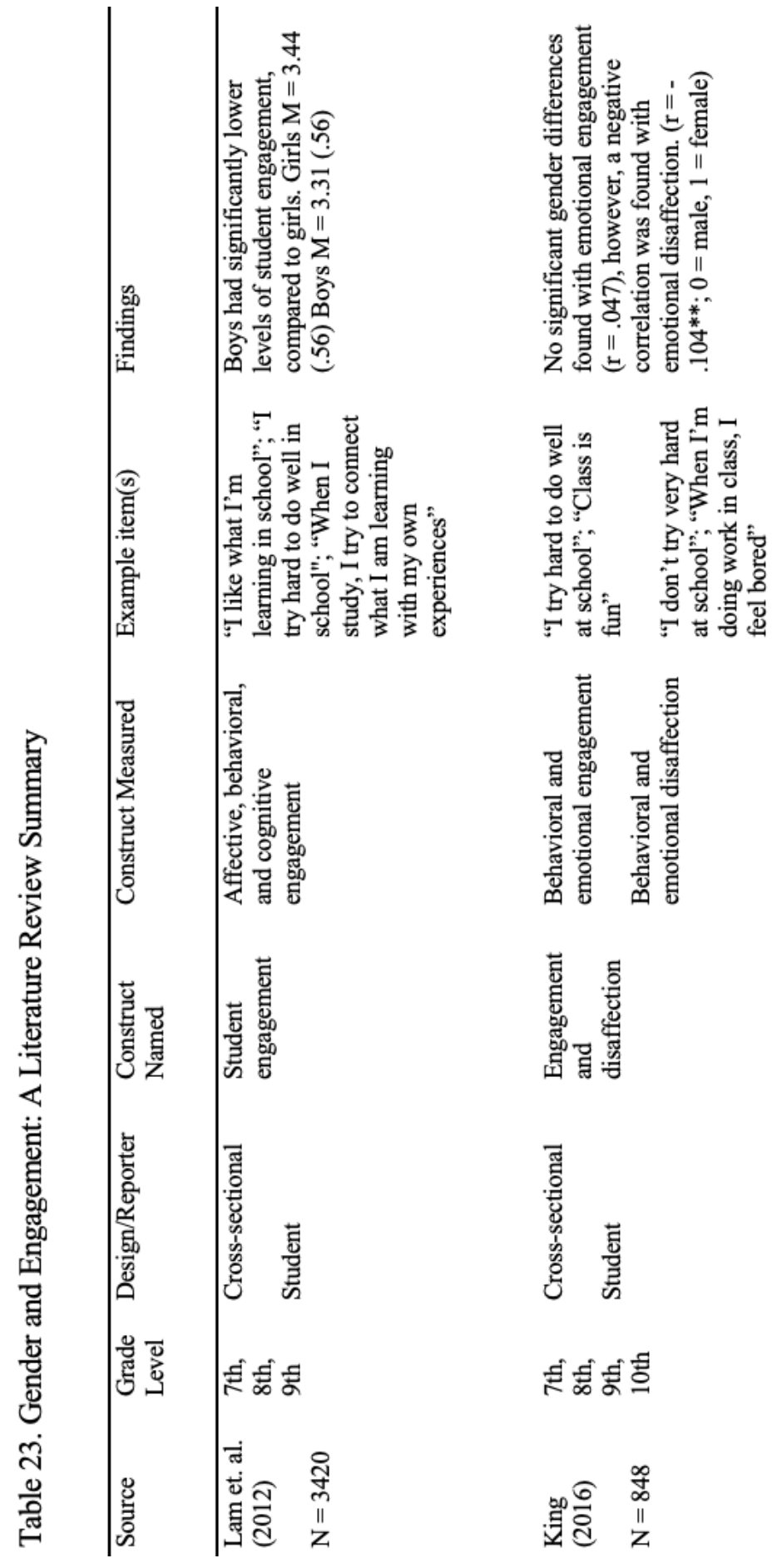




\section{BOYS' ENGAGEMENT AND INTERPERSONAL RESOURCES IN SIXTH GRADE}

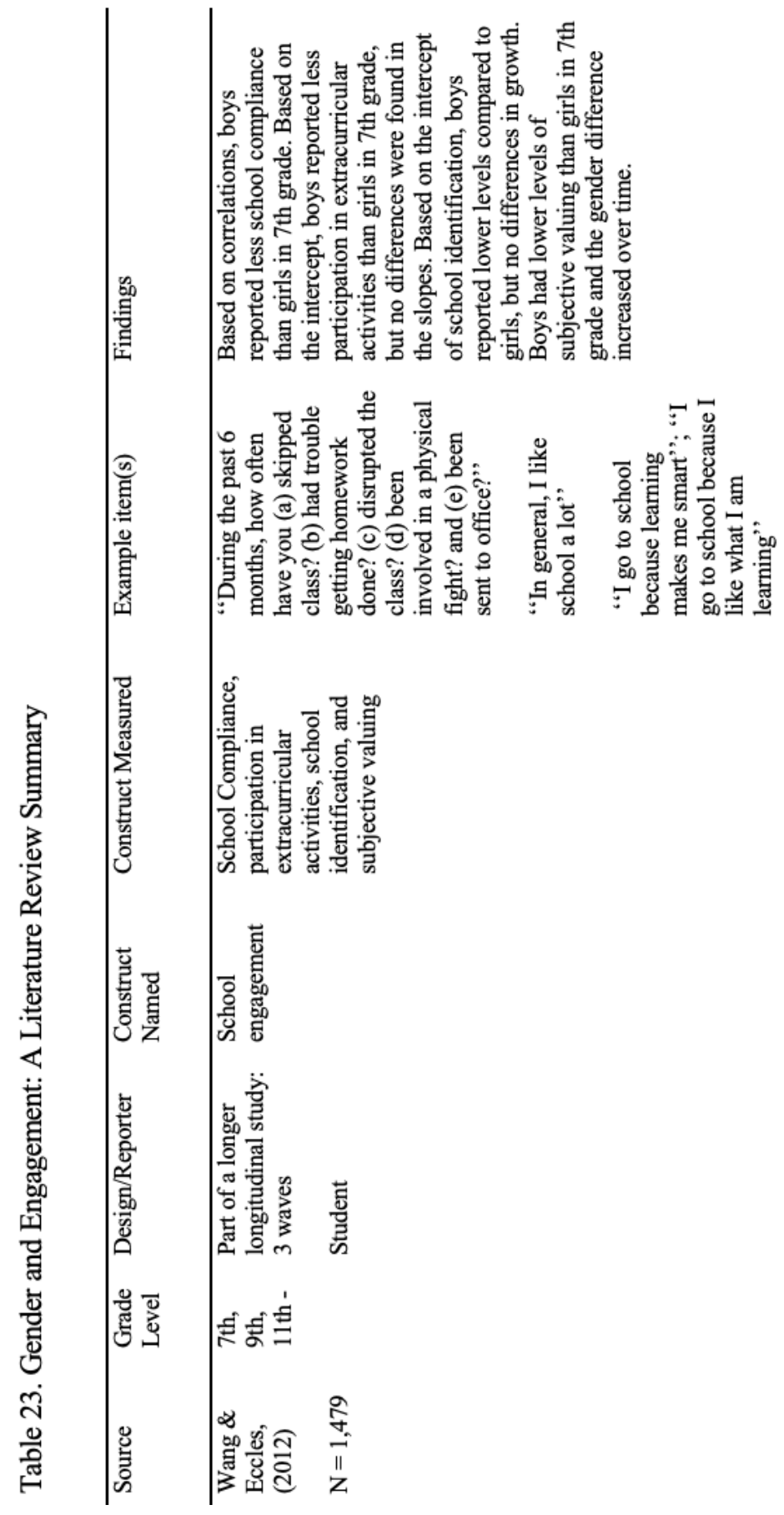




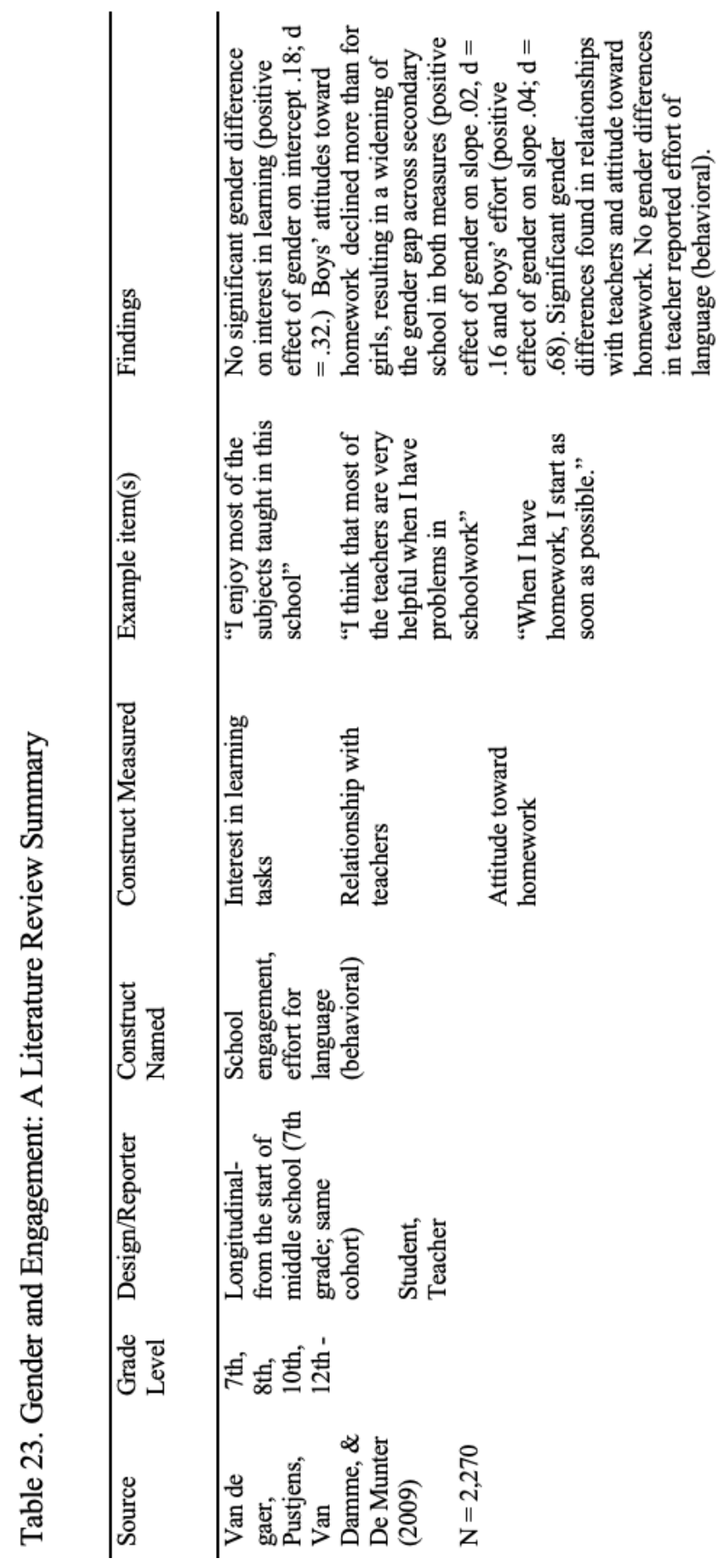




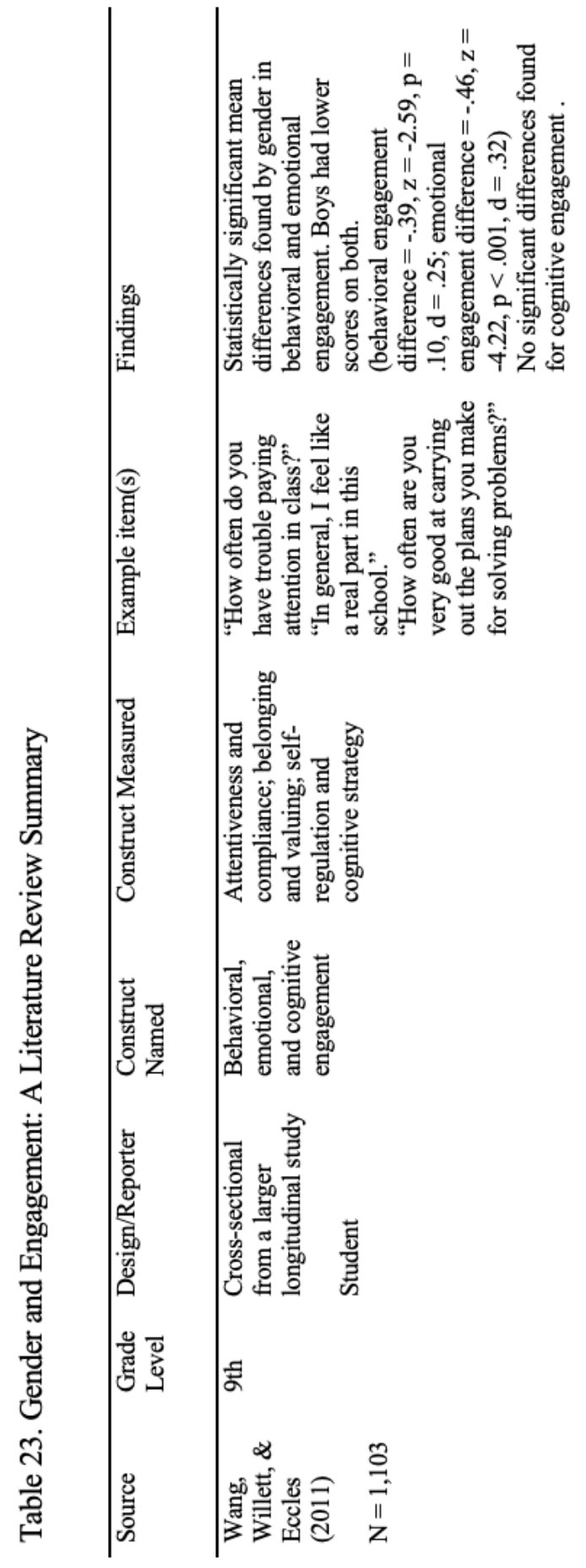




\section{BOYS' ENGAGEMENT AND INTERPERSONAL RESOURCES IN SIXTH GRADE}

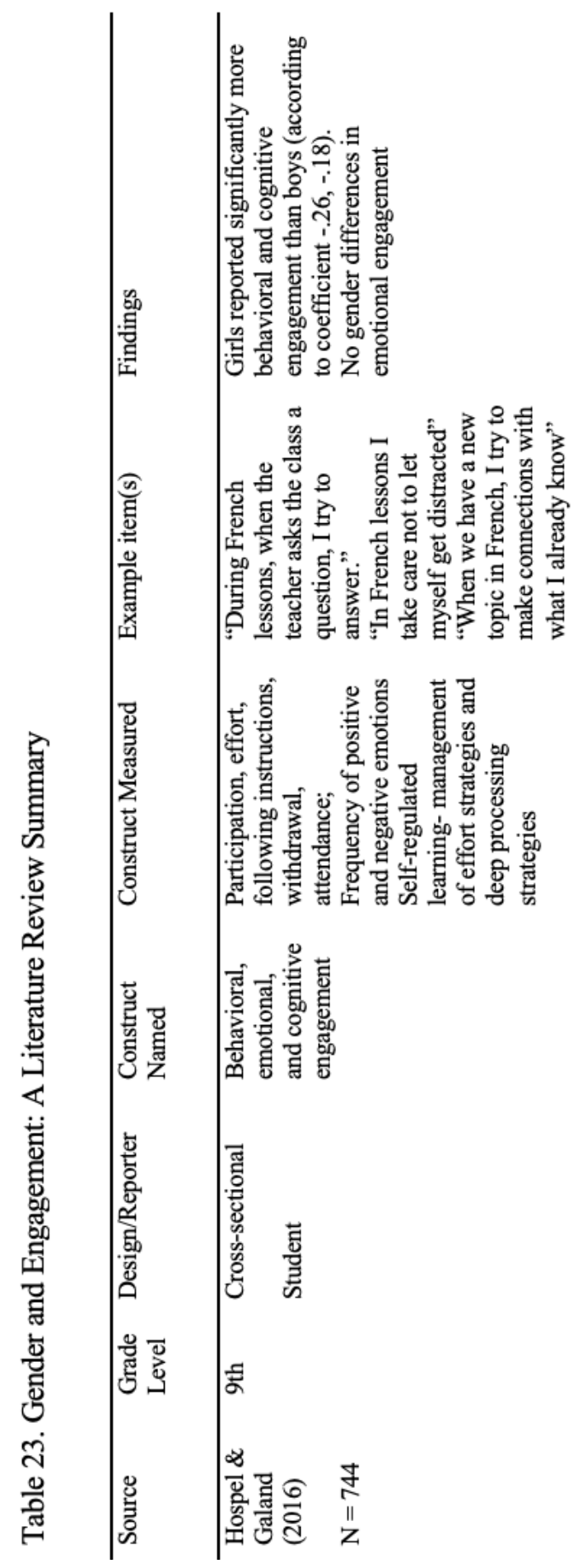




\section{BOYS' ENGAGEMENT AND INTERPERSONAL RESOURCES IN SIXTH GRADE}

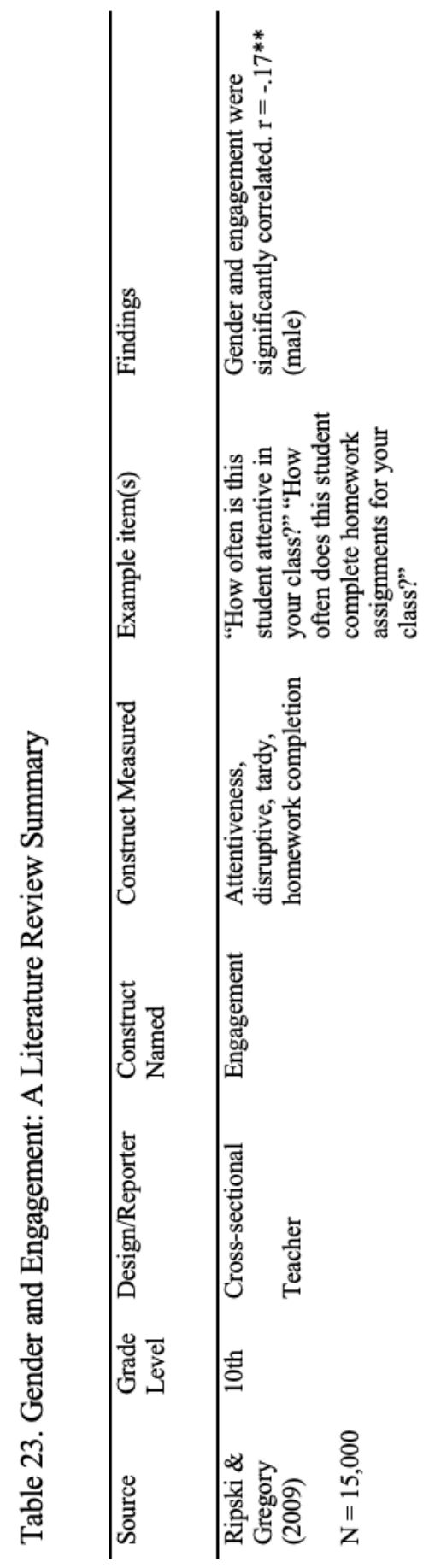


BOYS' ENGAGEMENT AND INTERPERSONAL RESOURCES IN SIXTH GRADE

\section{Appendix B. Follow-up Analyses for Research Question Two}

\section{Follow-Up Analyses B.1}

\section{Peer group engagement (top 20\%)}

Results of an independent-samples t-test indicated that, compared to boys whose peer networks are low in engagement in the beginning of the school year, boys with peer groups with high average levels of engagement had higher levels of individual engagement in the fall (high: $M=3.36, S D=.58$; low: $M=2.86, S D=.60, t=4.57, p<$ $.001, C I, .28, .72, \mathrm{~d}=.84$ ) and spring of the sixth grade year (high: $M=3.19, S D=.58$ low: $M=2.86, S D=.64, t=2.86, p<.01, C I, .10, .56, d=.52)$.

A repeated measurement showed that individual student engagement did not change significantly over the school year for boys with low and high peer engagement averages at the beginning of the school year, although approached significance, Wilks' Lambda $=.98, F(1,191)=3.88, p=.05$, and these groups change differently in engagement across the school year, Wilks' Lambda $=.98, F(1,191)=4.01, p<.05$. The mean level trends were not in the expected direction; boys with lower levels of peer group engagement remained stable in individual engagement across the school year, whereas boys with higher levels experienced losses in engagement across the sixth-grade year. The analyses do not support the research hypothesis.

\section{Follow-up Analyses B.2}

Peer Group Size (top 20\%) 


\section{BOYS' ENGAGEMENT AND INTERPERSONAL RESOURCES IN SIXTH GRADE}

Results of an independent-samples t-test indicated that, compared to boys with smaller peer group networks (six or fewer) in the beginning of the school year, boys with larger networks (seven or more) did not differ in levels of engagement in the Fall (high: $M=3.13, S D=.63$; low: $M=2.92, S D=.63, t=1.67, n s)$, or Spring of the sixth grade year (high: $M=2.96, S D=.75$; low: $M=2.92, S D=.62, t=.38, n s$ ).

A repeated measurement showed that engagement did not change significantly over the school year for boys with low and high numbers of peers in their network at the beginning of the school year, Wilks' Lambda $=.98, F(1,191)=3.44, n s$, nor did these groups change differently in engagement across the school year, Wilks' Lambda $=.99$, $F(1,191)=2.98, n s$. The mean level trends were not in the expected direction suggesting losses in engagement for boys with larger networks, whereas boys with a smaller peer network size remained stable in individual engagement across the school year. The analyses do not support the research hypothesis.

\section{Follow-up Analyses B.3}

\section{Reciprocated Friendships (top 30\%)}

Results of an independent-samples t-test indicated that, compared to boys with lower numbers of reciprocal friends (two or fewer) in the beginning of the school year, boys with higher numbers of reciprocal friends (three or more) had higher levels of engagement in the Fall (high: $M=3.44, S D=.52$; low: $M=2.82, S D=.59, t=6.28, p<$ 


\section{BOYS' ENGAGEMENT AND INTERPERSONAL RESOURCES IN SIXTH GRADE}

$.001, C I, .43, .82, d=1.09$ ) and Spring of the sixth grade year (high: $M=3.36, S D=.55$; low: $M=2.80, S D=.62, t=5.34, p<.001, C I, .35, .76, d=.92)$.

A repeated measurement showed that engagement did not change significantly over the school year for boys with low and high numbers of reciprocal friendships at the beginning of the school year, Wilks' Lambda $=.99, \mathrm{~F}(1,191)=1.51$, ns, nor did these groups change differently in engagement across the school year, Wilks' Lambda $=1.00$, $F(1,191)=.69, n s$. Although the mean level trends were in the expected direction, suggesting losses for boys with high numbers of reciprocal friends, the analyses do not support the hypothesis that these boys experienced lower losses in overall engagement than boys with smaller numbers of reciprocal friends.

\section{Follow-up Analyses B.4}

\section{Self-Reported Friendships (top 20\%)}

Results of an independent-samples t-test indicated that, compared to boys with low numbers of self-reported friends (10 or less) in the beginning of the school year, boys with higher numbers of self-reported friends (11 or more) had higher levels of engagement in the Spring (high: $M=3.16, S D=.68$; low: $M=2.87, S D=.63, t=2.37, p$ $<.05, C I, .05, .52, d=.45$ ), but not in fall of the sixth grade year (high: $M=3.16, S D=$ .74 ; low: $M=2.91, S D=.60, t=1.83, n s$, equal variances not assumed).

A repeated measurement showed that engagement did not change significantly over the school year for boys with low and high numbers of self-reported friendships at 


\section{BOYS' ENGAGEMENT AND INTERPERSONAL RESOURCES IN SIXTH GRADE}

the beginning of the school year, Wilks' Lambda $=1.00, F(1,191)=.18, n s$, nor did these groups change differently in engagement across the school year, Wilks' Lambda $=1.00$, $F(1,191)=.19, n s$. Mean level trends were in the expected direction, suggesting stable engagement for boys with high numbers of self-reported friends. The analyses do not support the hypothesis that these boys experienced lower losses in overall engagement than boys with smaller numbers of self-reported friendships.

\section{Follow-up Analyses B.5}

\section{Peer-Reported Friendships (top 20\%)}

Results of an independent-samples t-test indicated that, compared to boys with low numbers of peers who reported them as friends (eight or fewer) in the beginning of the school year, boys with higher numbers of peers who reported them as friends (nine or more) had higher levels of engagement in the fall (high: $M=3.29, S D=.59$; low: $M=$ $2.89, S D=.62, t=3.28, p<.01, C I, .16, .63, d=.64)$, and spring of the sixth-grade year (high: $M=3.19, S D=.61$; low: $M=2.87, S D=.64, t=2.50, p<.05, C I, .07, .56, d=$ $.49)$.

A repeated measurement showed that engagement did not change significantly over the school year for boys with low and high numbers of peers who reported them as friends at the beginning of the school year, Wilks' Lambda $=.99, F(1,191)=1.67, n s$, nor did these groups change differently in engagement across the school year, Wilks' Lambda $=1.00, F(1,191)=.81, n s$. Although the mean level trends were in the expected 


\section{BOYS' ENGAGEMENT AND INTERPERSONAL RESOURCES IN SIXTH GRADE}

direction, suggesting losses for boys with high numbers of peer-reported friends, the analyses do not support the hypothesis that these boys experienced lower losses in overall engagement than boys with smaller numbers of peer-reported friends. 